NASA Technical Memorandum 100751

\title{
Algorithm for Atmospheric Corrections of Aircraft and Satellite Imagery
}

Robert S. Fraser, Richard A. Ferrare, Yoram J. Kaufman, and Shana Mattoo

DECEMBER 1989

\section{N/SA}

(NASA-TM-100751) ALGOKITHM FOK ATMOSPHERTC

N90-13976 CORPECTIONS OF AIRCPAFT ANO SATELLITE 
NASA Technical Memorandum 100751

\section{Algorithm for Atmospheric Corrections of Aircraft and Satellite Imagery}

Robert S. Fraser

Goddard Space Flight Center

Greenbelt, Maryland

Yoram J. Kaufman

University of Maryland

College Park, Maryland
Richard A. Ferrare

University Space Research Association Greenbelt, Maryland

Shana Mattoo

Applied Research Corporation

Landover, Maryland

\section{Nosh}

National Aeronautics and

Space Administration

Goddard Space Flight Center

Greenbelt, MD 


\begin{abstract}
This report describes a simple and fast atmospheric correction algorithm used to correct radiances of scattered sunlight measured by aircraft and/or satellite above a uniform surface. The atmospheric effect, the basic equations, a description of the computational procedure, and a sensitivity study are discussed. The program is designed to take the measured radiances, view and illumination directions, and the aerosol and gaseous absorption optical thicknesses to compute the radiance just above the surface, the irradiance on the surface, and surface reflectance. Alternatively, the program will compute the upward radiance at a specific altitude for a given surface reflectance, view and illumination directions, and aerosol and gaseous absorption optical thicknesses. The algorithm can be applied for any view and illumination directions and any wavelength in the range $0.48 \mu \mathrm{m}$ $2.2 \mu \mathrm{m}$. The relation between the measured radiance and surface reflectance, which is expressed as a function of atmospheric properties and measurement geometry, is computed using a radiative transfer routine. The results of the computations are tabulated in a look-up table which forms the basis of the correction algorithm. The algorithm can be used for atmospheric corrections in the presence of a rural aerosol. The sensitivity of the derived surface reflectance to uncertainties in the model and input data is discussed.
\end{abstract}


Table of Contents

Page

Abstract $\quad$ iii

List of Tables vii

List of Figures viii

1.0 Introduction 1

1.1 Background 1

1.2 Intervening Atmosphere 1

1.3 Atmospheric Corrections 3

1.4 Algorithm 5

$\begin{array}{lll}2.0 & \text { Atmospheric Effect } & 6\end{array}$

2.1 General Discussion 6

$\begin{array}{ll}2.2 & \text { Mathematical Description }\end{array}$

$\begin{array}{ll}3.0 \text { Correction Algorithm } & 11\end{array}$

$\begin{array}{lll}3.1 & \text { Model Wavelengths } & 12\end{array}$

$\begin{array}{lll}3.2 & \text { Aerosol Properties } & 14\end{array}$

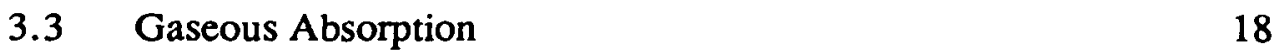

$\begin{array}{ll}3.4 & \text { Altitude Profiles } \\ \end{array}$

3.5 Molecular and Aerosol Optical Thickness 22

$\begin{array}{lll}3.6 & \text { Measurement Altitudes } & 23\end{array}$

4.0 Look-up Tables $\quad 24$

$\begin{array}{lll}5.0 & \text { Computational Procedure } & 24\end{array}$

$\begin{array}{lll}5.1 & \text { General } & 24\end{array}$

$\begin{array}{lll}5.2 & \text { Input } & 29\end{array}$ 


\subsection{Output}

5.4 Summary of Error Messages

6.0 Sensitivity Study

6.1 Model Errors

6.1.1 Aerosol Single Scattering Phase Function

6.1.2 Polarization

6.1.3 Water Vapor and Ozone Absorption

6.1.4 Aerosol Absorption

6.1.5 Vertical Distribution of Aerosols

6.1.6 Bidirectional Reflectance

6.2 Interpolation Errors

6.3 Input Errors

73

7.0 Conclusion

8.0 References

9.0 Listing of FORTRAN program 


\section{List of Tables}

Table

Page

1 Spectral bands, aerosol indices of refraction, and optical thicknesses

$2 \quad$ Aerosol size distribution parameters

3 Variables in the FIFEWAV program and associated subroutines and their equivalent in the text

$4 \quad$ Examples of input data

5 Examples of output results for the examples in Table 4

6 An example of output for interpolated radiation parameters

7 Examples of error messages for various errors in the input data

8 Case numbers assigned to sensitivity tests for the atmospheric correction algorithm

$9 \quad$ Summary of sensitivity results $\quad 48$

$10 \quad$ Sensitivity results $\quad 52$ 


\section{List of Figures}

Figure

Page

1 Surface reflectance and corresponding radiance above the atmosphere for a typical vegetation

2

Angular coordinates

10

3 Surface reflectance at the FIFE site

15

Aerosol particle number density altitude profiles

21

5

Aerosol single scattering phase functions

67 


\subsection{Introduction}

\subsection{Background}

The purpose of this report is to describe a fast and simple atmospheric correction algorithm to derive the surface reflectance, and other parameters, from radiances measured by satellite and/or aircraft in the visible and near IR parts of the spectrum. The original version of this algorithm was developed to correct the radiances measured during FIFE (Eirst ISLSCP Eield Experiment - Sellers et al., 1988) which is taking place at the Konza Prairie in Kansas. While the algorithm has been designed to correct radiances measured over a rural site for the wavelength range $0.48 \mu \mathrm{m} \leq \lambda \leq 2.2 \mu \mathrm{m}$, a sensitivity study has shown that the algorithm can be a practical tool for many applications of remote sensing, for which a uniform surface can be assumed, and for which the optical characteristics of the aerosol do not differ significantly from the rural aerosol (the algorithm should not be applied for correcting for the effect of desert dust or fog). As a result we would like to bring the algorithm to the attention of the scientific and engineering community.

\subsection{The Intervening Atmosphere}

Atmospheric aerosols, which are liquid or solid particles suspended in the air, have a significant importance in evaluating satellite imagery for remote sensing of the earth's surface. The atmospheric aerosol results from natural sources (e.g. desert dust, condensation and oxidation of gases released from the biosphere and oceans) and anthropogenic sources (e.g. biomass burning and the industrial emission of gases which participate in atmospheric chemical reactions and condense into liquid particles). In the Southern Hemisphere, near Australia, the aerosol concentration is usually very low (aerosol optical thickness in the visible is less than 0.10 ) due to the low population, large ocean areas, and low humidity. In desert areas, dust storms can increase the optical thickness $(\tau)$ to $\tau=2.0$ and above (hiding the sun). In the Northern Hemisphere the concentration may be rather large during long period of times, (e.g. the aerosol optical thickness is around 0.6 in the Eastern part of the United States during July and August - Kaufman and Fraser, 1983; Peterson et al., 1981), due to industrial pollution. In the state of Rondonia, Brazil, biomass burning due to deforestation generates dense smoke (optical thickness 1.0-3.0) that covers the area during most of the dry season. For an aerosol optical thickness over land larger than 0.20 , aerosols affect a significant share of the outgoing visible radiation for a cloudless sky. 
Therefore, since aerosols affect satellite imagery of the earth's surface, attempts for its correction should be taken.

Satellite images of the Earth's surface in the solar spectrum are contaminated by sunlight scattered towards the sensor by atmospheric molecules, aerosols, and clouds (path radiance). In addition, solar energy that is reflected from the Earth's surface and serves as the remote sensing signal, is attenuated by the atmosphere. This combined atmospheric effect is wavelength dependent, varies in time and space, and depends on the surface reflectance and its spatial variation. Correction for this atmospheric effect can produce remote sensing signals that are more closely related to the surface characteristics. Molecular scattering and absorption in the atmosphere can be accounted for satisfactorily. Gaseous absorption is minimized by choosing sensor bands in atmospheric windows. Therefore, aerosol scattering and absorption, and the presence of subpixel clouds, are the main variables in the atmospheric effect on satellite imagery.

For a cloudless sky, aerosol scattering is the major variable component of the atmospheric effect for dark surfaces, while aerosol absorption is important for bright surfaces (Fraser and Kaufman, 1985). In order to perform atmospheric corrections of remotely sensed data, the optical characteristics of the atmosphere must be estimated. These characteristics may be given in varying levels of detail--from considerable detail (profile of the extinction coefficient, the single-scattering albedo and the scattering phase function), to less detail (the vertical optical thickness, the average aerosol scattering phase function and single-scattering albedo).

In order to demonstrate the effect of the atmosphere on remote sensing we shall discuss vegetation as an example. We may distinguish among the following ecological regions:

- Over remote land areas, with no substantial anthropogenic aerosol contribution, and no dust, the aerosol optical thickness may vary between $0.02-0.10$. For this variation and for typical aerosol characteristics (single scattering albedo $\omega_{0}=0.96$ ), the reflectance of the atmosphere alone will increase about 0.01 (Fraser and Kaufman, 1985), and a vegetation index (ratio between the difference in reflectances between the near IR and the visible and the sum - NDVI) of NDVI $=0.60$, as measured by satellite, will change to 0.58 (Holben, 1986). These changes are relatively small and, therefore, atmospheric correction in this case is not important for most applications. (Remote sensing of ocean color is affected by even a small aerosol optical thickness (Gordon et al., 1983).) 
- Over typical land areas, anthropogenic aerosols and/or dust may generate optical thicknesses in the range 0.05-0.25. The corresponding atmospheric effect would change a surface reflectance of $\rho=0.02$ to 0.04 , and vegetation index of NDVI $=0.60$ to 0.55 . These are significant errors which necessitate atmospheric correction.

- Over polluted areas, with anthropogenic aerosols from industrial sources (e.g all of Eastern U.S. and Europe during the summer) or areas affected by dust, fog or smoke (tropical regions, regions in the far east and Sahel), the aerosol optical thickness may vary in the range 0.1-1.0. In this range of variation the atmospheric effects are very large. The surface reflectance would vary from 0.02 to 0.08 and the vegetation index would decrease from 0.6 to 0.45 .

\subsection{Atmospheric Corrections}

The correction procedure requires information about the atmospheric optical characteristics. Due to the difficulty in determining these characteristics, the only operational use of atmospheric corrections today is that of the ocean color (Gordon et al., 1983), where the corrections depend on the condition of the very low reflectance of the water in the red. Otherwise, information on the atmospheric optical characteristics can be obtained from three different sources:

Climatology: Documented information on the atmospheric characteristics and their variation can be used to estimate the expected atmospheric effect for a specific part of the world and a specific season. Such documentation can be obtained from the analysis of measurements taken from the ground, and partially from the analysis of satellite data (Fraser et al., 1984; Kaufman, 1987; Kaufman et al., 1988). This source of information will be used for optical characteristics that cannot be determined otherwise for the particular image being corrected.

Measurements from the ground: The aerosol optical thickness can be obtained from sun-photometer measurements (King et al., 1978; Kaufman and Fraser, 1983). The phase function can be determined from inversion of solar almucantar measurements, and the single-scattering albedo from the collection of particles on filters, preferably by aircraft sampling of the entire atmospheric boundary layer. The single-scattering albedo can also be determined by measurements of the diffuse and direct flux (Herman et al., 1975; King and Herman, 1979; King, 1979) and by lidar techniques (Spinhirne et al., 1980). The 
application of such measurements for atmospheric corrections is useful for intense field measurements, or for establishing the climatology of a given area.

Determination from satellite imagery: For the purpose of atmospheric corrections, the path radiance and the corresponding aerosol optical thickness can be derived from radiances detected by the satellite over a dark surface. Examples include many land surfaces in the blue spectrum, dense dark vegetation in the visible channels (Kaufman and Sendra, 1988), and water in the red and near IR. The wavelength dependence of the derived aerosol optical thickness (when available) can be used to estimate the particle size and the scattering phase function. In the past satellite imagery has been used to determine the aerosol optical thickness and other aerosol characteristics. The aerosol optical thickness has been derived from satellite imagery of oceans (Griggs, 1975; Mekler et al., 1977; Carlson, 1979; Koepke and Quenzel, 1979; Takayama and Takashima, 1986), and recently, over dense dark vegetation (Kaufman and Sendra, 1988). By using the difference in the brightness between a clear and a hazy day, Fraser et al. (1984) demonstrated that the difference in the optical thickness can be derived where the surface reflectance is less than 0.1 . Determination of the aerosol single-scattering albedo and particle size was suggested by Kaufman et al. (1988) and Kaufman (1987), and applied to trace the evolution of smoke from a large forest fire (Ferrare et al., 1988). This method is useful to determine the aerosol characteristics (from imagery that includes water-land interfaces) in areas that suffer from substantial aerosol outbreaks (e.g. desert dust storms, smoke from fires and concentrated anthropogenic aerosol).

Once the atmospheric characteristics are specified, an atmospheric correction can be performed with an equation relating relating measured radiance to the optical properties of the atmosphere and surface. The computation requires application of complex and time consuming radiative transfer programs (Dave, 1972 a,b,c,d; Ahmad and Fraser, 1982). This report presents an algorithm that simplifies the correction procedure by using an a priori prepared look-up table that is based on radiative transfer computations. In essence, the algorithm simplifies the atmospheric correction procedure to a desktop operation, by sacrificing the flexibility to select specific aerosol size distributions and refractive indexes, but not optical thickness. 


\subsection{The algorithm}

The algorithm is designed to compute the upward radiance for a given surface reflectance or to compute the surface reflectance for a given measured radiance, for almost any wavelength in the visible and near-IR spectrum (with appropriately specified gaseous absorption), for a wide range of observation zenith angles, solar illumination angles and azimuth angles between the observer and the solar rays, as well as any height of the observer (aircraft or satellite). Any practical value of the aerosol optical thickness can be used, but the algorithm is restricted to a specific aerosol size distribution and refractive index.

The relation between the measured radiance and the surface reflectance is expressed as a function of the path radiance, downward flux at the ground, atmospheric transmission, and the atmospheric backscattering ratio. Using this relation, a look-up table is constructed which relates the measured upward radiance to surface reflectance for several aerosol optical thicknesses, solar zenith angles, measurement wavelengths, and a range of observation directions. This look-up table is based on the tabulation of the results of radiative transfer computations which are made using a Dave (1972 a,b,c,d) code. It is assumed that the atmosphere and surface are horizontally homogeneous, and the surface reflects light according to Lambert's law. The light scattered by the atmosphere and the surface is assumed to be unpolarized. The atmosphere is also assumed to be cloud-free.

Radiation properties of the cloudless atmosphere depend on both molecular and aerosol constituents. Molecular scattering and absorption, except for water vapor absorption, are easy to account for. Aerosol effects are more variable and are therefore more difficult to correct. The parameters used to describe these aerosol effects are: the optical thickness which determines the amount of extinction, the single scattering albedo which determines the fraction of light scattered from the total extinction, and the single scattering phase function which describes how the light is scattered as a function of direction. For the most part, aerosol extinction is the dominant parameter in the aerosol component of the atmospheric effect (Fraser and Kaufman, 1985). Thus, in this algorithm the aerosol optical thickness is the only variable aerosol parameter. The algorithm uses a constant aerosol single scattering phase function and scattering albedo chosen to represent a rural environment. Because these assumptions can introduce error in the derived surface reflectances, a sensitivity analysis is performed to estimate the uncertainty in in derived surface reflectances. 
In the first part of this document, the atmospheric effect and its effects on the surface reflectance are discussed. Next, a description of the equations used in the algorithm and the construction of the look-up table is given. A sensitivity study is then performed to estimate the errors associated with the initial assumptions, interpolation algorithm, and uncertainties in the input data. Finally, the FORTRAN code for the algorithm is listed.

\subsection{Atmospheric Effect}

\subsection{General Discussion}

The atmospheric effect is caused by the scattering and absorption of solar radiation by molecules and aerosols. There are three components to this effect :

1) The downward solar radiation is absorbed and scattered by the atmosphere and it is diffused by forward scattering. Because this diffusion increases the angular distribution of the radiation, the downward radiation interacts with the surface in a wide range of directions. Thus the surface reflection coefficient for this radiation is different from the reflection coefficient for the direct solar beam (Lee and Kaufman, 1986).

2) Radiant energy reaching a remote sensor is reflected from the ground both within the instantaneous-field-of-view (ifov) and from the region outside of it. Part of the reflected energy within the ifov is transmitted directly to a sensor and can be considered signal; the remaining radiation is absorbed and scattered. Part of the radiation that is reflected from outside of the ifov passes through the column containing the ifov and is scattered there towards the sensor. This component is associated with the adjacency effect. It augments the measured radiance and is partially corrected for when deriving the surface reflectance.

3) Radiation is scattered by the atmosphere into the ifov without being reflected by the surface. This component is called the path radiance and increases the apparent reflection of the surface.

An example of the difference between the spectral surface reflectance for typical vegetation (assumed Lambertian) and the corresponding upward radiance above the atmosphere is shown in Figure 1. In this figure, the upward radiance is normalized by the incident solar flux to produce reflectance units. This normalized radiance is the apparent reflectance as seen from the sensor. The reflectance of the earth-atmosphere system can be greater than the surface reflectance, the same, or weaker. In the visible spectrum the 


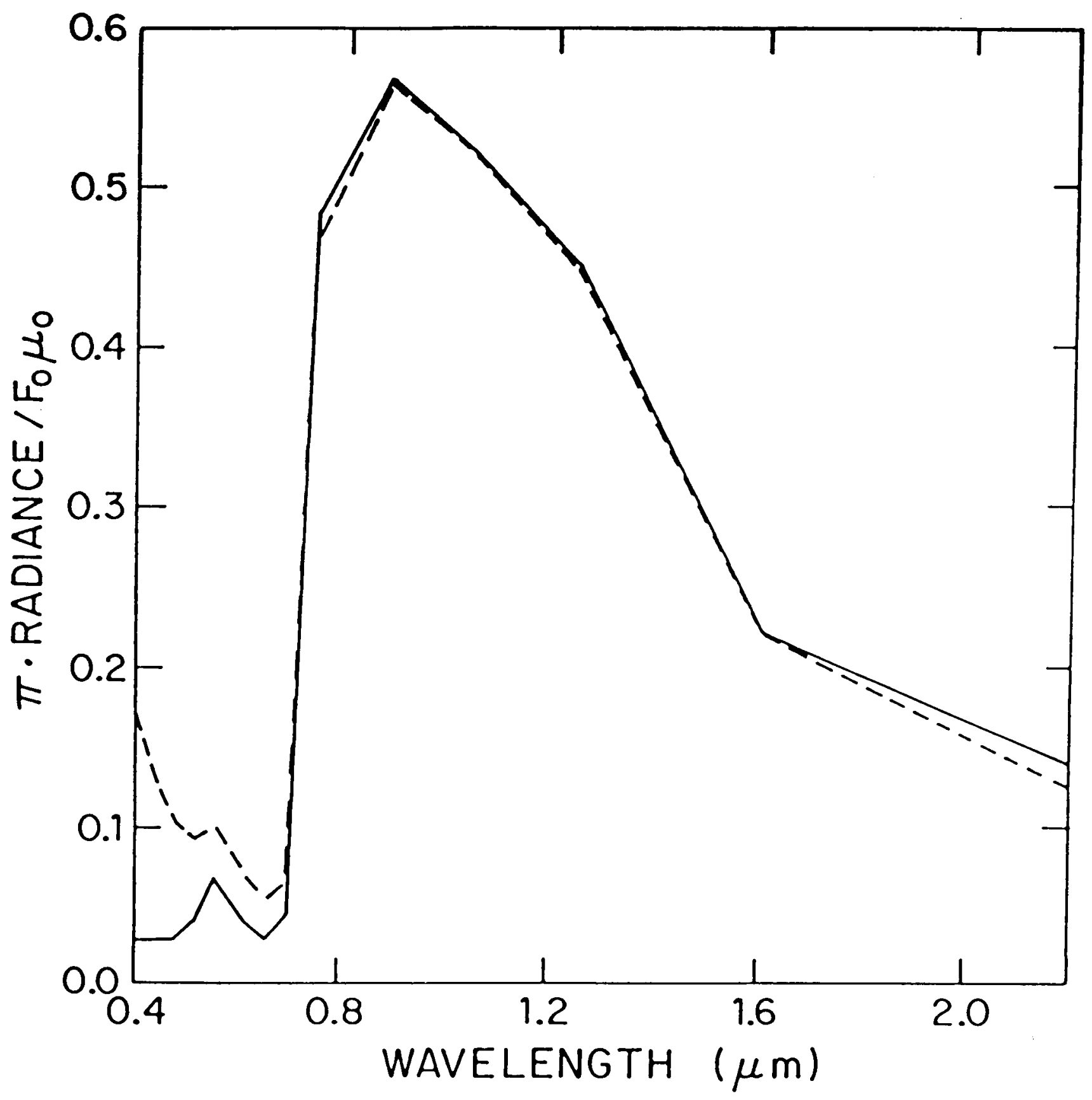

Figure 1. Surface reflectance $(\longrightarrow$ ) and the corresponding radiance $(--)$ above the atmosphere for a typical vegetation. The radiance is normalized by $F_{0}$, the incident solar flux, and by $\mu_{0}$, the cosine of the solar zenith angle (from Kaufman, 1987). 
surface reflectance is weak, the path radiance is relatively strong, and the reflectance above the atmosphere exceeds that at the ground. In the near infrared $(0.7<\lambda<1.6 \mu \mathrm{m})$ the surface reflectance is strong, and the reflectances at the surface and above the atmosphere are nearly the same. The loss of radiation from the surface by extinction is augmented at the same rate by atmospheric scattering. For wavelengths longer than $1.6 \mu \mathrm{m}$, atmospheric scattering does not compensate for the attenuation loss.

\subsection{Mathematical Description}

In order to correct for the atmospheric effects discussed in the previous section, a relation is developed between the upward spectral radiance $L^{m}$ measured from satellite or aircraft and the surface reflectance $\rho: L^{m}=f(\rho)$. The radiance is equivalent to the specific intensity as defined by Chandrasekhar (1960, p.1), except that the radiance, as used here, is the radiant energy within a unit wavelength interval instead of the energy per unit frequency. The function $f$ depends on the atmospheric and surface optical properties, observation and sun directions, and wavelength. The radiance $L^{m}$ can be expressed explicitly as a function of the path radiance $\mathrm{L}_{\mathrm{o}}$ (upward radiance for zero surface reflectance), the downward flux through a horizontal surface at the ground $F_{d}$ (for zero surface reflectance), the total (direct + diffuse) transmission from the surface to the observer $\mathrm{T}$, and the atmospheric backscattering ratio $\mathrm{s}$. It is assumed that the atmosphere and the surface are horizontally homogeneous, but the atmospheric optical properties vary in the vertical direction. The surface is assumed to reflect light according to Lambert s law. The light scattered by the cloud-free atmosphere and surface is assumed to be unpolarized. The relation between $\mathrm{L}^{\mathrm{m}}$ and $\rho$ is (Chandrasekhar, 1960)

$$
L^{m}=L_{0}+\frac{\left(\rho F_{d} T\right)}{\pi(1-s \rho)}
$$

Here $\mathrm{L}^{\mathrm{m}}$ is the spectral radiance measured from aircraft or satellite and is a function of $\lambda$. $\theta_{0}, \tau_{a}, \tau_{g s}, \omega_{0}, \tau_{g}, \theta, Z$, and $\varphi$, where

$\lambda$ is the wavelength of the radiation,

$\theta_{0} \quad$ is the solar zenith angle,

$\tau_{a} \quad$ is the aerosol optical thickness (used with base e), 
$\tau_{\mathrm{gs}} \quad$ is the molecular scattering optical thickness,

$\omega_{0} \quad$ is the ratio of the aerosol scattering and extinction optical thicknesses,

$\tau_{8} \quad$ is the gaseous absorption optical thickness,

$\mathrm{Z}$ is the observation height,

$\theta$ is the propagation direction zenith angle of the radiant energy at the ground,

$\varphi \quad$ is the azimuth angle (azimuthal angles are measured with respect to the principal plane through the sun; $0^{\circ}$ lies in the plane containing the direction of propagation of the direct sunlight).

Figure 2 shows the angular coordinates used in the algorithm. The functions $L_{0}, T, F_{d}$ and s have the following functional dependances:

$$
\begin{aligned}
\mathrm{L}_{\mathrm{o}}=\mathrm{L}_{\mathrm{o}}\left(\lambda, \theta_{\mathrm{o}}, \tau_{\mathrm{a}}, \tau_{\mathrm{gs}}, \tau_{\mathrm{g}}, \omega_{\mathrm{o}}, \mathrm{Z}, \theta, \varphi\right) & \mathrm{F}_{\mathrm{d}}=\mathrm{F}_{\mathrm{d}}\left(\lambda, \theta_{\mathrm{o}}, \tau_{\mathrm{a}}, \tau_{\mathrm{gs}}, \tau_{\mathrm{g},}, \omega_{\mathrm{o}}\right) \\
\mathrm{T}=\mathrm{T}\left(\lambda, \tau_{\mathrm{a}}, \tau_{\mathrm{gs}}, \tau_{\mathrm{g}}, \omega_{\mathrm{o}}, \mathrm{Z}, \theta\right) & \mathrm{s}=\mathrm{s}\left(\lambda, \tau_{\mathrm{a}}, \tau_{\mathrm{gs}}, \tau_{\mathrm{g}}, \omega_{\mathrm{o}}\right)
\end{aligned}
$$

The correction algorithm is based on the inverse of eq. (1), where the surface reflectance $\rho$ can be expressed in terms of the measured radiance $\mathrm{L}^{\mathrm{m}}$ :

$$
\rho=\frac{f}{(1+s f)}
$$

where

$$
f=\frac{\pi\left(L^{m}-L_{0}\right)}{\left(F_{d} T\right)}
$$

The algorithm will compute $L^{m}$ using (1) if $\rho$ is given or will compute $\rho$ using (2) and (3) if $\mathrm{L}^{\mathrm{m}}$ is given. Other quantities computed are: the total irradiant flux $\mathrm{F}_{\mathbf{g}}$ on a horizontal surface at the ground,

$$
F_{g}=\frac{F_{d}}{(1-s \rho)}
$$




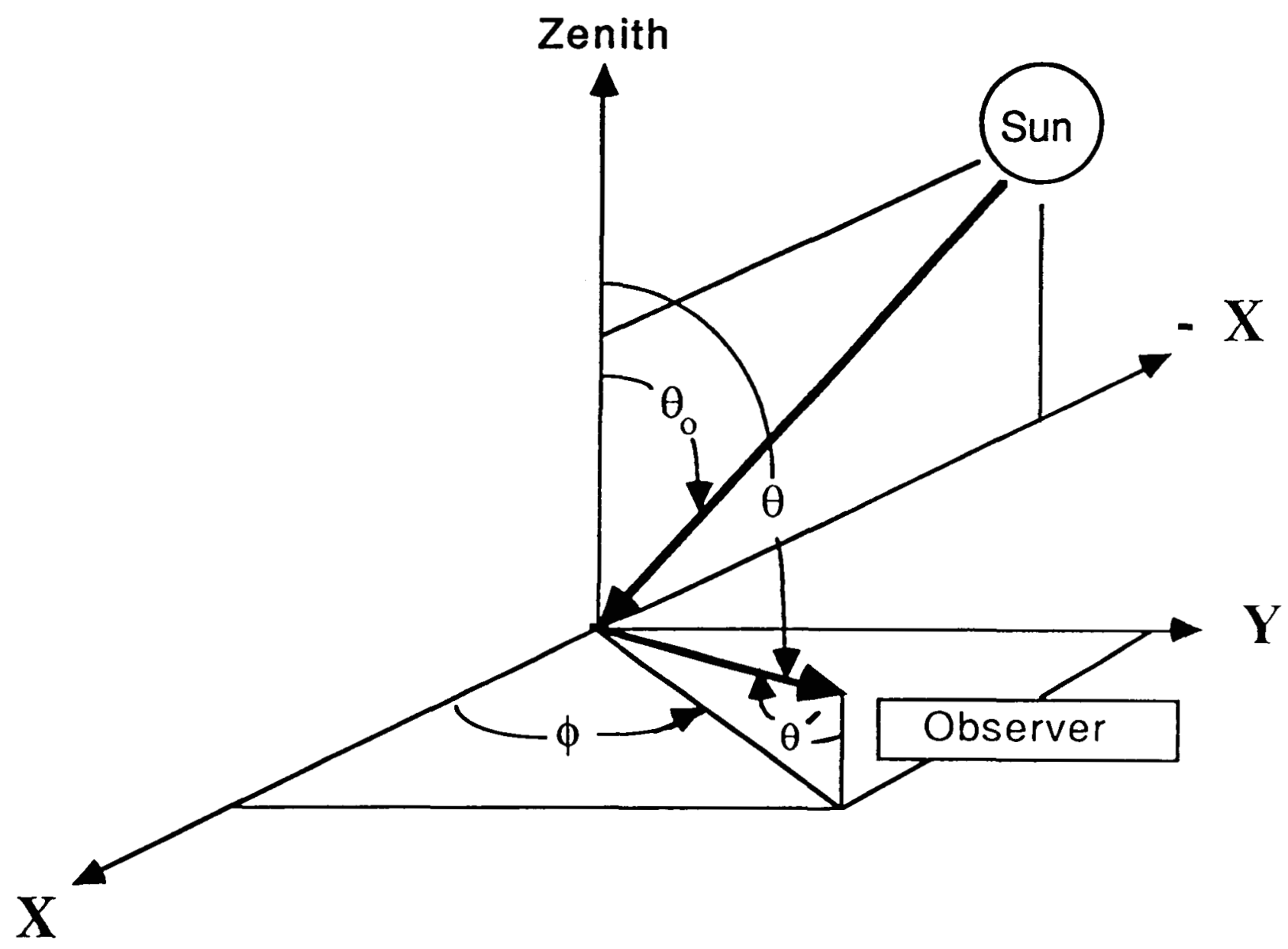

Figure 2. Angular coordinates used in the algorithm. The $\mathrm{X}-\mathrm{Y}$ plane is a horizontal plane tangent to the earth's surface at the observation point. The solar zenith angle $\theta_{0}$, observation zenith angle $\theta$, observation scan angle $\theta^{\prime}$, and observation azimuth angle $\phi$ are shown. In this particular representation of planar geometry $\theta=\theta^{\prime} ;$ the general relationship is given by eq. (9). 
and the upward radiance $\mathrm{L}_{\mathrm{g}}$ at the ground in the direction of observation.

$$
L_{g}=\frac{\rho F_{d}}{\pi(1-s \rho)}
$$

\section{$\underline{3.0 \text { Correction Algorithm }}$}

The correction program is based on the tabulation of the results of radiative transfer computations of $\mathrm{L}_{\mathrm{b}}, \mathrm{F}_{\mathrm{d}}, \mathrm{s}$, and $\mathrm{T} / \pi$ (note that the transmission $\mathrm{T}$ is not tabulated). The primed parameters are normalized flux and radiance rather than their absolute values. The normalized values are related to their corresponding absolute values by the following equations:

$$
F_{d}^{\prime}\left(\theta_{0}, \tau_{a}\right)=\frac{F_{d}}{F_{0} \cos \theta_{0}} \quad L_{o}^{\prime}\left(\theta_{0}, \theta, \phi, \tau_{a}, Z\right)=\frac{\pi L_{0}}{F_{0} \cos \theta_{0}}
$$

The value of $F_{0}$ represents the solar spectral flux passing through a surface orthogonal to its propagation at the top of the atmosphere. In order to use the table for atmospheric correction, the measured absolute radiance $\mathrm{L}^{\mathrm{m}}$ is converted to $\mathrm{L}^{\mathrm{m}}$ using

$$
\mathrm{L}^{\mathrm{m}^{\prime}}=\frac{\pi \mathrm{L}^{\mathrm{m}}}{\mathrm{F}_{\mathrm{o}}^{\prime} \cos \theta_{\mathrm{o}}}
$$

where

$$
F_{0}^{\prime}=\frac{F_{0}}{R^{2}} \quad R=\frac{d}{d^{\prime}}
$$

and $d$ is earth-sun distance for the day of the year when measurements are made, $d$ is the mean earth-sun distance, and $F_{0}$ is the solar flux now computed for each of the spectral bands using the solar spectral flux data from Neckel and Labs (1984). Since the look-up table tabulates observation zenith angle $\theta$ of the line-of-sight from the ground to the observing platform, the scan angle $\theta^{\prime}$ measured by aircraft or satellite is converted to observation zenith angle $\theta$ using 


$$
\theta=\sin ^{-1}\left[\left(1+\frac{Z}{r_{s}}\right) \sin \theta^{\prime}\right]
$$

where $\mathrm{Z}$ is the height of the sensor above the ground, and $\mathrm{r}_{\mathrm{S}}$ is the radius of the earth.

The computations are performed by a Dave code (1972a, b, c, d) with a series of radiative transfer programs. These programs compute the flux and radiance of the scattered radiation emerging at any level of a plane-parallel atmosphere. Henceforth, primed fluxes and radiances indicate that they have been normalized as in eq. 6. Variables with the superscript $\mathrm{m}$ are measured.

\subsection{Model Wavelengths}

The look-up table is computed for the following wavelengths: $0.639,0.845,0.486$, $0.587,0.663,0.837,1.663$, and $2.189 \mu \mathrm{m}$ which correspond to the following sensors: NOAA-9 AVHRR band $1(0.58-0.68 \mu \mathrm{m})$, band $2(0.725-1.10 \mu \mathrm{m})$; Landsat-5 TM and NS-001 TMS band $1(0.45-0.52 \mu \mathrm{m})$, band $2(0.52-0.60 \mu \mathrm{m})$, band $3(0.63-$ $0.69 \mu \mathrm{m})$, band $4(0.76-0.90 \mu \mathrm{m})$, band $5(1.55-1.80 \mu \mathrm{m})$, and band $7(2.10$ $2.35 \mu \mathrm{m})$. These wavelengths are listed in Table 1. The wavelength chosen to represent a particular band is computed by first calculating $\lambda^{*}$

$$
\lambda^{*}=\frac{\int \lambda L^{m^{\prime}} F_{0} \Psi d \lambda}{\int L^{m^{\prime}} F_{0} \Psi d \lambda}
$$

where

$$
\begin{aligned}
& L^{m^{\prime}}=\text { normalized radiance at the top of the atmosphere } \\
& F_{0}=\text { extraterrestrial solar spectral flux } \\
& \Psi=\text { response function of the sensor }
\end{aligned}
$$

The values for $F_{0}$ are obtained from Neckel and Labs (1984) while the values for $\Psi$ correspond to the specific sensor. For the NOAA-9 AVHRR and Landsat TM sensors, these values are obtained from Kidwell (1985) and Markham and Barker (1985), respectively. The effective wavelength $\lambda^{*}$ in eq. 10 is a function of the normalized radiance, which is a function of the surface reflectance, aerosol optical thickness, and 
Table 1. Spectral bands, aerosol refractive indices, and optical thicknesses.

AVHRR TM

$\begin{array}{llllllll}1 & 2 & 1 & 2 & 3 & 4 & 5 & 7\end{array}$

Sensor Wavelengths

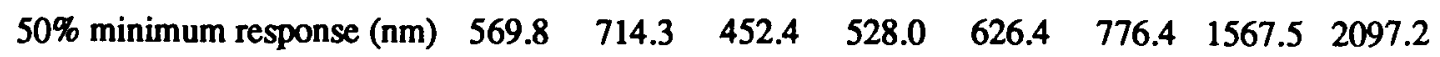

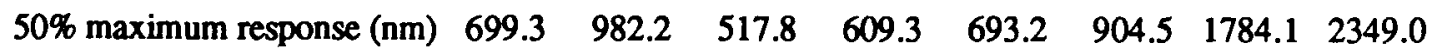

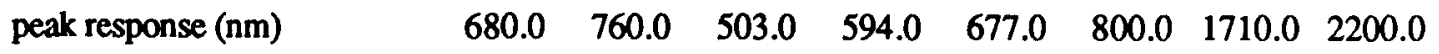

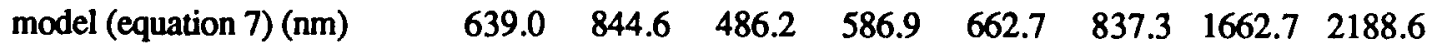

Indices of Refraction

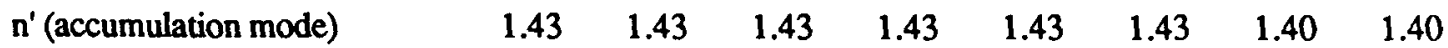

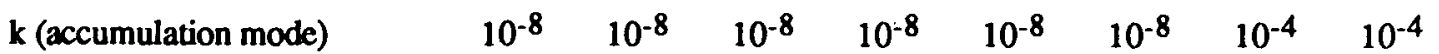

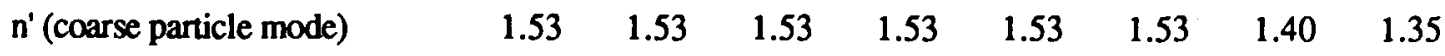

$\begin{array}{lllllllll}k \text { (coarse particle mode) } & 10^{-7} & 10^{-7} & 10^{-7} & 10^{-7} & 10^{-7} & 10^{-7} & 10^{-4} & 0.00814\end{array}$

Optical Thicknesses

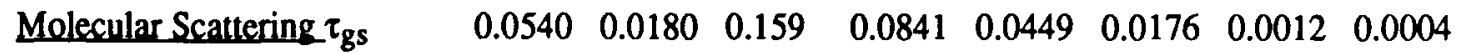

Gaseous Absorption

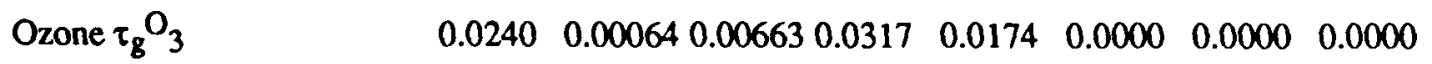

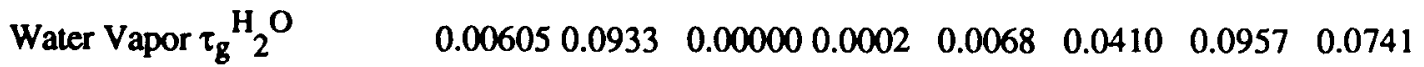

$\begin{array}{lllllllll}\text { Carbon Dioxide } \tau_{\mathrm{g}} \mathrm{CO}_{2} & 0.00071 & 0.0146 & 0.0000 & 0.0000 & 0.0000 & 0.0021 & 0.0077 & 0.0091\end{array}$

Aerosol Absorption $\left(\tau_{\mathrm{a}}=0.25\right)$

$\begin{array}{lllllllll}\tau_{\mathrm{a}}^{\mathrm{a}} & 0.0148 & 0.0223 & 0.0130 & 0.0142 & 0.0150 & 0.0218 & 0.0423 & 0.0189\end{array}$

Composite (section 3.3)
$\tau_{\mathbf{g}} \mathbf{H}$

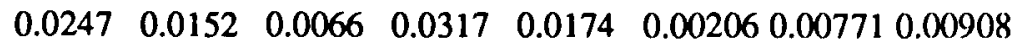
$\tau_{8} L$
$\begin{array}{llllllll}0.0208 & 0.1156 & 0.0130 & 0.0142 & 0.0218 & 0.0628 & 0.138 & 0.0930\end{array}$
$\tau_{\mathbf{g}}$
$\begin{array}{llllllll}0.0455 & 0.131 & 0.0196 & 0.0459 & 0.0392 & 0.0648 & 0.146 & 0.102\end{array}$ 
geometry. The normalized radiance is computed for different models of the earthatmosphere system representative of surface and atmospheric conditions expected for the FIFE Konza Prairie site. Figure 3 shows the surface reflectance profiles used to model this site. A similar approach can be used to determine the wavelengths which correspond to other sensors.

The algorithm is generalized to accept any wavelength in the range $0.48-2.2 \mu \mathrm{m}$. For wavelengths for which there are no entries in the look-up table (see Table 1), the algorithm will interpolate the atmospheric functions $\left(\mathrm{L}_{\mathrm{O}}, \mathrm{T}, \mathrm{F}_{\mathrm{d}}, \mathrm{s}\right)$ for the desired wavelength. The interpolation is performed assuming that aerosol parameters are proportional to the wavelength raised to a power:

$$
\ln \tau_{\mathrm{gs}} \sim-\ln \lambda, \quad \ln \tau_{\mathrm{a}} \sim-\ln \lambda, \quad \ln \mathrm{P} \sim \ln \lambda,
$$

where $\mathrm{P}$ is the scattering phase function. As a result, the radiances in the look-up table can be interpolated linearly between the wavelengths on a log - log scale. The only nonlinear relation is between the gaseous absorptions in the different wavelengths. Correction for the gaseous absorption is discussed in section 3.3.

\subsection{Aerosol Properties}

Because the absorption and scattering of light by atmospheric aerosols is highly variable, some assumptions regarding the size, shape, and composition of the aerosol must be made. In this model, the aerosols are assumed to be spheres so that Mie theory can be used to calculate the scattering by aerosols. Although in general the aerosol particles are not spherical, it is assumed that the sizes assigned to the aerosol particles are the sizes of spheres that have similar scattering properties to the measured aerosol distribution (Shettle and Fenn, 1979). This assumption has further basis because it has been found that the aerosol particles become more spherical as the relative humidity increases (Nilsson, 1979).

The algorithm uses a bimodal aerosol size distribution which combines the optically effective fraction of the accumulation mode $(0.1 \mu \mathrm{m} \leq \mathrm{d} \leq 1.0 \mu \mathrm{m})$ and the coarse particle mode $(\mathrm{d}>0.5 \mu \mathrm{m})$. For the accumulation mode, the dry particles are assumed to be composed of $80 \%$ water soluble sulfates and $20 \%$ water insoluble, dust-like material (Nilsson, 1979). At 70\% relative humidity, water composes half of the volume of these aerosols. The coarse particle mode aerosols are assumed to be made of mostly water insoluble, dust-like particles. The size distribution of the aerosols is represented as the sum of two log-normal distributions; the two distributions represent the accumulation and coarse 


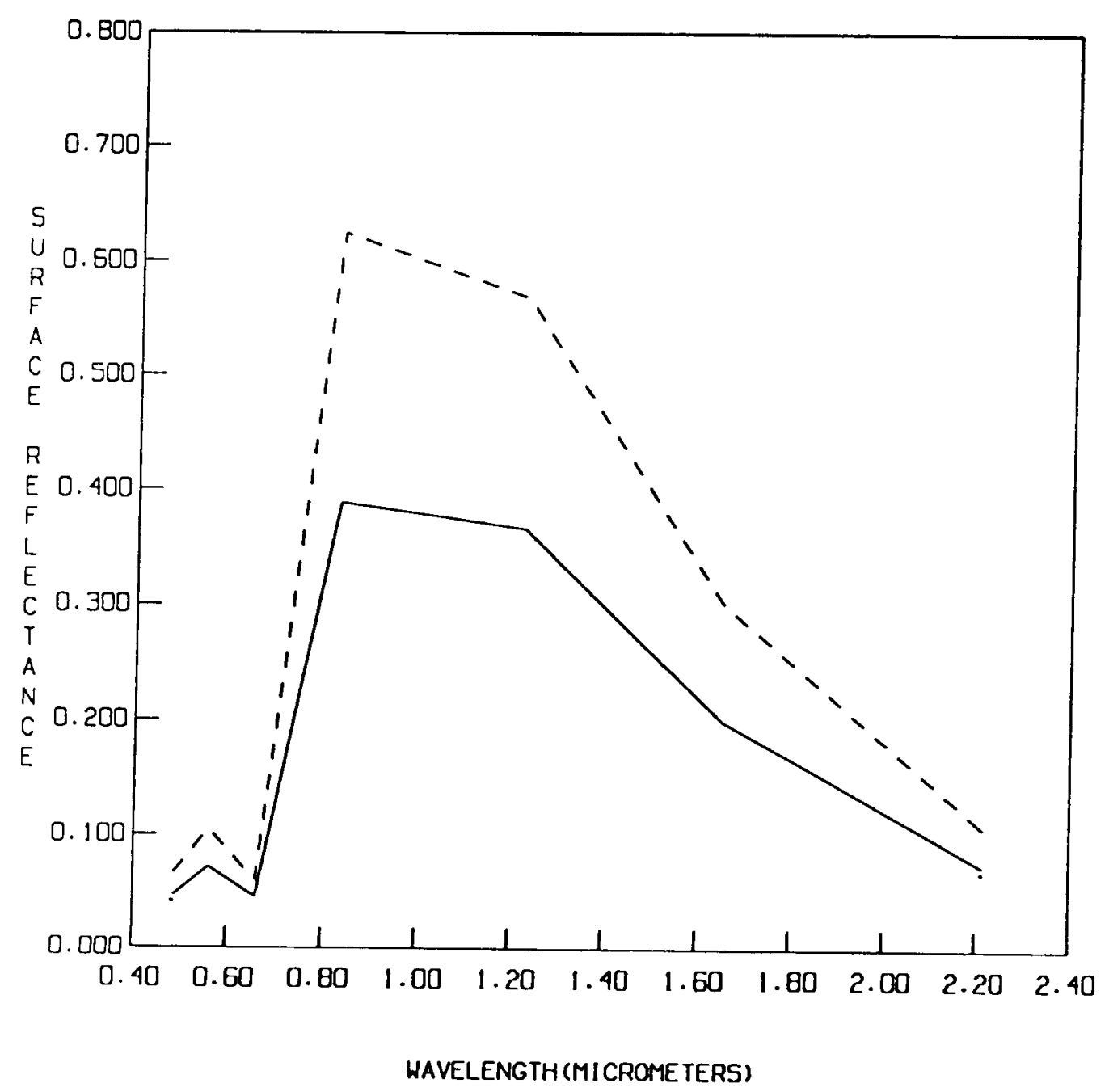

Figure 3. Surface reflectance for senescent grass from a burned surface on the Konza Praire at the FIFE site. The first profile $(\longrightarrow)$ is for nadir view, measured at 14:38 CDT on 15 July 1986 while the second profile $(---)$ is for an observation zenith angle of $45^{\circ}$ measured at 15:13 CDT on 15 July 1986 (Asrar, 1986, private communication). 
particle modes. The number density function of particles of radius $r$ per cubic centimeter of air per micrometer of radius is (Shettle and Fenn, 1979)

$$
n(r)=\frac{d N(r)}{d r}=\sum_{i=1}^{2}\left[\frac{N_{i}}{\ln (10) r \sigma_{i} \sqrt{2 \pi}}\right] \exp \left[\frac{-\left(\log r-\log r_{n}^{i}\right)^{2}}{2 \sigma_{i}^{2}}\right]
$$

where

$$
\begin{aligned}
& N(r)=\text { cumulative number density of particles of radius } r \\
& \sigma_{i}=\text { standard deviation of the logarithm of the radius } \\
& r_{n}^{i}=\text { geometric mean radius } \\
& N_{i}=\text { total number density in } i^{\text {th }} \text { mode }
\end{aligned}
$$

The values of $\mathrm{N}_{\mathrm{i}}, \mathrm{r}_{\mathrm{n}} \mathrm{i}$, and $\sigma_{\mathrm{i}}$ used in the model correspond to the $70 \%$ relative humidity, rural aerosol model of Shettle and Fenn (1979); these values are shown in Table 2. The values of $\mathrm{N}_{\mathrm{i}}$ shown in Table 2 are normalized such that $\mathrm{N}_{1}+\mathrm{N}_{2}=1$ particle $/ \mathrm{cm}^{3}$. This bimodal aerosol size distribution is assumed constant with height.

The composition of the aerosols is expressed in terms of the complex refractive index $n=n^{\prime}-i k$. The refractive index for both the accumulation and coarse particle modes is assumed to depend on the wavelength. Five different real refractive indices are chosen (Nilsson, 1979) and are listed in Table 1. The imaginary index of refraction is modeled assuming that most of the aerosol consists of weakly absorbing particles with $k<10^{-4}$, mixed with a small number of highly absorbing particles with $\mathrm{k} \sim 1.0$. Although Shettle and Fenn (1979) choose to represent mixtures of this type with a composite imaginary refractive index in the range $0.001<\mathrm{k}<0.01$, which is close to the values obtained by various remote sensing and in-situ techniques (Patterson and Grams, 1984; Reagan et al., 1980), this procedure is not adopted here because as Bohren and Huffman (1983) point out, no common substances exist which have an imaginary index in this range. In the correction algorithm, the imaginary refractive index corresponding to the weakly absorbing particles is used. The imaginary refractive indices for the accumulation mode, which are listed in Table 1, correspond to water while the values for the coarse particle mode correspond to crystalline quartz, which is a constituent of atmospheric dust (Nilsson, 1979). The aerosol refractive index is assumed to be constant with height. 
Table 2. Aerosol size distribution parameters.

Accumulation mode Coarse particle mode

Geometric mean radius $r_{n}{ }^{i}$

0.0285

0.457

Standard deviation of the

logarithm (base 10)

0.81

0.81

of the radius

$\sigma_{\mathbf{i}}$

Number density $\mathrm{N}_{\mathbf{i}}$

0.999875

0.000125 
The aerosol absorption needed to match the experimentally measured value is modeled by adding the necessary absorption to the gaseous absorption values. Thus, it is assumed that the absorbing particles are small compared to the wavelength and that they occur separately from the other particles (external mode); in this case their scattering effects are small relative to their absorptive effects (Fraser and Kaufman, 1985). The required additional aerosol absorption amount is determined by the aerosol single scattering albedo $\omega_{0}$ which is the ratio of scattering to extinction. Aerosol absorption is then given by $1-\omega_{0}$. The values of $\omega_{0}$ used in the algorithm are derived from the $70 \%$ relative humidity, rural aerosol model of Shettle and Fenn (1979). The single scattering albedos, shown in Table 1, range from 0.95 at $0.486 \mu \mathrm{m}$ to 0.86 at $2.550 \mu \mathrm{m}$. These values for the visible spectrum agree with those reported by Waggoner et al. (1981) which lie in the range $0.89 \leq \omega_{0} \leq 1.0$ for rural areas. The amount of additional aerosol absorption which is added to the gaseous absorption is

$$
\tau_{a}^{a}=\tau_{a}\left(\omega_{0}^{\prime}-\omega_{o}\right)
$$

where

$$
\begin{aligned}
& \tau_{\mathrm{a}}=\text { aerosol optical thickness } \\
& \omega_{0}{ }^{\prime}=\text { single scattering albedo for chosen refractive index } \\
& \omega_{0}=\text { desired single scattering albedo }
\end{aligned}
$$

Since in general $\mathrm{k} \ll 1$, then $\omega_{0}^{\prime} \approx 1$, and

$$
\tau_{a}^{a} \approx \tau_{a}\left(1-\omega_{0}\right)
$$

Should the algorithm be applied for an urban aerosol or smoke, where the single scattering albedo $\omega_{0}$ used in the formation of the look-up tables (see Table 1) may be smaller or larger than the new value $\omega_{0}{ }^{*}$, the difference in absorption can be corrected by adding (or subtracting) the excess absorption to the gaseous absorption:

$$
\Delta \tau_{\mathrm{a}}^{\mathrm{a}}=\tau_{\mathrm{a}}\left(\omega_{\mathrm{o}}-\omega_{\mathrm{o}}^{*}\right)
$$

\subsection{Gaseous Absorption}

For the most part, the Landsat TM and NOAA AVHRR visible and near IR bands have been selected to minimize gaseous absorption. However, in some cases, the sensor 
channel is either relatively broad (as in the case of AVHRR band 2) or lies within a broad gaseous absorption band (as in the case of TM bands 2 and 3 which lie within the ozone continuum) so that the absorption by atmospheric gases can be both significant and variable. In the atmospheric correction algorithm, gaseous absorption was computed using the LOWTRAN 6 code (Kniezys et. al., 1983) which computes atmospheric absorption from $0.250 \mu \mathrm{m}$ to $28.5 \mu \mathrm{m}$ due to water vapor, carbon dioxide (and other uniformly mixed gases), ozone, nitrogen continuum, oxygen, and HNO3. In the case of the AVHRR and TM bands, the absorbing gases are water vapor, carbon dioxide, and ozone. The gaseous absorption optical thickness in the vertical direction due to gaseous species $\mathrm{x}$ for each band is computed using

$$
\tau_{g}^{x}=-\frac{1}{m} \ln \left\lfloor\frac{\int T_{x} L^{m^{\prime}} F_{o} \Psi d \lambda}{\int L^{m^{\prime}} F_{o} \Psi d \lambda}\right\rfloor
$$

where

$$
\begin{aligned}
& m=\text { air mass along inclined path } \\
& T_{x}=\text { transmittance due to gaseous species } x
\end{aligned}
$$

Since the gaseous absorption is quite variable, the algorithm uses a weighted average of the absorption values computed using the tropical, mid-latitude summer, and mid-latitude winter atmospheres given in the LOWTRAN 6 code. The weighted average of the gaseous absorption $\tau_{g}^{x}$ used in the algorithm is given by

$$
\tau_{g}^{x *}=0.25 \tau_{g 1}^{x}+0.5 \tau_{g 2}^{x}+0.25 \tau_{g 3}^{x}
$$

where $\tau_{\mathrm{g} 1}^{\mathrm{X}}, \tau_{\mathrm{g} 2}^{\mathrm{X}}$, and $\tau_{\mathrm{g} 3}^{\mathrm{x}}$ are the gaseous absorption values computed using the mid-latitude winter, mid-latitude summer, and tropical values respectively. The absorption optical thicknesses due to water vapor, carbon dioxide, and ozone for each band are shown in Table 1 .

The algorithm can be applied to any specified gaseous optical thickness $\tau_{\mathrm{g}}$. An approximate correction is applied to the radiances in the look-up table to account for the excess (or deficit) in the absorption $\left(\Delta \tau_{g}\right)$. The user may compute the required value of $\tau_{g}$ based on the sensor spectral response using the LOWTRAN program (Kneizys et al., 1983). For the correction of the look-up table we may distinguish between $\Delta \tau_{\mathrm{gL}}$ - excess 
or deficit in the gaseous absorption in the lower part of the atmosphere (e.g. water vapor), assumed to be mixed uniformly with the aerosol; and $\Delta \tau_{\text {gH }}$ excess or deficit in the gaseous absorption in the upper part of the atmosphere, above the aerosol layer (e.g. $\mathrm{O}_{2}, \mathrm{O}_{3}$, $\mathrm{CO}_{2}$ ). The correction is performed by the following transformations in the look-up table:

$$
\begin{aligned}
L_{o} \rightarrow L_{o} \exp \left[-\left(\frac{\Delta \tau_{g L}}{2}+\Delta \tau_{g H}\right)\left(\frac{1}{\mu}+\frac{1}{\mu_{o}}\right)\right] \\
F_{d} \rightarrow F_{d} \exp \left[\frac{-\left(\Delta \tau_{g L}+\Delta \tau_{g H}\right)}{\mu_{o}}\right] \\
T \rightarrow T \exp \left[\frac{-\left(\Delta \tau_{g L}+\Delta \tau_{g H}\right)}{\mu}\right] \\
s \rightarrow s \exp \left[-2 \Delta \tau_{g L}\right]
\end{aligned}
$$

Here $\mu=\cos \theta$ and $\mu_{0}=\cos \theta_{0}$. In these equations the effect of multiple scattering on the path length through the atmosphere is neglected. It is also assumed that the path radiance $\mathrm{L}_{\mathrm{O}}$ is generated above the middle of the boundary layer. As result, the additional gaseous attenuation is made by half of the boundary layer, but all of the atmosphere above. The parameter $s$ is the reflectance of the atmosphere for radiation entering its base. The effective direction for reflection is $60^{\circ}$. Hence, the effective absorption optical thickness is twice the vertical value. Theses assumptions are based on our physical understanding of radiative transfer and are tested in Section 6.

\subsection{Altitude Profiles}

The radiative transfer computations require as input the altitude distributions of both the absorbing gases and aerosols. These two distributions have separate profiles. The altitude distribution of aerosols used in the algorithm is based on the 'average' distribution of Braslau and Dave (1973) which is shown in Figure 4. The aerosol altitude distribution is first scaled to obtain the desired aerosol optical thickness. 

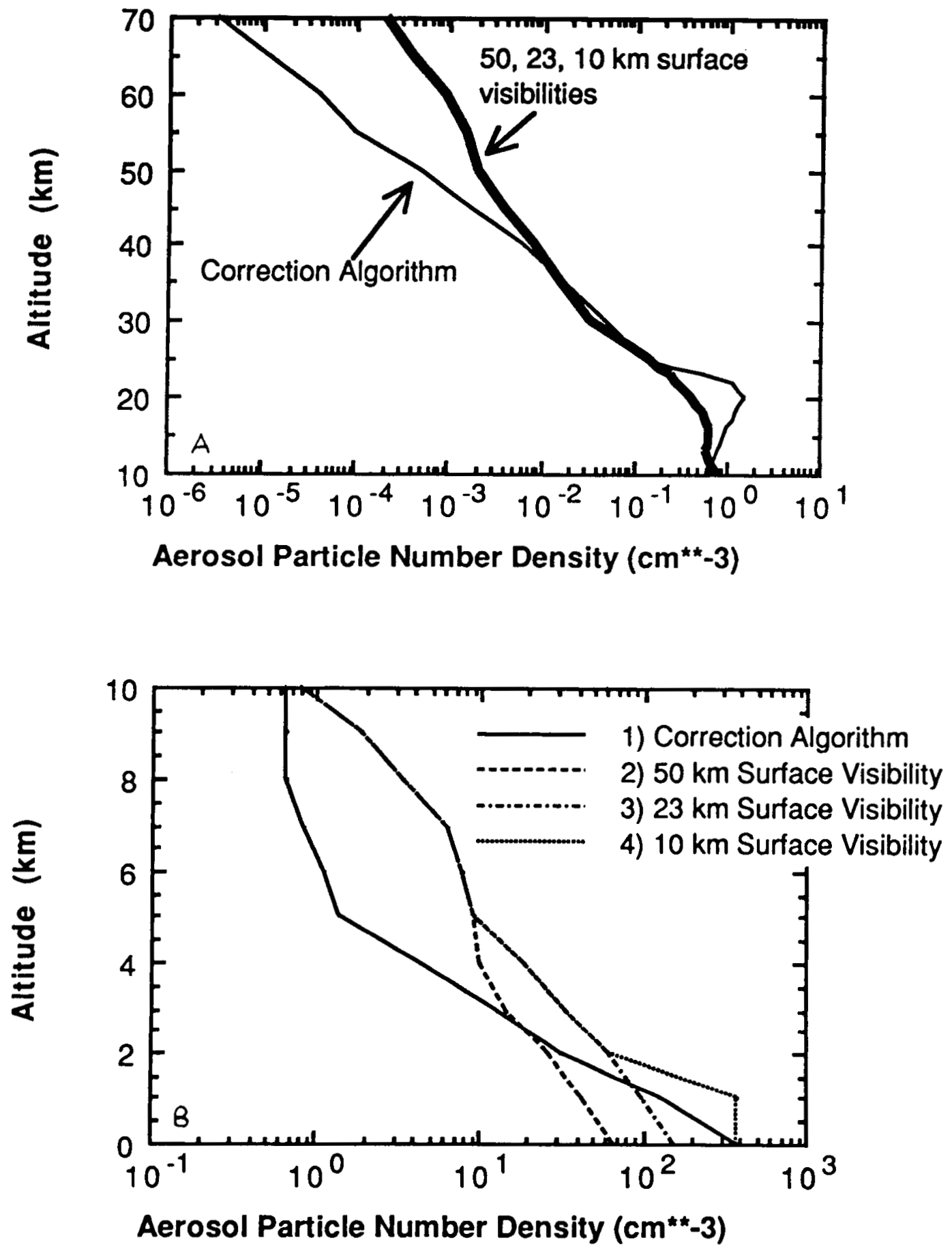

Figure 4. Aerosol particle number density profiles for: 1) 'average' distribution of Braslau and Dave (1973) used in the correction algorithm; 2) $50 \mathrm{~km}$ surface visibility ,3) $23 \mathrm{~km}$ surface visibility, and 4) $10 \mathrm{~km}$ surface visibility models from Shettle and Fenn (1979). Figure $4 \mathrm{a}$ is for altitudes between 10 and $70 \mathrm{~km}$ while figure $4 \mathrm{~b}$ is for altitudes between 0 and $10 \mathrm{~km}$. These profiles have been normalized for an aerosol optical thickness $\tau_{\mathrm{a}}=0.25$ at $0.55 \mu \mathrm{m}$. 
Because the various gaseous absorbers described in the previous section have different altitude distributions, a composite altitude distribution is computed which accounts for all the absorbing gases including the aerosol absorption described in section 2.2. In this method, the total gaseous absorption is divided into "low" and "high" components. The "low" component is composed of water vapor and aerosol absorption while the "high" component is composed of ozone and $\mathrm{CO}_{2}$ absorption. The "low" component uses an altitude distribution based on the 'average' aerosol profile of Braslau and Dave (1973), while the "high" component uses an altitude distribution based on the mid-latitude ozone profile of McClatchey et al. (1971). The altitude distributions of the "low" and "high" components are normalized and combined to produce an altitude profile that retains the maximum aerosol and water vapor absorption near the surface and the maximum ozone absorption in the lower stratosphere. Because the aerosol absorption is a function of the aerosol optical thickness (see eq. 13), the gaseous absorption profile is a function of aerosol optical thickness as well as wavelength. The atmospheric pressure profile used in the algorithm is adapted from the mid-latitude summer profile of McClatchey et al. (1971).

\subsection{Molecular and Aerosol Optical Thickness}

The molecular scattering (or Rayleigh) optical thickness $\tau_{\mathrm{gs}}$ is computed for sea level from (Hansen and Travis, 1974)

$$
\tau_{\mathrm{gs}}=0.008569 \lambda^{-4}\left(1+0.0113 \lambda^{-2}+0.00013 \lambda^{-4}\right)
$$

where the wavelength is in micrometers. This expression assumes the surface sea-level pressure is $1013 \mathrm{mb}$. In the case the surface is not at sea level. The value of the molecular scattering optical thickness $\tau_{\mathrm{gs}}$ is assumed to vary according to:

$$
\tau_{\mathrm{gs}}\left(\mathrm{Z}_{\mathrm{o}}\right)=\tau_{\mathrm{gs}}(0) \exp \left(\frac{-\mathrm{Z}_{\mathrm{o}}}{9}\right)
$$

where $\mathbf{Z}_{\mathbf{o}}$ is the height of the surface above sea level in kilometers. In order to avoid a need for a new radiative transfer computation for each height of a surface, the computations are performed for $Z_{0}=0.4 \mathrm{~km}$, and the look-up table is adjusted each time the user specifies a different height. The algorithm adjusts the look-up table to account for the different molecular optical thickness by adjusting the wavelength of the radiation. Substitution of the relationship between $\lambda$ and $\tau_{\text {gs }}$ (eq. 18) yields 


$$
\lambda\left(Z_{0}\right)=\lambda(0.4) \exp \left[\frac{\left(Z_{0}-0.4\right)}{36}\right]
$$

For example, for $Z_{0}=0 \mathrm{~km}, \lambda$ will increase by $1.1 \%$, whereas for $Z_{0}=2 \mathrm{~km}, \lambda$ will increase by $4.3 \%$. The error introduced by this method is in the effective scattering phase function, but this change is negligible relative to the general uncertainty in the scattering phase function due to the uncertainty in the aerosol size distribution.

The relation between upward radiance and surface reflectance for each spectral band is computed for four aerosol optical thicknesses, $\tau_{\mathrm{a}}=0.0,0.25,0.50$, and 1.00, except for TM bands 5 and 7 where only the first two values are used. These values are selected to cover the range of aerosol optical thicknesses which could be expected for most remote sensing applications.

\subsection{Measurement Altitudes}

The radiative transfer computations are tabulated at three measurement altitudes above the ground: $0.45 \mathrm{~km}, 4.5 \mathrm{~km}$, and $80 \mathrm{~km}$. The algorithm will use these altitudes to interpolate to the input measurement altitude. Since 80.0 kilometers is above the atmosphere, corrections to satellite measurements are made with the $80 \mathrm{~km}$ tables.

For altitudes less than $0.45 \mathrm{~km}$, it is assumed that the aerosols and the absorbing gases are well mixed and it is possible to linearly interpolate between the atmospheric optical properties $\left(L_{0}\right.$ and $\left.T\right)$ at $Z=0 \mathrm{~km}$ and at $Z=0.45 \mathrm{~km}$ above the ground:

$$
\begin{aligned}
& \mathrm{L}_{\mathrm{o}}(\mathrm{Z})=\mathrm{L}_{\mathrm{o}}(\mathrm{Z}=0.45)\left(\frac{\mathrm{Z}}{0.45}\right) \\
& \mathrm{T}(\mathrm{Z})=(\mathrm{T}(0.45) \mathrm{Z}+(0.45-\mathrm{Z})) / 0.45
\end{aligned}
$$

For altitudes above $4.5 \mathrm{~km}$, interpolations are performed between values of $\mathrm{L}_{0}$ and $T$ at $4.5 \mathrm{~km}$ and $80 \mathrm{~km}$. Although the atmospheric model contains aerosols between these altitudes, the interpolations are based on the assumption that $\mathrm{L}_{\mathrm{O}}$ and $\mathrm{T}$ depend essentially on molecular scattering between 4.5 and $80 \mathrm{~km}$. The interpolations are performed linearly as a function of the molecular scattering coefficient $\sigma_{\mathrm{gs}}(\mathrm{Z})$ :

$$
\sigma_{g s}(Z)=\sigma_{g s}(0) \exp \left(\frac{-Z}{9}\right)
$$

Hence the transmission and $\mathrm{L}_{0}$ become 


$$
\begin{aligned}
& T(Z)=(T(80.0)-T(4.5)) * \frac{\exp (-4.5 / 9)-\exp (-Z / 9)}{\exp (-4.5 / 9)-\exp (80 / 9)} \\
& L_{0}(Z)=\left(L_{0}(80.0)-L_{0}(4.5)\right) * \frac{\exp (-4.5 / 9)-\exp (-Z / 9)}{\exp (-4.5 / 9)-\exp (80 / 9)}
\end{aligned}
$$

Between $0.45 \mathrm{~km}$ and $4.5 \mathrm{~km}$ the interpolation is uncertain due to the inhomogeneity of the aerosol layer. Since the linear interpolation used below $0.45 \mathrm{~km}$ is usually suitable to extrapolate for heights below $1 \mathrm{~km}$, and the aerosol concentration decreases rapidly above $3 \mathrm{~km}$ so that the interpolation used above $4.5 \mathrm{~km}$ is appropriate for extrapolation to heights between 3 and $4.5 \mathrm{~km}$, the algorithm extrapolates from these two regions to the desired height $\mathrm{h}(0.45 \mathrm{~km}<\mathrm{Z}<4.5 \mathrm{~km})$, and chooses the result that shows a minimal atmospheric effect. Thus, the lower values of $L_{0}$ and higher values of $T$ are chosen for the solution.

\subsection{Look-up Tables}

The look-up tables used by the correction algorithm contain the normalized radiances and fluxes computed by the radiative transfer routines. The values generated are stored to be used by the main program. Eight look-up tables are produced, one table for each of the 2 AVHRR bands of 0.639 and $0.845 \mu \mathrm{m}$ and one for each of the $6 \mathrm{TM}$ bands of 0.486 , $0.587,0.663,0.837,1.663$ and $2.189 \mu \mathrm{m}$. Each table is arranged for 3 heights of 0.45 , 4.5 and 80.0 kilometers. Each table contains values for 9 solar zenith angles $\theta_{0}(10,20$, $30,40,50,60,66,72$, and $\left.78^{\circ}\right), 13$ observation zenith angles $\theta\left(0^{\circ}\right.$ to $78^{\circ}$, every $\left.6^{\circ}\right), 19$ observation azimuth angles ( $0^{\circ}$ to $180^{\circ}$, every $10^{\circ}$, plus $5^{\circ}$ and $175^{\circ}$ ), and 4 aerosol optical thicknesses $\tau_{\mathrm{a}}(0.0,0.25,0.50$ and 1.0$)$ for all wavelengths, except for 1.663 and $2.189 \mu \mathrm{m}$ where only first two optical thicknesses of 0.0 and 0.25 are used.

\subsection{Computational Procedure}

\subsection{General}

Input data to the correction program consists of the date, time, measurement wavelength, aerosol and gaseous absorption optical thicknesses at the measurement wavelength $\lambda$, solar zenith angle $\theta_{\mathrm{o}}$, observation scan angle $\theta^{\prime}$, observation azimuth angle $\phi$, height of the surface above sea level $\mathrm{Z}_{0}$, measurement height $\mathrm{Z}^{\mathrm{m}}$, and the measured spectral radiance in absolute $\mathrm{L}^{\mathrm{m}}$ or reflectance $\mathrm{L}^{\mathrm{m}}$ units (option 1 ), or surface reflectance $\rho$ (option 2). The wavelength, solar and observation angles, and aerosol optical thickness 
data must be in the ranges discussed above as no extrapolation is performed. If the selected wavelength or altitude does not match the values used to construct the look-up table, the algorithm interpolates on wavelength and altitude as described above.

If option 1 is selected, the program computes the surface reflectance $\rho$, total spectral irradiance on the surface $F_{g}$, and total spectral radiance of the ground $L_{g}$ in the direction of observation using eq. $2,3,4$ and 5 . The total spectral irradiance $F_{g}$ is computed in Watts $/ \mathrm{m}^{2} / \mu \mathrm{m}$ and total upward spectral radiance $\mathrm{L}_{\mathrm{g}}$ is computed in Watts $/ \mathrm{m}^{2} / \mu \mathrm{m} / \mathrm{sr}$. If option 2 is selected, the program computes the absolute and normalized radiances $\mathrm{L}^{\mathrm{m}}$ and $\mathrm{L}^{\mathrm{m}}$, total spectral irradiance on surface $F_{g}$ and the total upward spectral radiance $L_{g}$ in Watts $/ \mathrm{m}^{2} / \mu \mathrm{m} / \mathrm{sr}$.

The program for making atmospheric corrections consists of a main program called FIFEWAV. The computations are performed in single precision and seven subroutines are called at different stages by the main program. The listings of the main program and subroutines are given in section 9 . The statement numbers for the program and subroutines are given in parentheses. Table 3 lists the variables appearing in the main program and associated subroutines and their equivalent in the text. The asterisk superscript indicates interpolated values. The subroutines called by the main program FIFEWAV are listed below:

Subroutine READIN (6350 - 6580): This subroutine reads the input data from unit number 5 and writes it on unit number 6 . The purpose of this subroutine is to perform a check on the input data set.

Subroutine FINDW (6620 - 6860) : This subroutine checks to see if $\lambda^{m}$ falls in the range of wavelengths for which look-up tables are available and picks two wavelengths between which $\lambda^{\mathrm{m}}$ falls. The subroutine prints an error message and returns the control to the main program if $\lambda^{\mathrm{m}}$ does not fall in the range of wavelengths look-up table provides. The main program processes a new data point.

Subroutine INTSFX (6900 - 7100): This subroutine computes values of the sun-earth distance $R$ for 365 days of the year. These values are returned to the main program, which chooses the value of $\mathrm{R}$ for the day the measurements were made.

Subroutine INTHGH (7140 - 8530): This subroutine computes interpolated values of $L_{0}$ and $T / \pi$ for the measured height MHGHT (eq. 21a , 21b, 23 and 24). The transmission $T$ is divided by $\pi$ to account for the $\pi$ appearing in eq. (1). 
Table 3. Variables appearing in FIFEWAV program and associated subroutines, and their equivalent in the text.

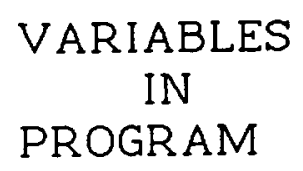

ABSRAD

AIRR

AMUO

ANGLE, PHI

ARAD

FDOWN

FFLUX

FINT

FOIRR

FT

INT

IRRID

MHGHT

MINT

MPHI

MTAU

MTHET

MTHETO

MWAV

NFDOWN

OPTH

PIT

$R, R R$

RHO

RHOS

SBAR

THE

THETO

WAV
VARIABLES

IN

TEXT

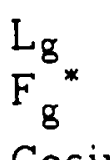

Cosine $\left(\theta_{0}{ }^{m}\right)$

$\mathrm{L}_{\mathrm{g}}{ }^{*}$

$F_{d}$

$F_{0}^{\prime}$

$L^{\prime *} \circ$

F。

$\mathrm{T}^{*} / \pi$

L 0

$F_{g}$

$\mathrm{Z}^{\mathrm{m}}$

$L^{m}, L^{\prime m}$

$\varphi^{\mathrm{m}}$

$\tau_{\mathrm{a}}^{\mathrm{m}}$

$\theta^{\mathrm{m}}$

$\theta_{0}^{\mathrm{m}}$

$\lambda^{\mathrm{m}}$

$F^{\prime *}$

$\tau_{a}$

$\mathrm{T} / \pi$

$\mathrm{R}$

$\rho$

$\rho^{*}$

$s$

$\theta$

$\theta_{\mathrm{o}}$

$\lambda$

26 (section 5)

(section 5)

(eq. 1, 22)

(eq. 1)

(section 5)

(section 5)

(eq. 22, 23)

(section 5)

(eq. 6)

(section 5)

(section 5)

(section 5)

(eq.1)

(eq. 1, 22)

(eq. 1)

(eq. 1)

(eq. 1)

(eq. 1)

(eq. 1)

(section 5)

(eq. 1)

(section 5)

(eq. 23)

(section 5)

(section 5)

(eq. 1)

(eq. 1)

(eq. 1)

(eq. 1) 
Subroutine INTERP (8570 - 9020): The purpose of this subroutine is to return to the main program the interpolated values of $L^{1 *}{ }_{0}, F^{*}{ }_{d}, T^{*} / \pi$, and $s^{*}$. This is a general purpose interpolation routine and is called at different stages by the main program. This subroutine does not allow any extrapolation and an error message is printed when the values are out of bounds. The asterisk indicates in most cases values interpolated from the look-up table.

Subroutine INTEXP (9040 - 9840): This subroutine sends exponantially interpolated values of $L^{\prime *}{ }_{0}, F^{\prime *}{ }_{d}, T^{*} / \pi$ and $s^{*}$ for the measured optical thickness MTAU. It calles a systems subroutine ZXGSN residing in IMSL math package.

Subroutine ZXGSN (9520): This subroutine is called by subroutine INTEXP, it computes the minimum of function on certain interval which is used for exponantial interpolation.

\section{PROCEDURE:}

Subroutine READIN is called (490) to read the input data from unit number 5 and write it on unit number 6 as well as to perform a check on the input data. The main program reads the first two data cards from unit number 5 and writes the labels for output on unit number 6 and $56(690$ - 840). The program reads from unit 20 the solar spectral irradiances, which are used to compute the solar flux for the measured wavelength MWAV (870 - 950). The program enters into a loop over the number (INUM) of data points to be processed (1020). The program reads the values of time, $\lambda^{\mathrm{m}}, \tau_{\mathrm{a}}^{\mathrm{m}}, \theta_{\mathrm{o}}{ }^{\mathrm{m}}, \theta^{\mathrm{m}}, \varphi^{\mathrm{m}}, \mathrm{Z}^{\mathrm{m}}, \mathrm{L}^{\mathrm{m}}$ or $\mathrm{L}^{\mathrm{m}^{\prime}}, \tau_{\mathrm{gL}}, \tau_{\mathrm{gH}}$, and $\mathrm{Z}_{0}$ if NOPT is 1 , and values of time, $\lambda^{\mathrm{m}}, \tau_{\mathrm{a}}^{\mathrm{m}}, \theta_{0}{ }^{\mathrm{m}}, \theta^{\mathrm{m}}, \varphi^{\mathrm{m}}, \mathrm{Z}^{\mathrm{m}}$, $\rho^{m}, \tau_{\mathrm{gL}}, \tau_{\mathrm{gH}}$ and $\mathrm{Z}_{0}$ if NOPT is 2 (1190 - 1230). If values of absorptions $\tau_{\mathrm{gL}}$ and $\tau_{\mathrm{gH}}$ are 0.0 , default values are computed by interpolating linearly from the values of TAUGL $(\lambda)$ and TAUGH $(\lambda)(330-340)$ for the measured wavelength $\lambda^{m}(1300-1600)$.

Subroutine FINDW is called to select the look-up table for the two wavelengths between which $\lambda \mathrm{m}$ lies by assigning the proper file number NFILE1 and NFILE2 (1700 - 1740). A new data point is read if subroutine FINDW does not find the input wavelength lying in the range of wavelengths for which look-up table is provided $(0.486$ $2.2 \mu \mathrm{m})$.

The ratio of earth-sun distance ( $R$, eq. 8 ) is computed for 365 days of the year by subroutine INTSFX. The program (1870 - 2020) changes the month and day to the 
Julian day if MOPT is 1 . The corrected values of incident solar flux $\mathrm{F}_{0}^{\prime}$ are computed by using eq. 8 (2150).

The observation scan angle of satellite or aircraft is changed to observation zenith angle at the ground by using eq. 9 (2250).

Statements $(2610$ - 3040) read the look-up table chosen for the two wavelengths on each side of the measured wave length $\lambda^{m}$. The parameters $\theta, \varphi, \lambda, \tau_{a}, \theta_{0}, s, F_{d}^{\prime}, L_{o}^{\prime}$, and $T / \pi$ are read for four optical thicknesses, except for wavelengths of $1.663 \mu \mathrm{m}$ and $2.189 \mu \mathrm{m}$, for which look-up tables are available for only two optical thicknesses of 0.0 and 0.25 . The subroutine INTHGH (3120) is called to compute the interpolated values of $\mathrm{L}_{0}{ }^{\prime}$ and $\mathrm{T} / \pi$ for the measured height MHGHT (eq. 21a, 21b, 23 and 24). The statements (3170 - 3180) adjust the look-up table for the surface height SHGHT and then interpolate values of $s, F_{d}{ }^{\prime}, L_{o}{ }^{\prime}$ and $T / \pi(3230-3410)$ for the measured wavelength $\lambda^{m}$ (see documentation sec. 3.1). The excess or deficit gaseous absorption in the upper and lower atmosphere is computed (3450 - 3500) using $\tau_{\mathrm{gL}}$ and $\tau_{\mathrm{gH}}$ whose values are supplied as input parameters; or if values read are zero, default values computed earlier in program (1300 - 1600) are used. New values of $s, L_{0}^{\prime}, F_{d}{ }^{\prime}$, and $T / \pi$ are computed (3540 - 3780) after adjusting for the excess and deficit of gaseous absorption (eq. 17a, 17b, 17c, and 17d).

The next step is to compute the interpolated values of $L_{0}^{\prime}, F_{d}^{\prime}$, and $T / \pi$ for the measured height and geometry $\left(\theta_{0} \mathrm{~m}, \theta^{\mathrm{m}}\right.$, and $\left.\varphi^{\mathrm{m}}\right)$. The mesh of the tables is small enough to allow accurate linear interpolations. The interpolations are made for each of the four aerosol optical thicknesses: $0.00,0.25,0.50$, and $1.00 . \mathrm{L}^{*}{ }_{0}$ is interpolated from the data set $L_{0}$ for $\theta_{0} m, \varphi^{m}$, and $\theta^{m} ; F^{*}{ }_{d}$ is interpolated from the data set $F_{d}$ for $\theta_{0}{ }^{m}$; and $T^{*} / \pi$ is interpolated from the data set $T / \pi$ for $\theta_{m}$. To make these interpolations, subroutine INTERP ( 4050 - 4140) is called to compute the interpolated values of both $\mathrm{L}_{0}$ ' and $F_{d}$ for $\theta_{0} \mathrm{~m}$. The part of program between 4270 to 4430 calls subroutine INTERP to compute the interpolated values of $L_{0}$ for $\varphi_{m}$. Subroutine INTERP is called again to compute the interpolated value of $L_{o}{ }^{\prime}$ and $T / \pi$ for $\theta_{m}(4680-4770)$. If the measured $\theta_{o}{ }^{m}, \varphi^{m}$, or $\theta^{m}$ are out of the range of data tabulated for $\theta_{0}, \varphi$, and $\theta$, subroutine INTERP returns control to the main program after printing an appropriate message. It does not allow any extrapolation. The program will then process a new data point if the error message is printed. 
Subroutine INTEXP (4910) is called to perform exponential interpolations on four radiation parameters $\mathrm{L}^{*}{ }_{0}, \mathrm{~F}^{*}{ }_{\mathrm{d}}, \mathrm{s}$, and $\mathrm{T}^{*} / \pi$ for measured optical thickness MTAU(4960 5190). Subroutine INTEXP checks the four parameters one by one for linearity and sends the control back to the main program if any of the functions are linear. The main program then calls the subroutine INTERP to perform linear interpolation.

Statement $\mathbf{5 2 7 0}$ sends control to statement $\mathbf{5 5 5 0}$ to compute the spectral radiance, if NOPT is 2. Statements 5280 to 5380 use the interpolated values $\mathrm{L}^{1 *}{ }_{\mathrm{o}}, \mathrm{F}^{*}{ }_{\mathrm{d}}$, and $\mathrm{T}^{*} / \pi$ to compute the surface reflectance $\rho$, total spectral irradiance $F_{g}$, and total spectral radiance of the ground $\mathrm{L}_{\mathrm{g}}$ in the direction of observation (eq. 2, 3, and 4). The total spectral irradiance $F_{g}$ is computed in Watts $/ \mathrm{m}^{2} / \mu \mathrm{m}$, and the total upward spectral radiance $L_{g}$ is computed in Watts $/ \mathrm{m}^{2} / \mu \mathrm{m} / \mathrm{sr}$. Statements 5440 - 5450 write the output on FORTRAN logical units 6 and 56.

Statements 5540 - 5790 use the interpolated values $\mathrm{L}^{*}{ }_{0}, \mathrm{~F}^{* *}{ }_{\mathrm{d}}$, and $\mathrm{T}^{*} / \pi$ to compute the spectral radiance $L^{m}$, total spectral irradiance $F_{g}$, and total spectral radiance of the ground $\mathrm{L}_{\mathrm{g}}$ in the direction of observation (eq. 2,3, and 4) if MOPT is 2. The total spectral irradiance $F_{g}$ is computed in Watts $/ \mathrm{m}^{2} / \mu \mathrm{m}$, and the total upward spectral radiance $L_{g}$ is computed in Watts $/ \mathrm{m}^{2} / \mu \mathrm{m} / \mathrm{sr}$. The output is written on FORTRAN logical units 6 and 56 .

\subsection{Input}

Input data to this program consists of two input files. The first file (FORTRAN logical unit number 5) describes input to a particular case, while the second file (FORTRAN logical unit number 20) reads solar spectral irradiances (Neckel and Labs, 1984) as function of wavelength. The program uses 8 look-up tables which are not to be changed by the user (FORTRAN logical unit numbers 7 - 14). In order to demonstrate the input data, four cases representative of different options are presented. The input cards for all four runs are listed in Table 4.

\section{INPUT FROM UNIT NUMBER 5: (see Table 4)}

1. The first card contains the labels to identify the input parameters in step 2 below.

2. The second card contains the options for determining the units for the measured reflectance or radiance, the format for the date of the measured data, and the option either to compute the surface reflectance or radiance. 
TABLE 4. EXAMPLES OF INPUT DATA.

(RUN 1)

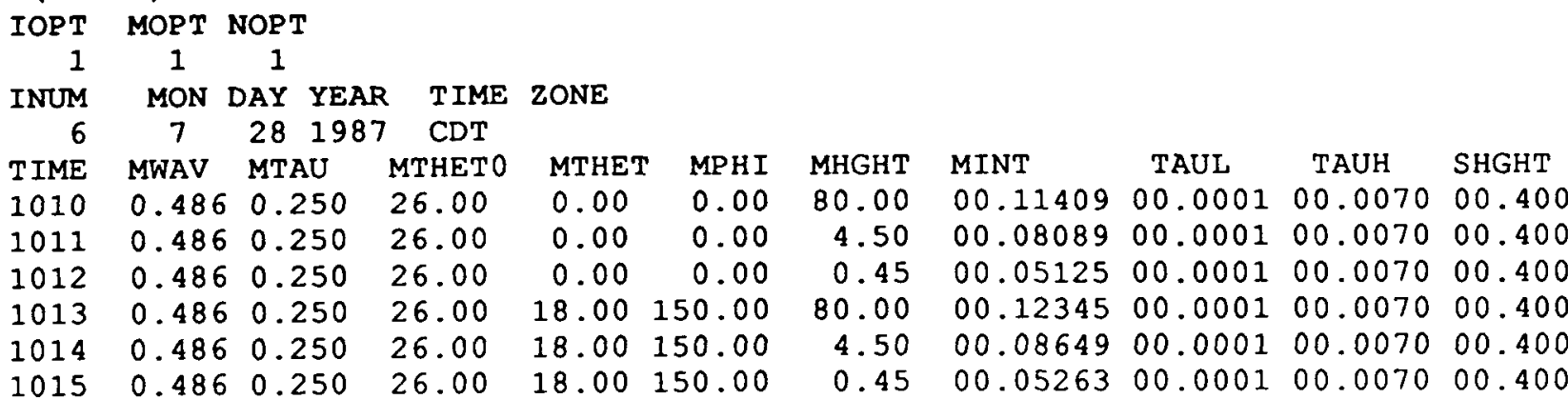

(RUN 2)

IOPT MOPT NOPT

$\begin{array}{lll}1 & 2 & 1\end{array}$

INUM DAY YEAR TIME ZONE

$\begin{array}{llll}6 & 209 & 1987 & \mathrm{CDT}\end{array}$

1010

MWAV MTAU MTHETO

$0.486 \quad 0.250 \quad 26.00$

MTHET MPHI

MHGHT

MINT

TAUL TAUH SHGHT

1011

$0.486 \quad 0.250$

26.00

0.00

0.00

80.00

00.1140900 .000100 .007000 .400

1012

$0.4860 .250 \quad 26.00$

$00 \quad 0.00$

4.50

$\begin{array}{llllll}00.08089 & 00.0001 & 00.0070 & 00.400\end{array}$

1013

$0.486 \quad 0.250 \quad 26.00$

$0.00 \quad 0.00$

0.45

$00.0512500 .000100 .0070 \quad 00.400$

1014

$0.486 \quad 0.250$

26.00

18.00150 .00

80.00

$00.12345 \quad 00.000100 .0070 \quad 00.400$

1015

0.4860 .250

26.00

$18.00 \quad 150.00$

4.50

$00.0864900 .000100 .0070 \quad 00.400$

(RUN 3)

IOPT MOPT NOPT

$\begin{array}{lll}2 & 1 & 1\end{array}$

INUM MON DAY YEAR TIME ZONE

$\begin{array}{lllll}6 & 7 & 28 & 1987 & \text { CDT }\end{array}$

TIME MWAV MTAU MTHETO

$\begin{array}{llllll}\text { TIME } & \text { MWAV } & \text { MTAU } & \text { MTHETO } & \text { MTHET } & \text { MPHI } \\ 1010 & 0.486 & 0.250 & 26.00 & 0.00 & 0.00\end{array}$

1011

MHGHT

MINT

TAUL

TAUH SHGHT

80.00

$\begin{array}{lllll}63.12500 & 00.0001 & 00.0070 & 00.400\end{array}$

$0.486 \quad 0.250 \quad 26.00$

0.00

0.00

4.50

$\begin{array}{lllll}44.75500 & 00.0001 & 00.0070 & 00.400\end{array}$

1012

$0.486 \quad 0.250$

26.00

$0.00 \quad 0.00$

0.45

$28.35600 \quad 00.000100 .0070 \quad 00.400$

80.00

$68.30400 \quad 00.000100 .0070 \quad 00.400$

1014

0.4860 .250

26.00

$18.00 \quad 150.00$

1015

$0.486 \quad 0.250$

26.00

4.50

$47.85900 \quad 00.000100 .0070 \quad 00.400$

(RUN 4)

IOPT MOPT NOPT

$\begin{array}{rcrlll}1 & 1 & 2 & & & \\ \text { INUM } & \text { MON } & \text { DAY } & \text { YEAR } & \text { TIME } & \text { ZONE } \\ 6 & 7 & 28 & 1987 & \text { CDT } & \end{array}$

TIME

1010

MWAV MTAU

MTHETO

MTHET MPHI

MHGHT

MRHO TAUL TAUH SHGHT

$\begin{array}{llllll}0.486 & 0.250 & 26.00 & 0.00 & 0.00\end{array}$

80.00

$00.05000 \quad 00.000100 .0070 \quad 00.400$

$\begin{array}{llll}0.486 & 0.250 \quad 26.00\end{array}$

0.00

4.50

$00.05000 \quad 00.000100 .0070 \quad 00.400$

1012

0.4860 .250

26.00

0.00

0.00

0.45

$00.05000 \quad 00.000100 .0070 \quad 00.400$

1013

0.4860 .250

26.00

18.00150 .00

80.00

$00.05000 \quad 00.000100 .0070 \quad 00.400$

$\begin{array}{llllll}0.486 & 0.250 & 26.00 & 18.00 & 150.00\end{array}$

4. 50

$00.05000 \quad 00.000100 .0070 \quad 00.400$

1015

0.4860 .250

$26.00 \quad 18.00 \quad 150.00$

0.45

$00.05000 \quad 00.000100 .0070 \quad 00.400$ 
IOPT , MOPT , NOPT (FORMAT: 3I5)

For IOPT $=1 \quad$ measured radiance should be in reflectance units $-\mathrm{L}^{\mathrm{m}}$.

For IOPT $=2$ measured radiance should be in absolute radiance units of Watts $/ \mathrm{m}^{2} / \mathrm{sr} / \mu \mathrm{m}$.

For MOPT = 1 the day, month and year should be provided.

For MOPT $=2$ the day of year (Julian date) and year should be given.

For NOPT $=1 \quad$ surface reflectance (RHOS) is computed.

For NOPT $=2$ radiance (MINT) is computed for the input geometry and height; the measured surface reflectance (MRHO) is input. The variable name MINT is used for programming convenience. MINT is a computed and not measured when NOPT $=2$.

Run 1 and run 2 choose the IOPT $=1$ option for selecting reflectance units of measured radiance and NOPT $=1$ option to compute surface reflectance. MOPT (the option to select the day of year) is set to 1 and 2, respectively. Run 3 chooses IOPT $=2$ and MOPT $=$ NOPT $=1$. Run 4 selects NOPT to be 2 and IOPT and MOPT to be 1 .

3. The third card contains the labels to identify the input parameters in step 4 below.

4. The fourth card contains the information about the number of data points INUM to be processed, the date, and information about the time zone (e.g Central, Pacific, or Mountain and Daylight or Standard Time). The information about the time zone is not used for any computations. There are two options for this input card depending on the value of MOPT (FORMAT 4I5, 30A1):

For MOPT = 1: INUM, IMONTH, IDAY, IYEAR, TIME ZONE

e.g.: $(1,12,25,1987, \mathrm{CDT})$ for 1 data point to be processed for December 25, 1987, and the time zone is CDT or Central Daylight Time.

For MOPT = 2: INUM, IDAY, IYEAR, TIME ZONE e.g.: $(1,359,1987, \mathrm{CDT})$ 
The fourth row of run 1 reads number of data points, month, day, and year. The fourth row of run 2 reads number of data points, the Julian day and year for which the measurements are made. The radiance is read in reflectance units for both runs 1 and 2 .

5. The fifth card contains the labels to identify the input parameters in step 6 below.

6. The sixth card can be repeated for the number of data points INUM. The data points should be for the same date. The following names in parentheses are the variable names used by the program. The sixth card contains values of time in hours and minutes (without punctuation; this input parameter is not used in any computations but is merely for the record) (MTIME), measured wavelength $\lambda^{m}$ (MWAV) in micrometers, measured aerosol optical thickness $\tau_{\mathrm{a}}^{\mathrm{m}}$ (MTAU) for the measured wavelength $\lambda^{\mathrm{m}}$, solar zenith angle $\theta_{0}{ }^{m}$ (MTHET0) in degrees, observation scan angle $\theta^{\mathrm{m}^{\prime}}$ (MTHET) in degrees, observation azimuth angle $\varphi^{m}$ (MPHI) in degrees, observation height $Z^{m}$ (MHGHT) in kilometers, and spectral radiance $L^{\mathrm{m}^{\prime}}$ or $\mathrm{L}^{\mathrm{m}}$ (MINT) from satellite or aircraft in reflectance or absolute units depending on option (IOPT ) read in the first card, $\tau_{\mathrm{gL}}$ (TAUGL), $\tau_{\mathrm{gH}}$ (TAUGH), and $\mathrm{Z}_{0}$ (SHGHT) in the following format:

\section{MTIME, MWAV, MTAU, MTHET0, MTHET, MPHI, MHGHT, MINT, TAUGH, TAUGL, SHGHT}

FORMAT (I5,1x, F 6.3, F 6.3, 4F7.2,F10.5,3F8.4)

Card 6 for run 3 reads the measured radiance in absolute units . Card 6 for run 4 when NOPT is 2 reads the surface reflectance value MRHO in the following format:

MTIME, MWAV, MTAU, MTHETO, MTHET, MPHI, MHGHT, MRHO, TAUGH, TAUGL, SHGHT

FORMAT (15,1x, F 6.3, F 6.3, 4F7.2,F10.5,3F8.4)

\section{INPUT FROM LOOK-UP TABLE (UNIT NUMBERS 7 - 14):}

The input from the look-up table is read after the execution of the statements given in parentheses. Subroutine FINDW (1610) searches the data base and then reads only the 
required table for the two wavelengths between which measured wavelength $\lambda^{\mathrm{m}}$ (MWAV) lies. The following are obtained:

1. values of observation zenith angle $\theta$ in degrees $(2610,2650)$

2. values of observation azimuth angle $\varphi$ in degrees $(2610,2660)$

3. values of wavelength $\lambda$ in micrometers, aerosol optical thickness $\tau_{\mathrm{a}}$, reflectance of atmosphere s, flux incident on surface $F_{d}^{\prime}(2830$ - 2840)

4. a blank line

5. values of atmospheric radiance $L_{o}^{\prime}$ in reflectance units $(2920-2950)$

6. values of transmission from surface $T / \pi(3000)$.

\subsection{Output}

A successful execution of this FORTRAN program will result in the output described below, which is written to FORTRAN logical unit numbers 6 and 56. Four cases representative of the different options discussed in section 5.2 are shown in Table 5.

\section{QUTPUT TO UNIT NUMBER 6: (see Table 5.)}

The innput data set is written as it is read from unit number 5. The message 'END OF INPUT DATA SET AS READ FROM UNIT NUMBER 5 ' marks the end of input data set. The next line of this output contains the information about the date for which measurements are made:

For MOPT = 1, month, day, year, and time zone will be written (Table 5, run 1).

For MOPT = 2, Julian day, year, and time zone will be written (Table 5, run 2).

Each subsequent line gives the measured and derived output for each data point processed. The first seven entries on a line provide information about the following input parameters as read from logical unit number 5: time (Central, Pacific, or Mountain and Daylight or Standard) in hours and minutes, measured wavelength $\left(\lambda^{m}\right)$ in micrometers, measured aerosol optical thickness $\left(\tau_{\mathrm{a}}{ }^{\mathrm{m}}\right)$, solar zenith angle $\left(\theta_{\mathrm{o}}{ }^{\mathrm{m}}\right)$ in degrees at the time of observation, measured observation zenith angle $\left(\theta^{\mathrm{m}}\right)$ in degrees, measured observation azimuth angle $\left(\varphi^{\mathrm{m}}\right)$ in degrees, and measured observation height $\left(\mathrm{Z}^{\mathrm{m}}\right)$ in kilometers. The 


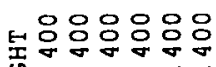
뀎영ㅇㅇㅇ 운우웅우우

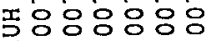

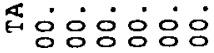

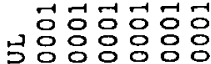
๓่อ่อ่อ่อ่ on n 0 06 궁ํㅇำ영 총요요

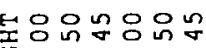

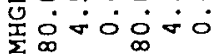
붕ㅇㅇㅇㅇ음

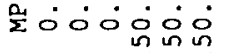
뚰요요용 次 इंல்

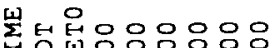

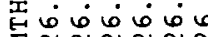
先市 函

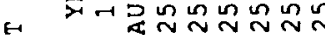

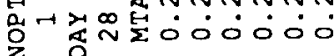

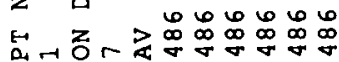

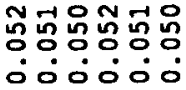

式

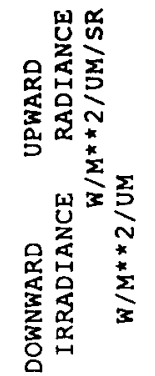

눙ㅇㅇ윤응

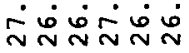

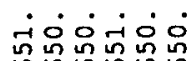

ชู

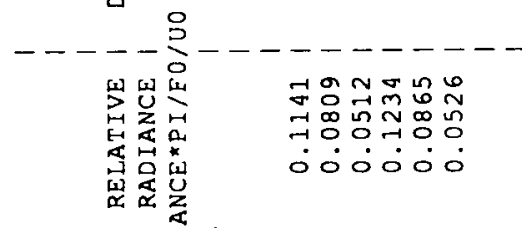

z

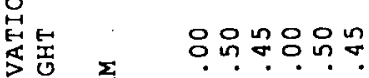

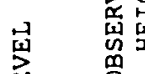

$\sum$

요 $\dot{0} \dot{0}$

$\rightarrow \quad$

哥

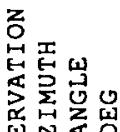

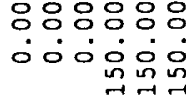

药

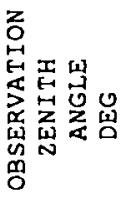

옹음 겅용

$\therefore \dot{0} 00 \infty \infty$

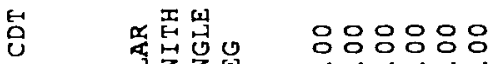

닉 号贸者

嵓

w

$\sum_{5}$

点

品空

-0ं0்

क

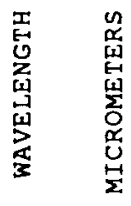

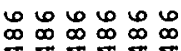
००0000

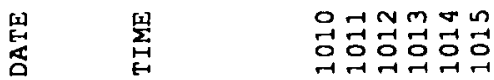



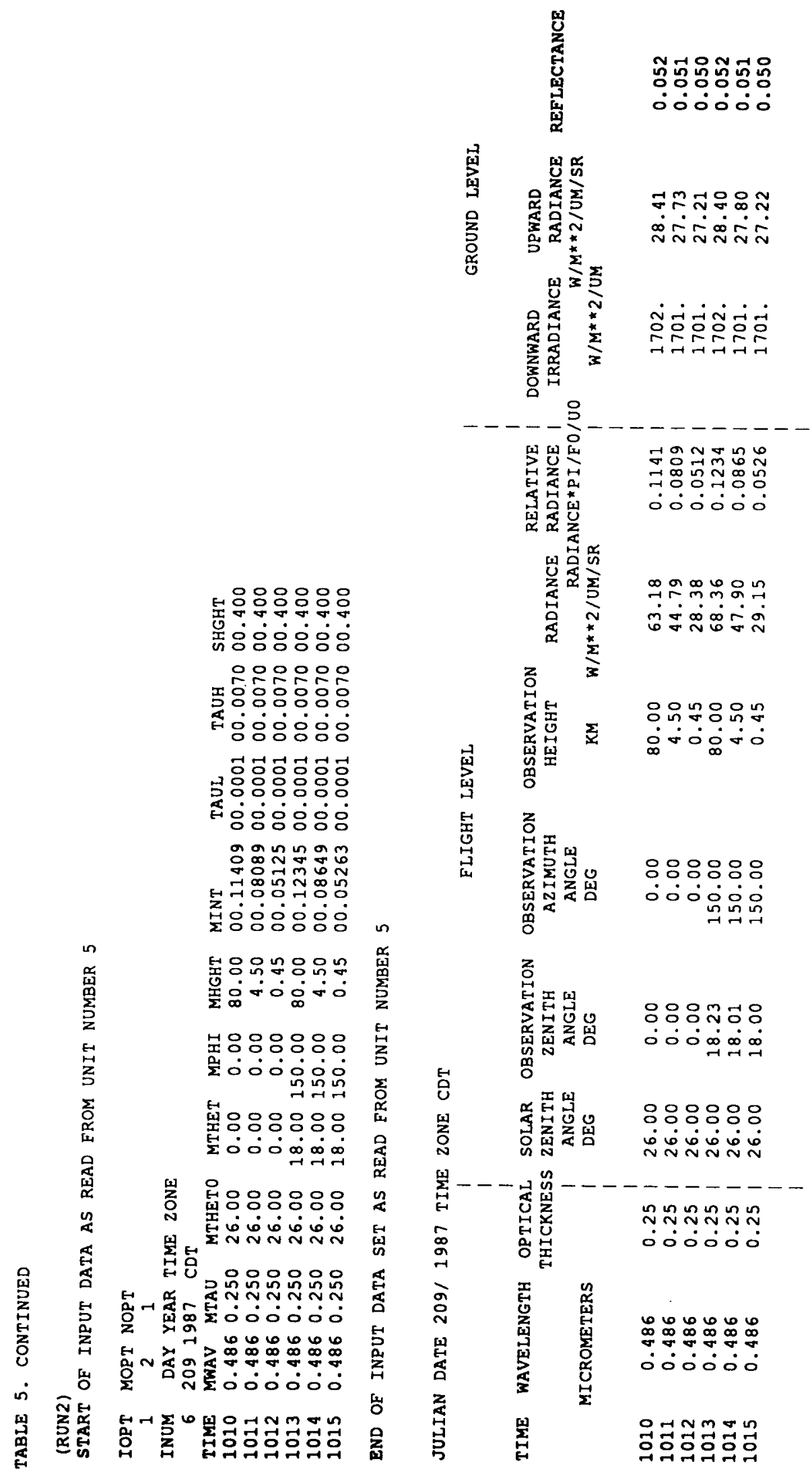

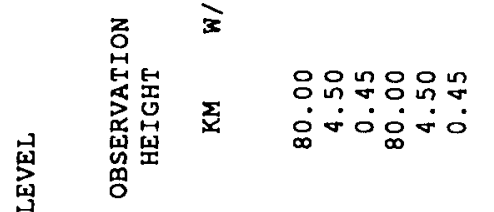

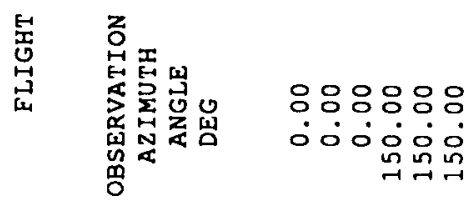

品

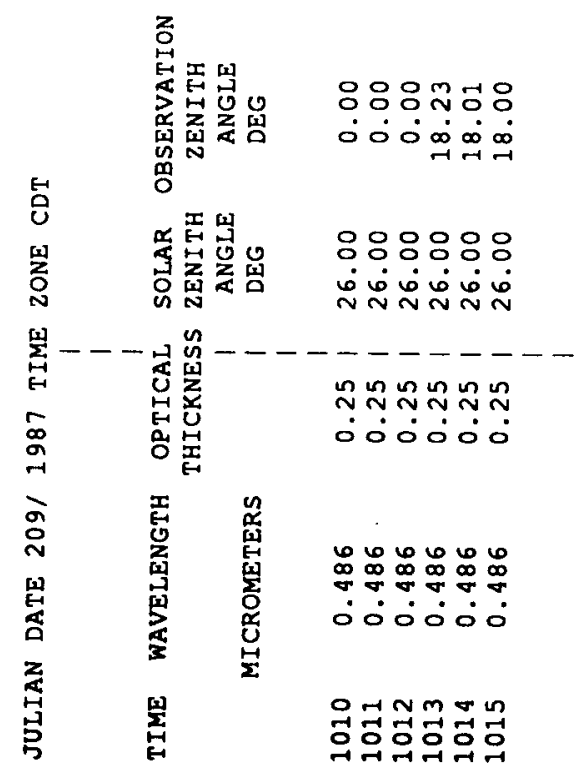




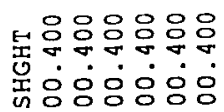

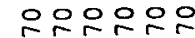

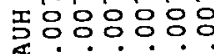

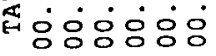

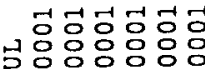

รั่อ่อ่อ่

웅ㅇㅇㅇㅇㅇ

in in 6 \%

는

艺

年

부웅으뭉

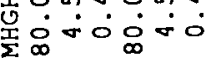

농ㅇㅇㅇㅇㅇ응

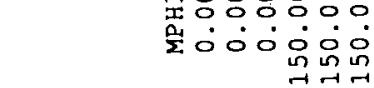

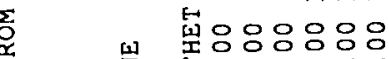

峞 $\Sigma$

떨 단응응ㅇㅇㅇㅇㅇ

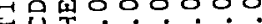

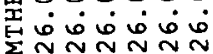

起 영 웅ㅇㅇㅇㅇ

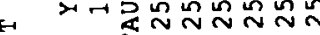

合

H $Z>\infty \infty_{\infty}^{\infty} \mathbb{\infty}_{\infty}^{\infty} \infty_{\infty}^{\circ}$

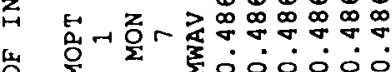

त̂t

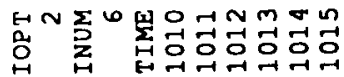
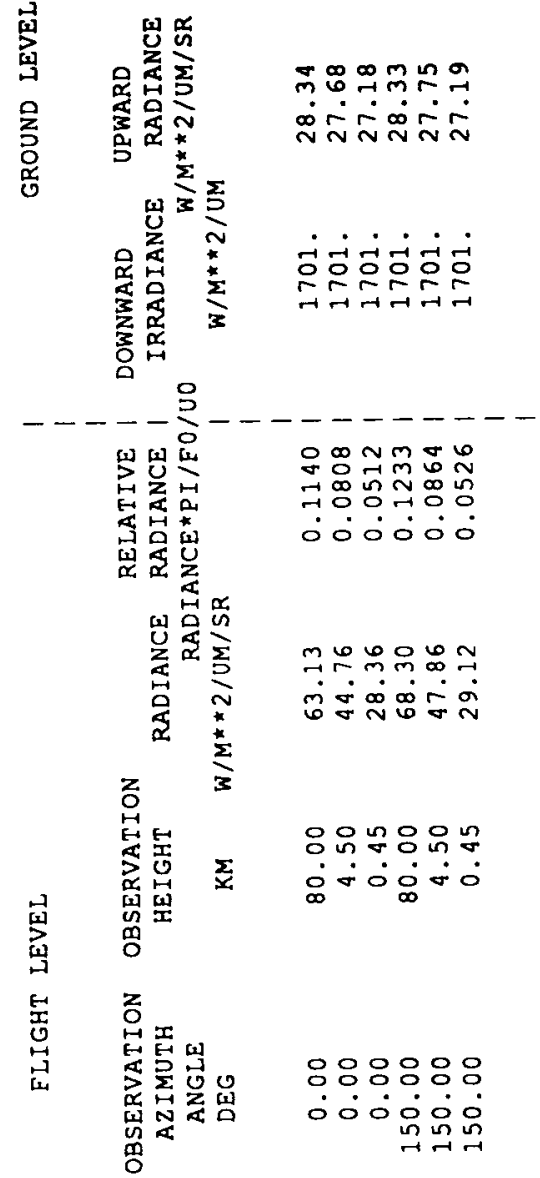

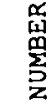

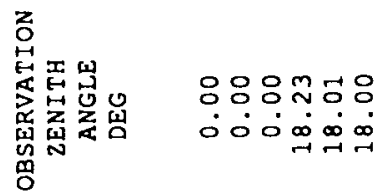

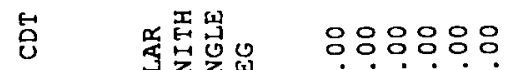
号急等

崖_-

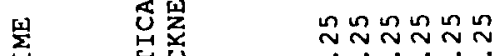

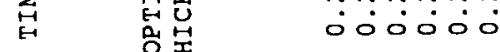

r

$\stackrel{\infty}{-\infty}$

i

$\stackrel{\infty}{\sim}$

폰

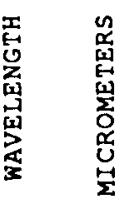

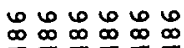
00000

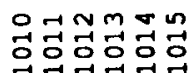



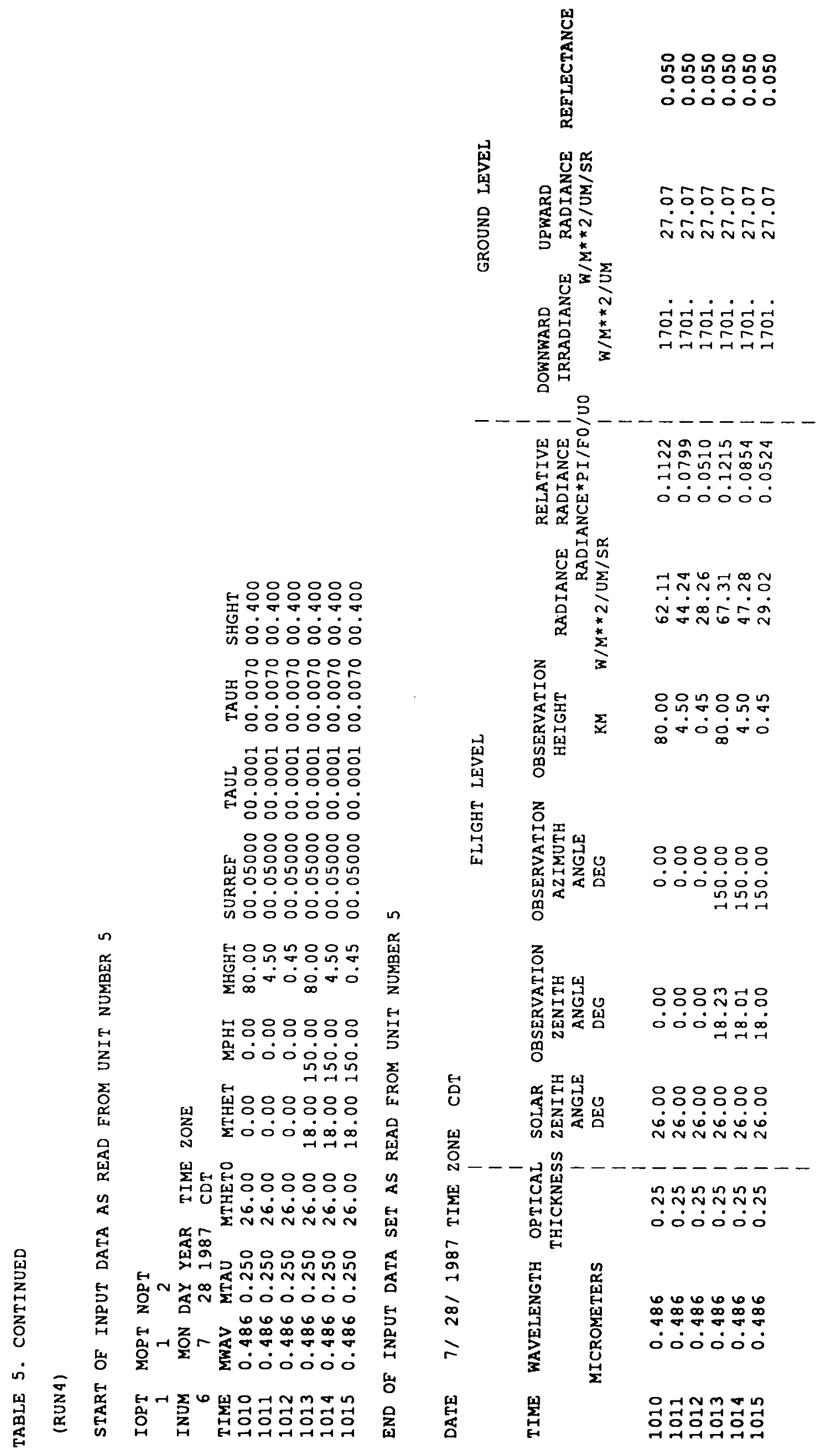
eighth and ninth entries depend on IOPT. For IOPT $=1$, the measured radiance $L^{\mathbf{m}}$ is given in reflectance units and labeled under RELATTVE RADIANCE; the corresponding radiance in absolute units is computed by the the program and is labeled under

RADIANCE. For IOPT $=2$, the measured radiance $\mathrm{L}^{\mathrm{m}}$ is given in absolute units and is labeled under RADIANCE; the corresponding radiance in reflectance units is computed by the the program and is labeled under RELATIVE RADIANCE. Next three surface quantities are computed and given as values for total spectral irradiance $F_{g}$, total spectral radiance $L_{g}$, and surface reflectance $\rho$ (eq.2,3 and 4). The output in Table 5 for run 4 computes the eighth and ninth columns, since NOPT $=2$ and the surface reflectance is input (column 12).

\section{OUTPUT TO UNIT NUMBER 56: (see Table 6)}

The label for this output shown in table 6 reads 'INTERPOLATED RADIATION PARAMETERS. The second line gives information about the date and time zone of the input data set. Each subsequent line gives the measured and derived output for each data point processed. The first seven entries on a line provide information about the following input parameters as read from logical unit number 5: time (Central, Pacific, or Mountain and Daylight or Standard) in hours and minutes, measured wavelength $\left(\lambda^{m}\right)$ in micrometers, measured aerosol optical thickness $\left(\tau_{a}{ }^{m}\right)$, solar zenith angle $\left(\theta_{0}{ }^{m}\right)$ in degrees at the time of observation, measured observation zenith angle $\left(\theta^{\mathrm{m}}\right)$ in degrees, measured observation azimuth angle $\left(\varphi^{\mathrm{m}}\right)$ in degrees, and measured observation height $\left(\mathrm{Z}^{\mathrm{m}}\right)$ in kilometers. The eighth and ninth entries depend on IOPT and NOPT. For IOPT $=1$ and NOPT $=1$, the measured radiance $\mathrm{L}^{\mathrm{m}}$ is given in reflectance units and labeled under RELATIVE RADIANCE; the corresponding radiance in absolute units is computed by the the program and is labeled under RADIANCE. For IOPT $=2$ and NOPT $=1$, the measured radiance $L^{m}$ is given in absolute units and is labeled under RADIANCE; the corresponding radiance in reflectance units is computed by the the program and is labeled under RELATIVE RADIANCE. IF NOPT $=2$ the values of radiance in absolute and reflectance units are computed by the program. Next three quantities are computed and given as values for $\mathrm{L}_{\mathrm{o}}{ }^{\prime}, \mathrm{F}_{\mathrm{d}}{ }^{\prime}, \mathrm{s}$, and transmission $\mathrm{T}$ (eq. 6).

\subsection{Summary of Error Messages}

A summary of error messages is given in Table 7. First, examples of input data are given followed by the different error messages that would result. For the sixth row and second column of the upper table, where the input measured wavelength $\lambda^{m}=0.345$, it 


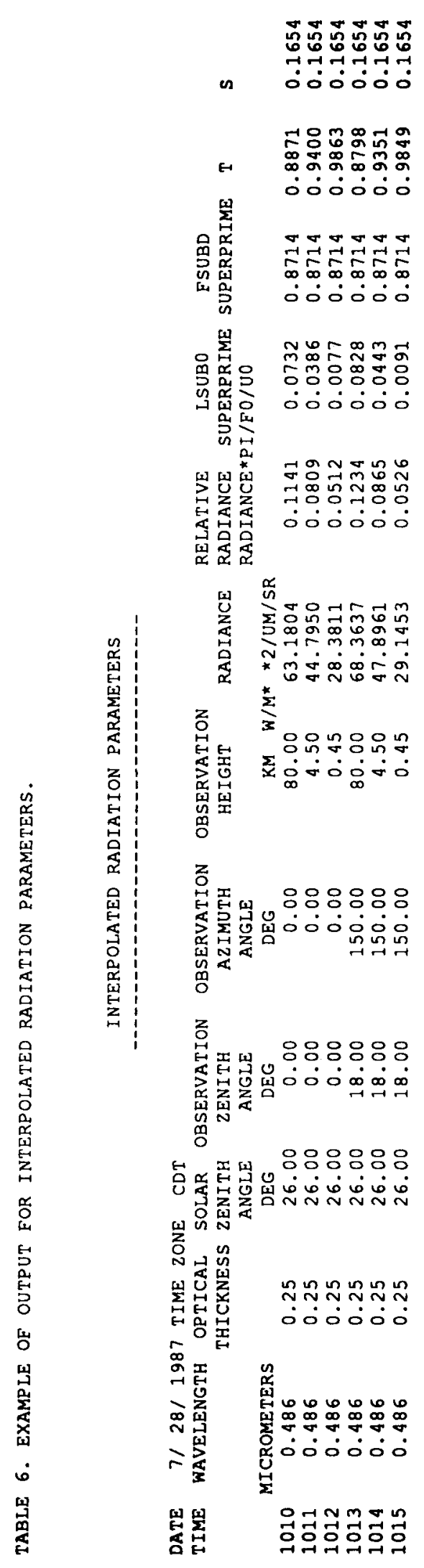




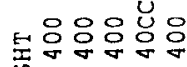
숬용ㅇㅇ

우우웅으

족ㅇㅇㅇㅇㅇㅇㅇㅇ

जि:ㅇㅇㅇ

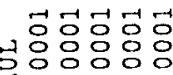

형ㅇㅇㅇ

의넨의

웅 거워

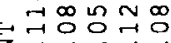

영ㅇㅇㅇ

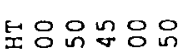

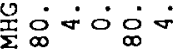

in

我

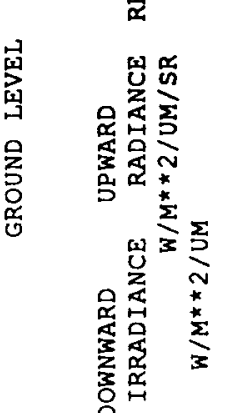

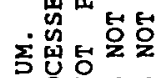

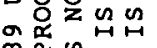

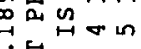

话m

的青员品

嵌絫芯芯

武舆

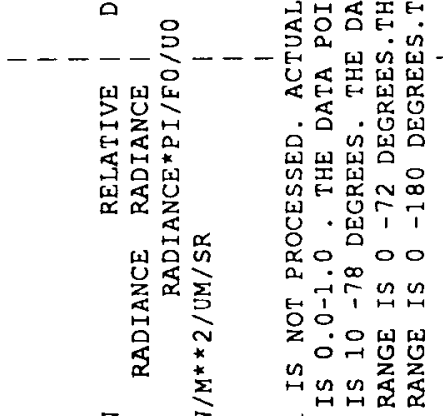

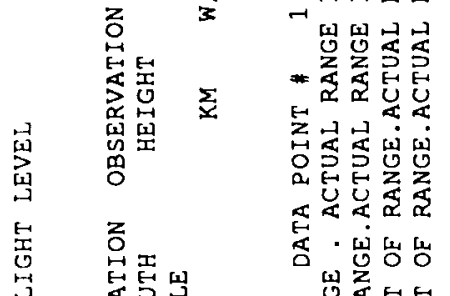

点

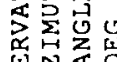

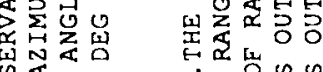

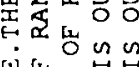

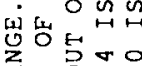

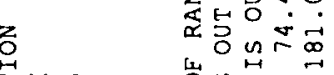

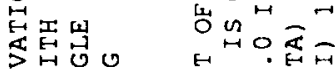

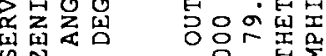

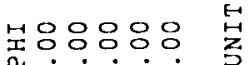

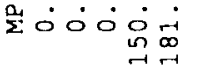

떹형ㅇㅇㅇㅇㅇㅇㅇㅇ

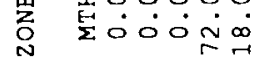

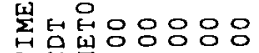

至完家完

我市

离

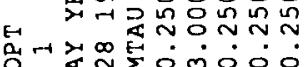

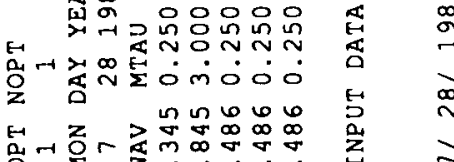

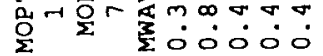

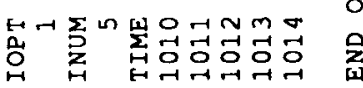

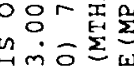

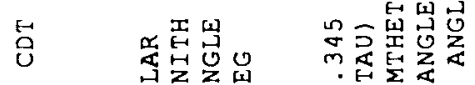

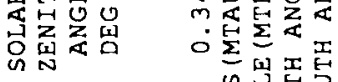

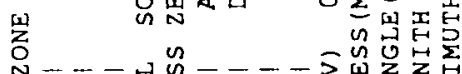

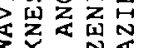

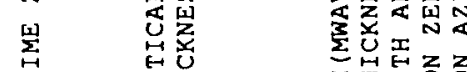

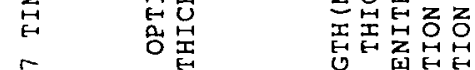

क

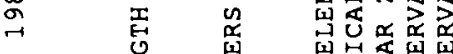

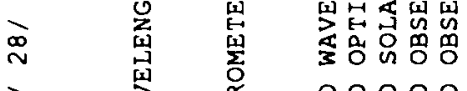

$\therefore \quad \frac{1}{3}$

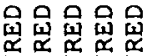

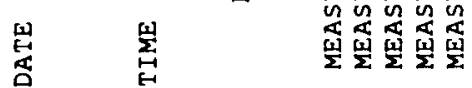


does not lie between the range $(0.486-2.2 \mu \mathrm{m})$, for which the look-up table is available (section 4.0). The subroutine FINDW prints an error message 'Measured wavelength 0.345 is out of range. The data point \#1 is not processed; Actual range $(0.486-2.2 \mu \mathrm{m})^{\prime}$. For the following rows $(2,3,4$, and 5$)$ of input data, the measured aerosol optical thickness $\tau_{a}^{\mathrm{m}}$, solar zenith angle $\theta_{0}^{\mathrm{m}}$, observation zenith angle $\theta^{\mathrm{m}}$, and observation azimuth angle $\varphi^{\mathrm{m}}$ are out of the ranges of values provided by the look up table (section 4.0). The subroutine INTERP prints error messages stating the variables which are out of range.

\subsection{Sensitivity Study}

A careful error analysis would be extensive, because so many measurement and surface parameters are involved. Instead an attempt is made to estimate the maximum errors that might occur during FIFE in estimating the surface reflectance $(\rho)$. The errors given here are are not root-mean-square errors. The surface radiance $\mathrm{L}_{\mathrm{g}}$ error can be calculated with the reflectance error and eq. 5. The irradiance at the ground $\left(\mathrm{F}_{\mathrm{g}}\right.$ (eq.4) and also $F_{d}$ (eq. 4 and 5)) is not affected appreciably by the perturbations. The main source of error usually is caused in estimation of the path radiance $\left(\mathrm{L}_{0}\right)$. The absolute surface reflectance error is insensitive to strength of the reflectance.

The perturbations are placed in three categories: model errors, interpolation errors, and uncertainties in the input data (input errors). The model parameters studied are:

1) uncertainty in the aerosol single scattering phase function

2) uncertainty due to the neglect of polarization in the radiative transfer computations

3) uncertainty in water vapor and ozone absorption

4) uncertainty in aerosol absorption

5) uncertainty in the height distribution of aerosols

Since the algorithm must interpolate parameters on aerosol optical thickness $\tau_{\mathfrak{a}}$, solar zenith angle $\theta_{0}$, observation zenith angle $\theta$, azimuth angle $\phi$, wavelength $\lambda$, and height $Z$, the errors introduced by these interpolations are studied. Finally, because the input data will have some uncertainty associated with them, the effects of errors in the input radiance, input aerosol optical thickness, and input geometry are studied. The studies described above are mostly performed for a wavelength $\lambda=0.486 \mu \mathrm{m}$, since the atmospheric effects generally are the greatest at the shortest wavelength. Unless stated otherwise, the 
unperturbed simulation model has an aerosol optical thickness $\tau_{\mathfrak{a}}=0.25$, three observation altitudes $\left(0.45 \mathrm{~km}, 4.5 \mathrm{~km}, 80 \mathrm{~km}\right.$ ), and two view geometries (Model 1: $\theta_{0}=30^{\circ}, \theta=$ $0^{\circ}, \phi=0^{\circ}$; Model 2: $\theta_{0}=30^{\circ}, \theta=18^{\circ}, \phi=150^{\circ}$ ). In order to estimate the largest errors, the wavelength, geometry, and aerosol optical thickness are varied in a few cases where the errors are larger.

In the discussion which follows, a description of each type of sensitivity test is given in Table 8, followed by a discussion of the results. The first part gives results of model errors, the second part of interpolation errors, and the third part of input errors. A summary of the sensitivity results is shown in Table 9, which shows the errors in the derived surface reflectance for two observation geometries in the case of the model errors. For interpolation and input errors, the resulting errors in the derived surface reflectance are shown for only one geometry. Table 10 gives additional details concerning the errors and radiation parameters.

\subsection{Model Errors}

The atmospheric correction algorithm causes errors because the model does not represent exactly the state of the atmosphere at the time of an observation. The simulated measured remote radiance or surface reflectance is first computed with a radiative transfer model that contains the perturbation. These computations produce a given perturbed radiance $\mathrm{L}^{\mathrm{m}}+\Delta \mathrm{L}^{\mathrm{m}}$ at the sensor altitude, as well as the other radiation parameters. The perturbed radiance $L^{m}+\Delta L^{m}$ serves as an input in the correction algorithm, resulting in a derived perturbed surface reflectance $\rho+\Delta \rho$.

\subsubsection{Aerosol Single Scattering Phase Eunction}

The scattering effects of aerosols increase with increasing aerosol optical thickness, which usually is largest at the shortest wavelengths; but compared with molecular scattering, the relative contribution by the aerosols to backward scattering decreases with decreasing wavelength. Therefore, an intermediate wavelength of $0.639 \mu \mathrm{m}$ (AVHRR band 1 ) is used for the phase function sensitivity study.

The phase function sensitivity test is performed using two phase functions which differ appreciably from the one used in the model. As discussed previously, the aerosol single scattering phase function used in the algorithm is computed for two log-normal aerosol size distributions combined, which are chosen to represent accumulation and coarse particle modes. The first phase function used in this sensitivity analysis is chosen from a 


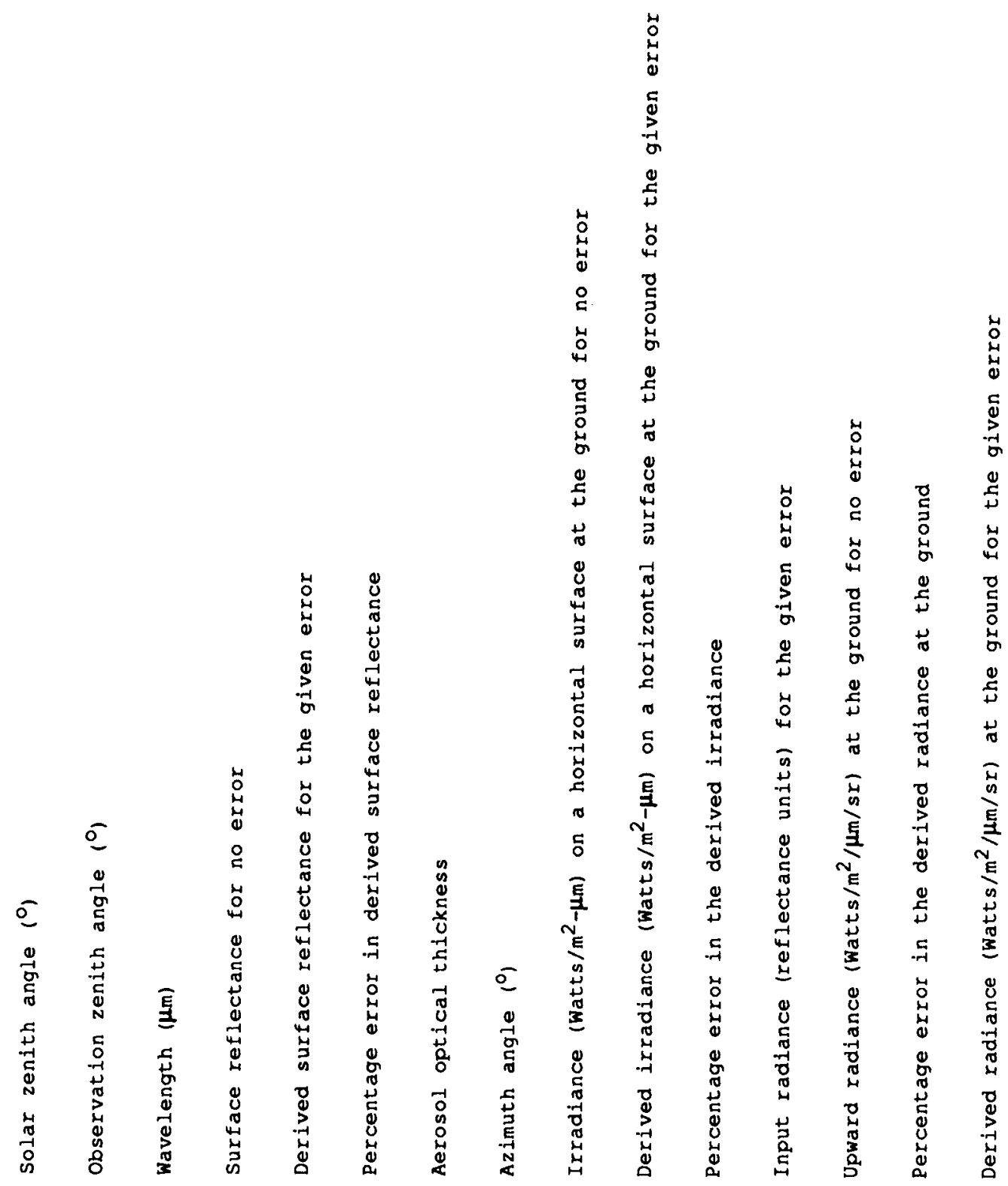




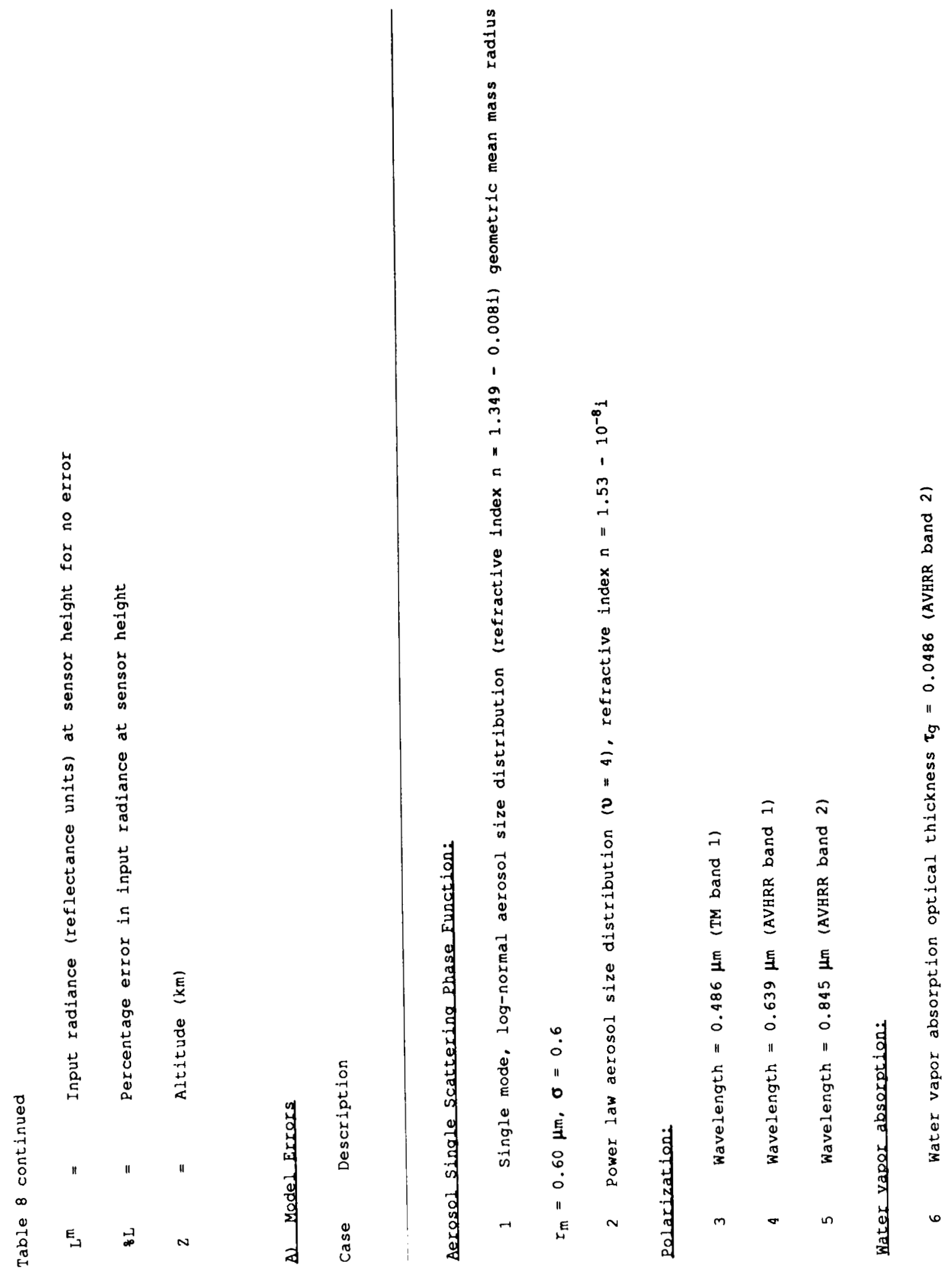




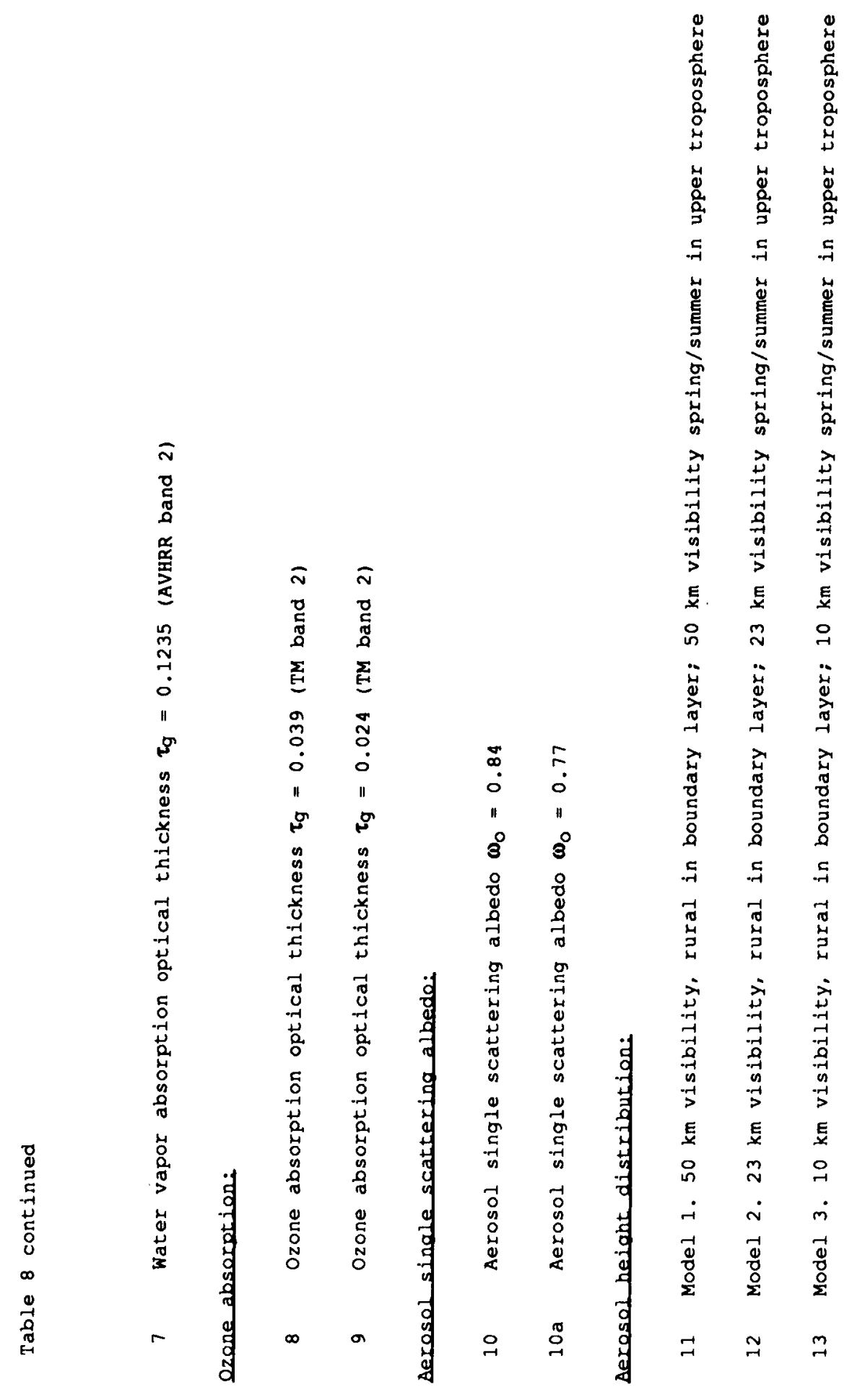




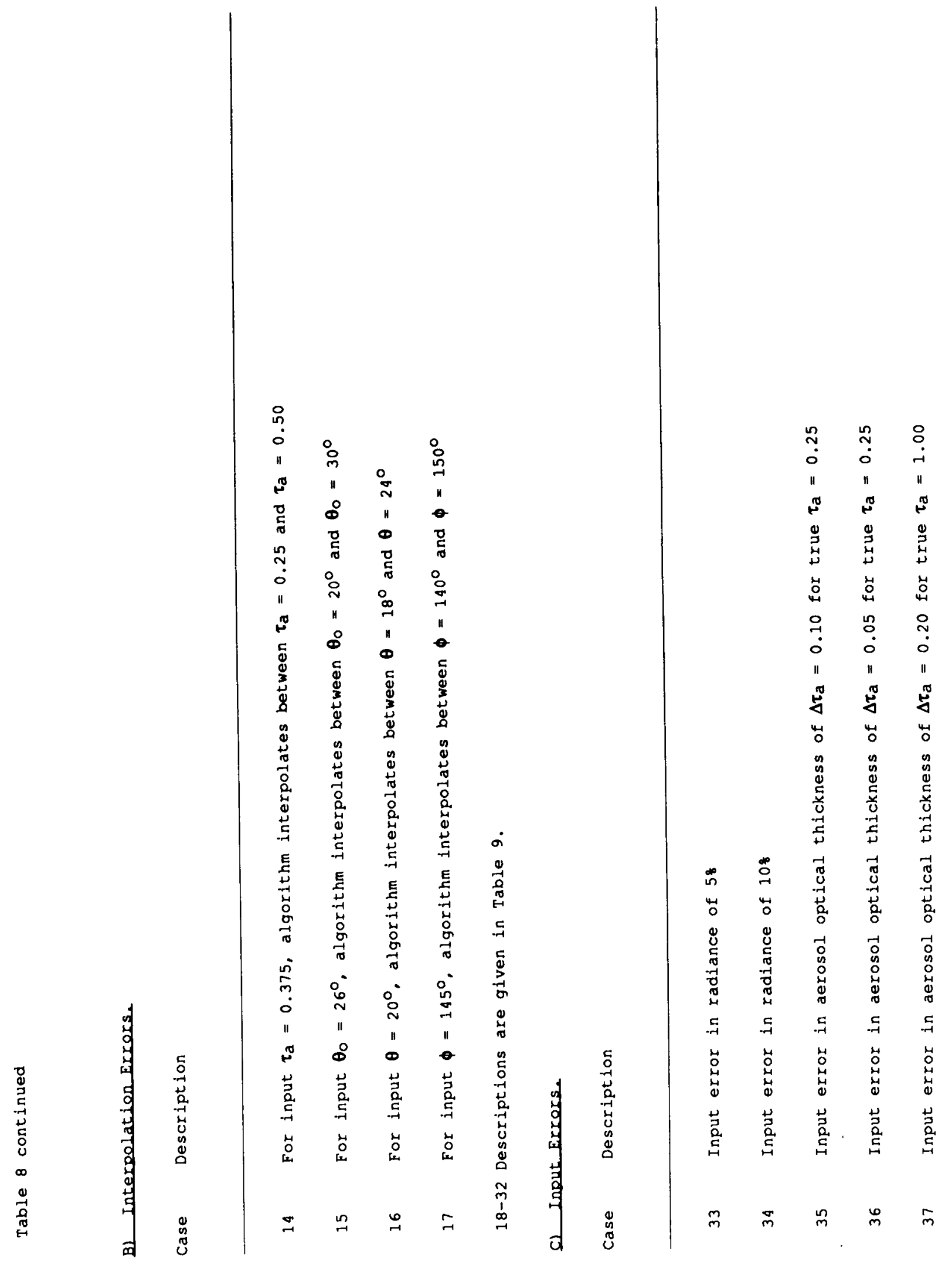




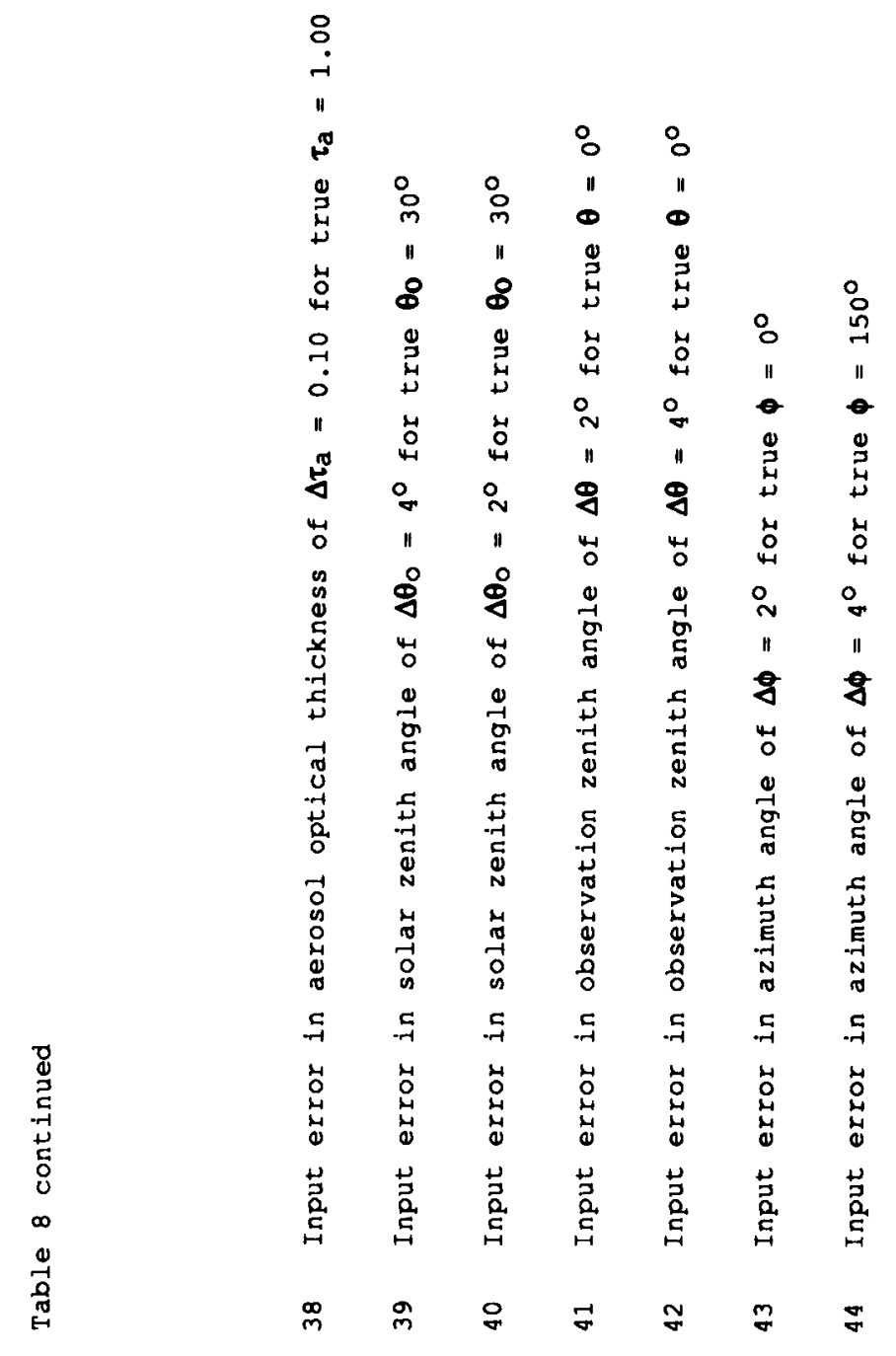




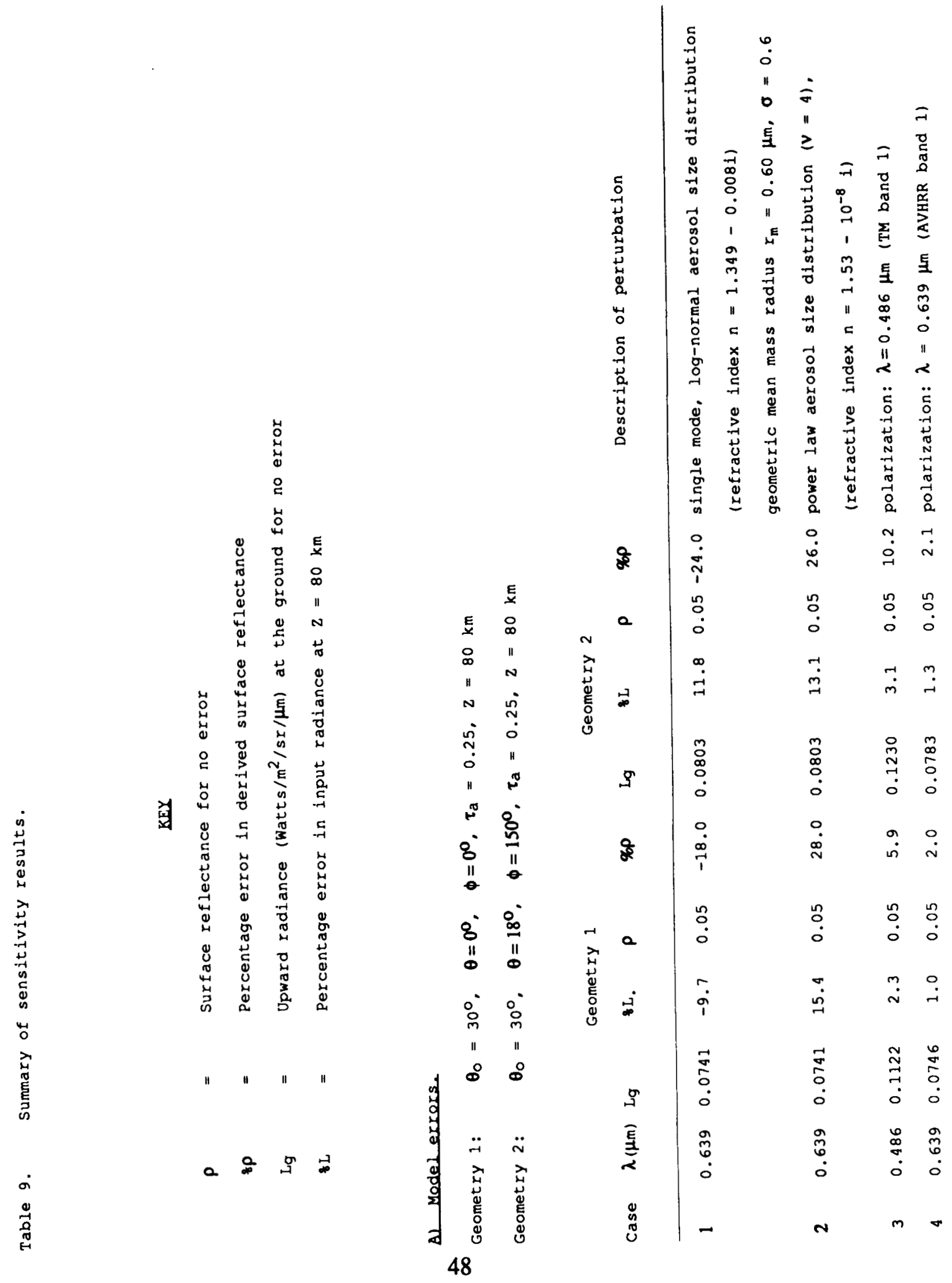




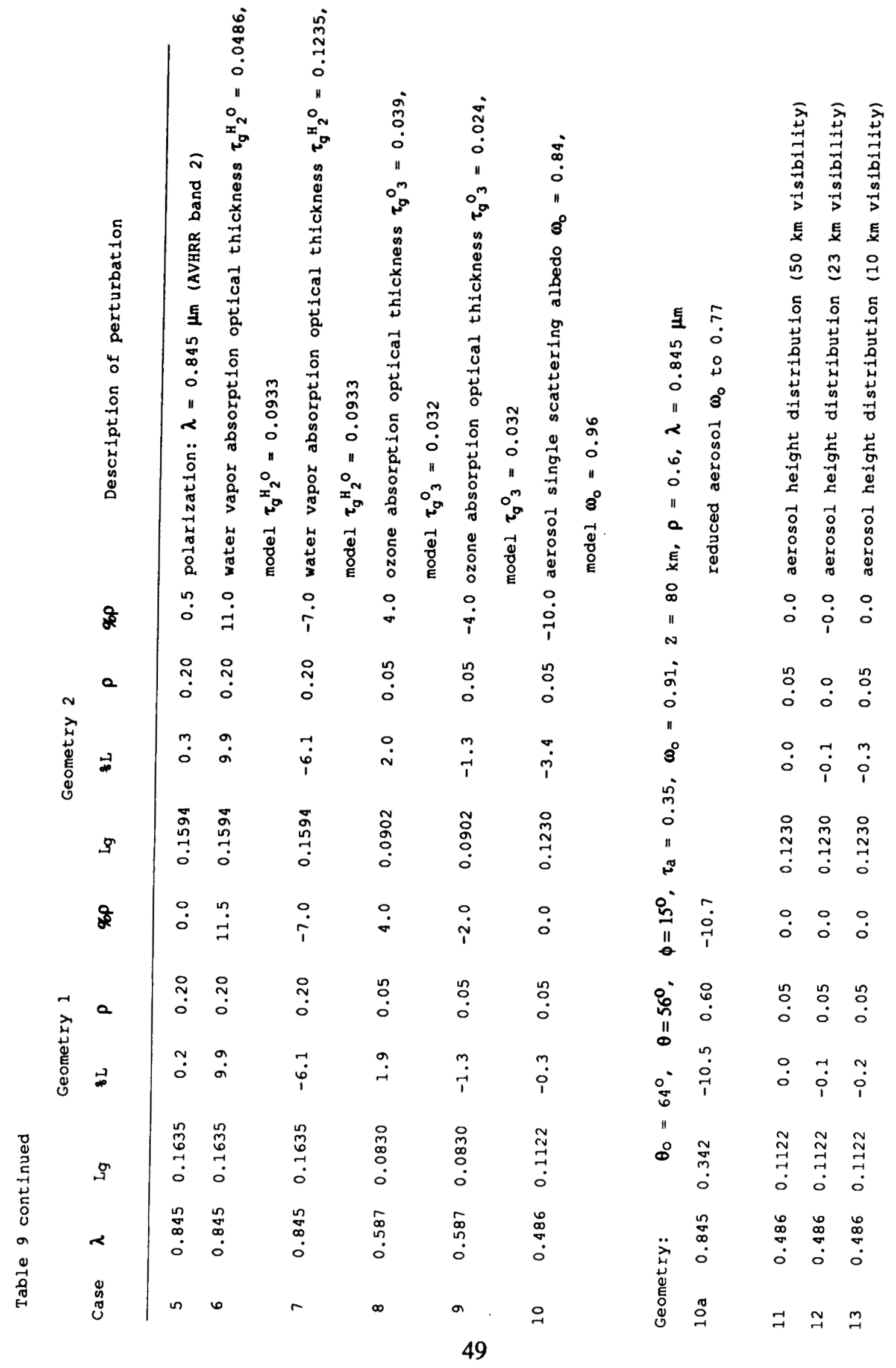




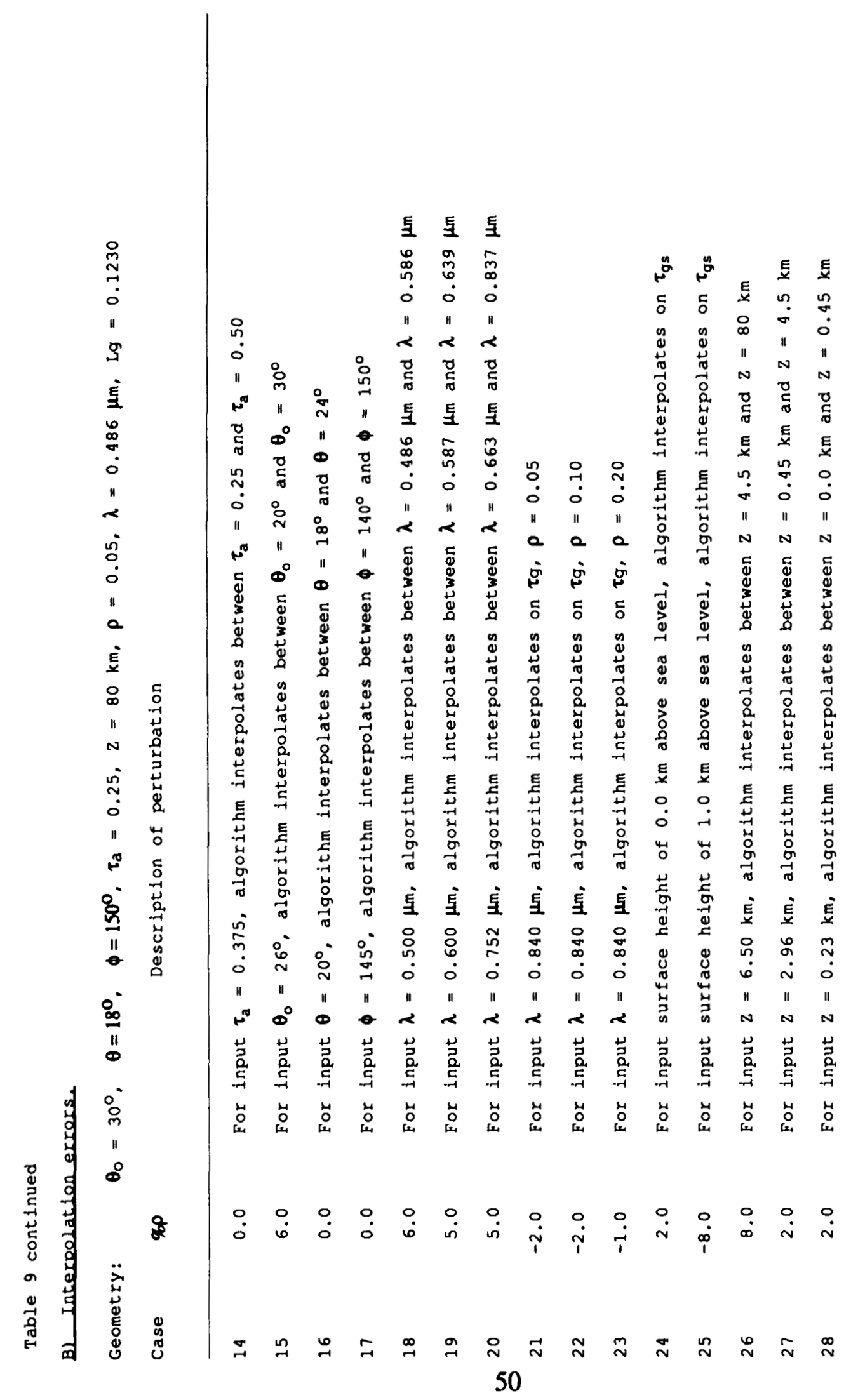




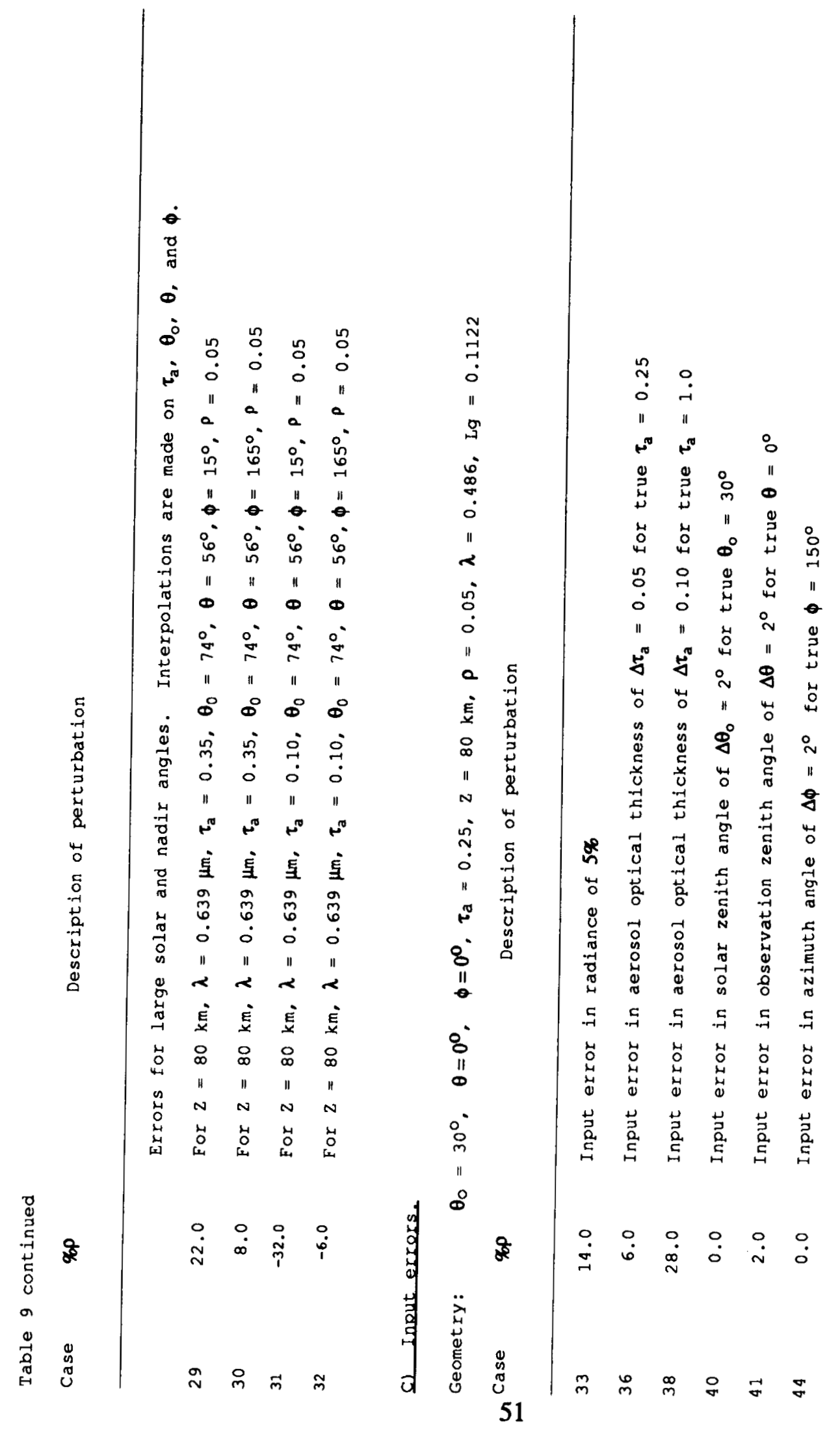




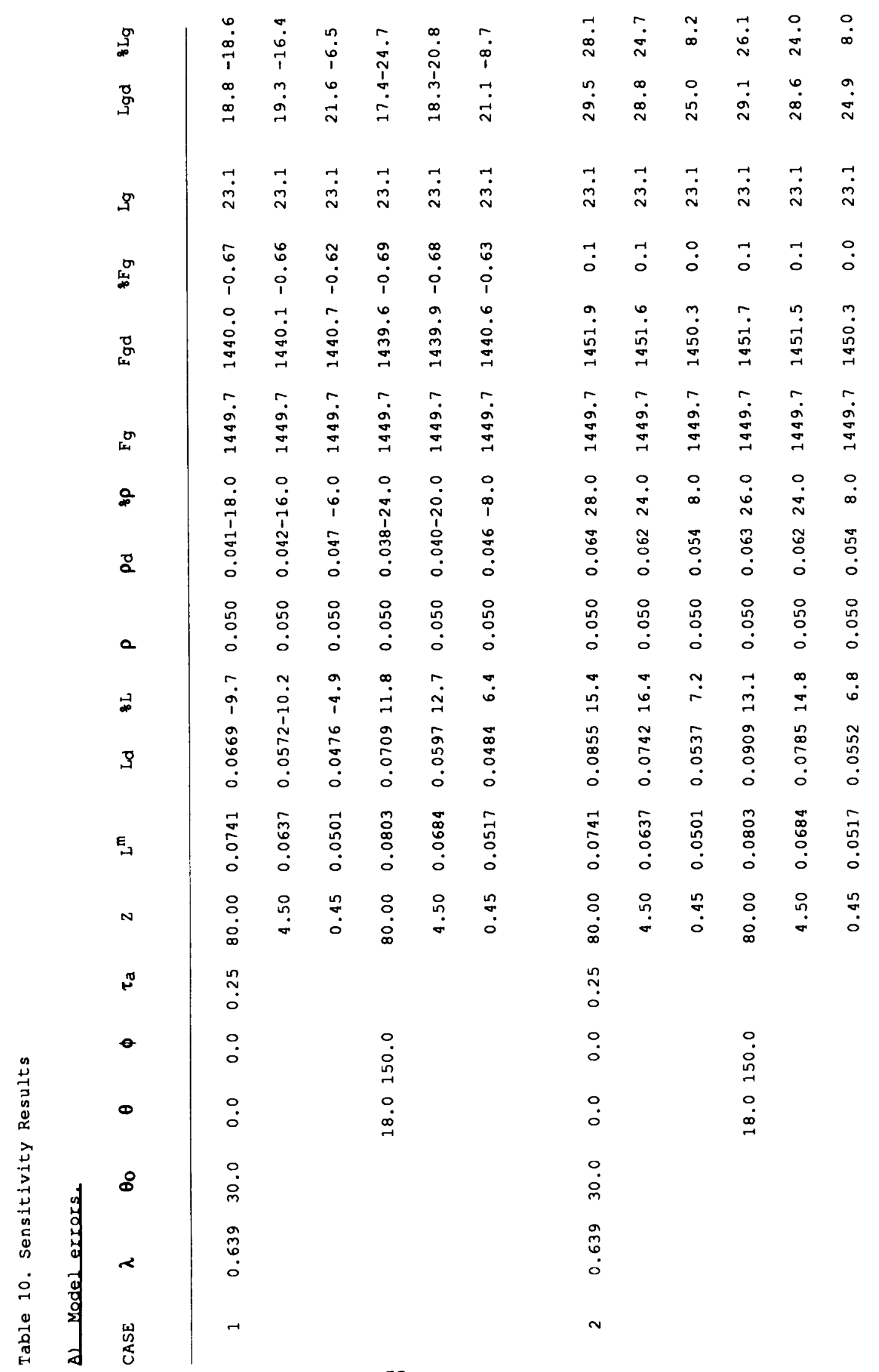




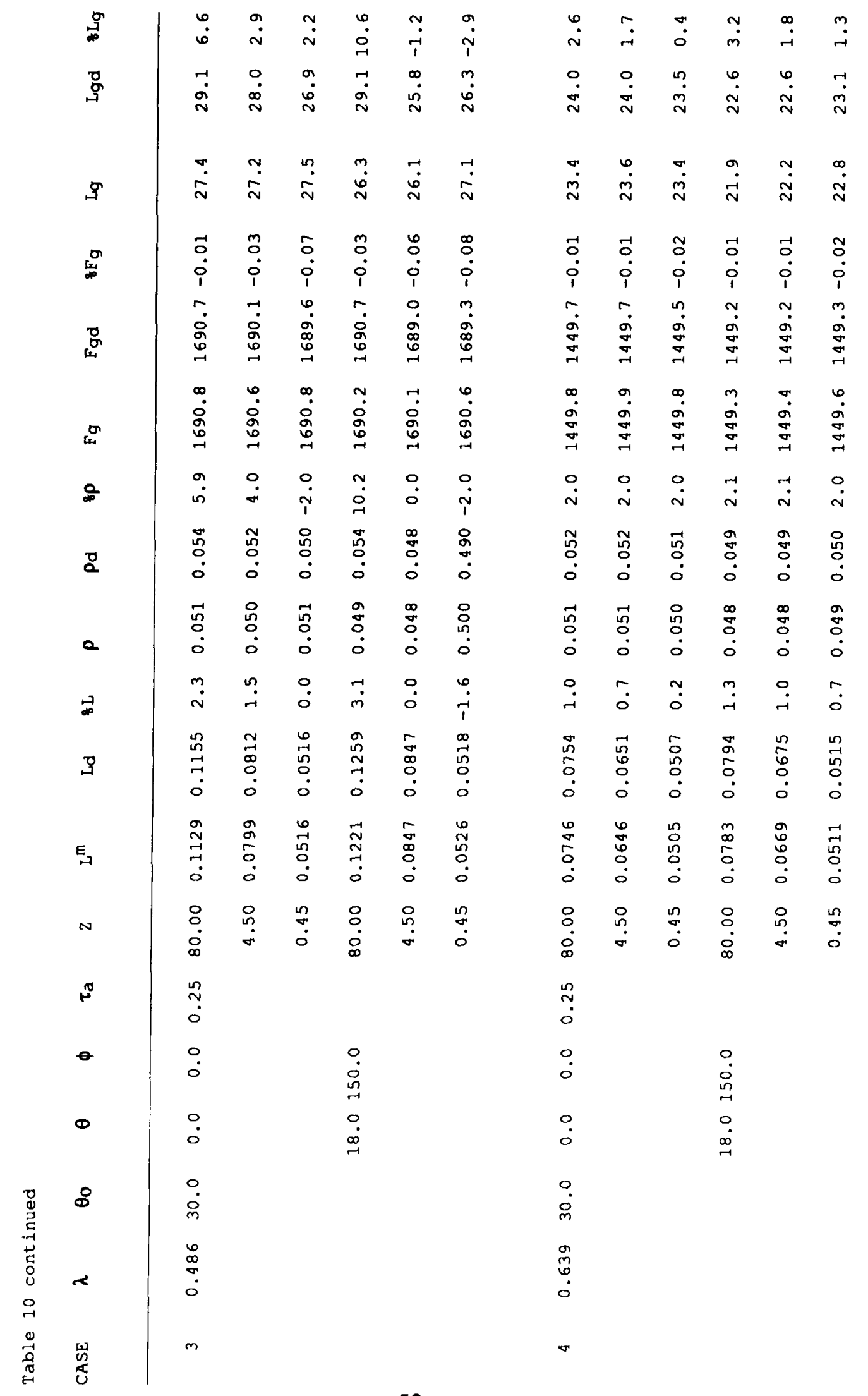




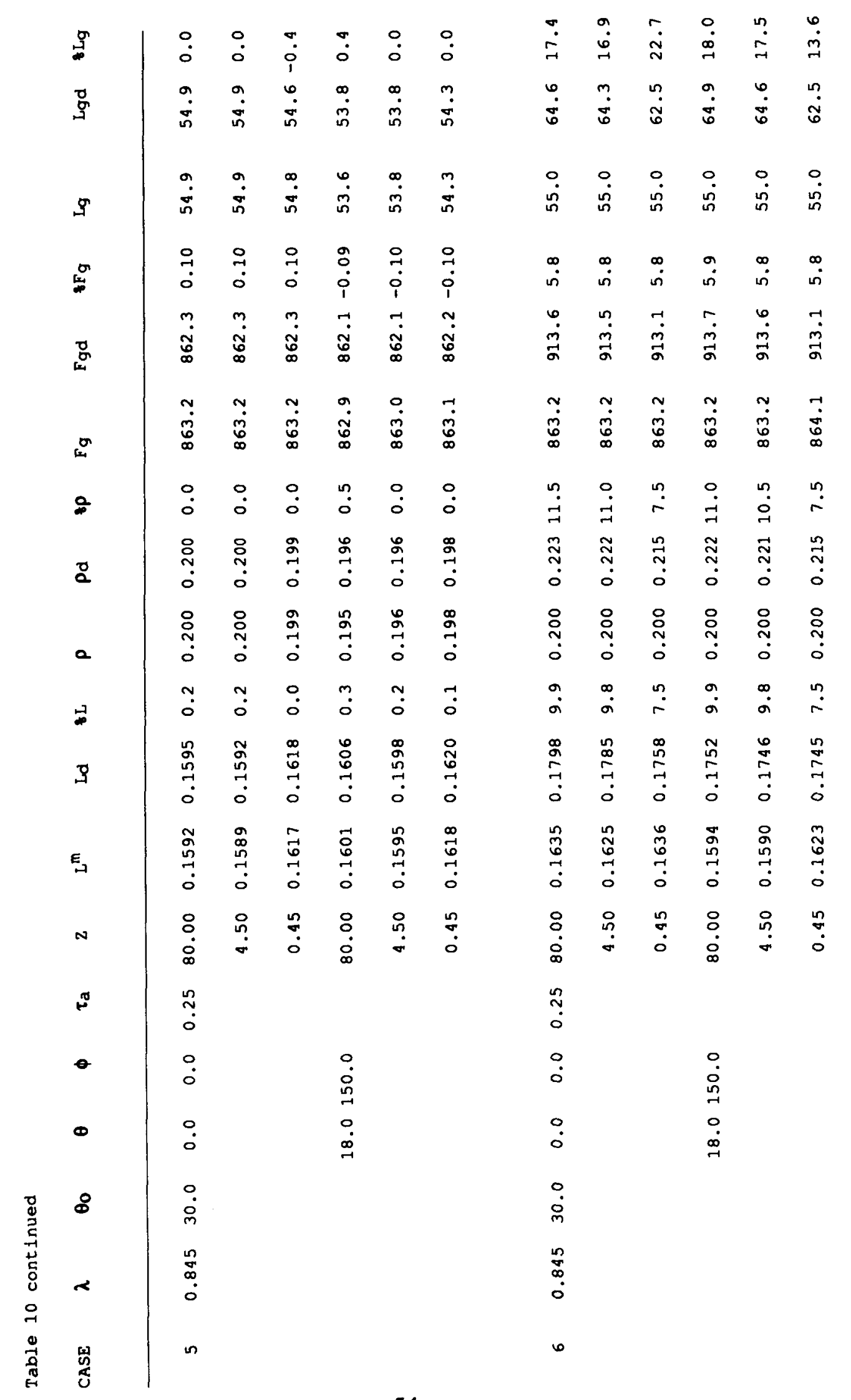




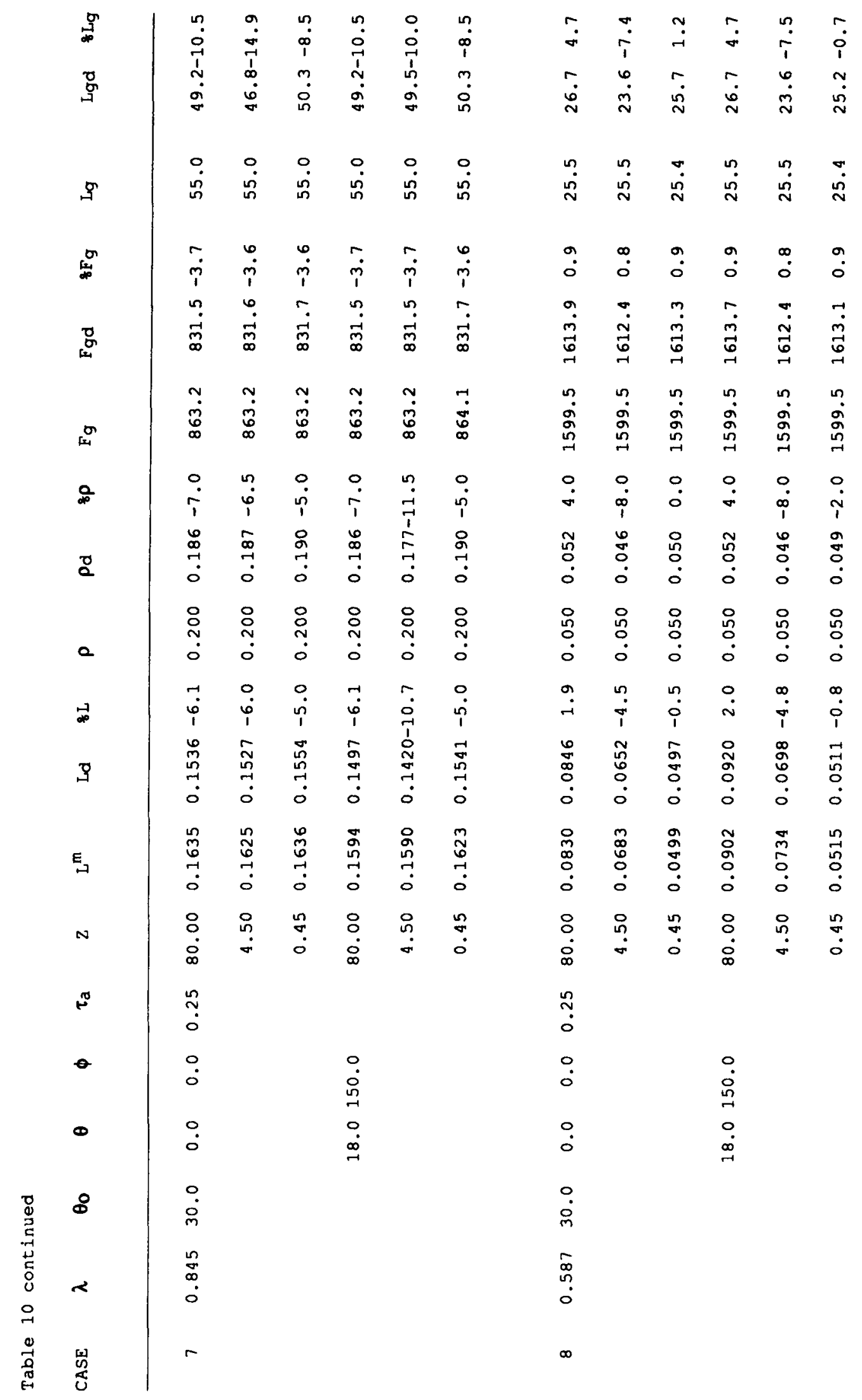




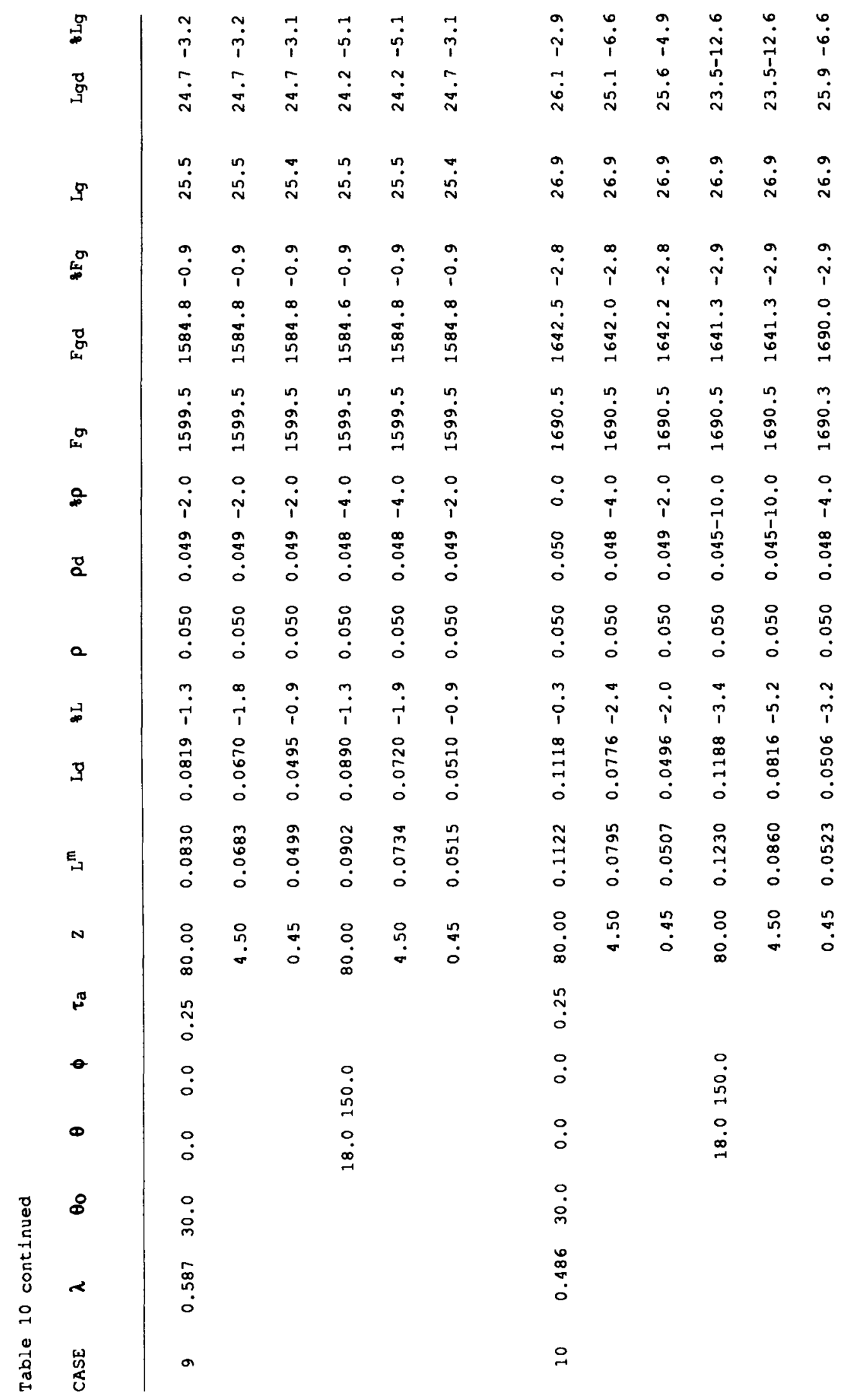




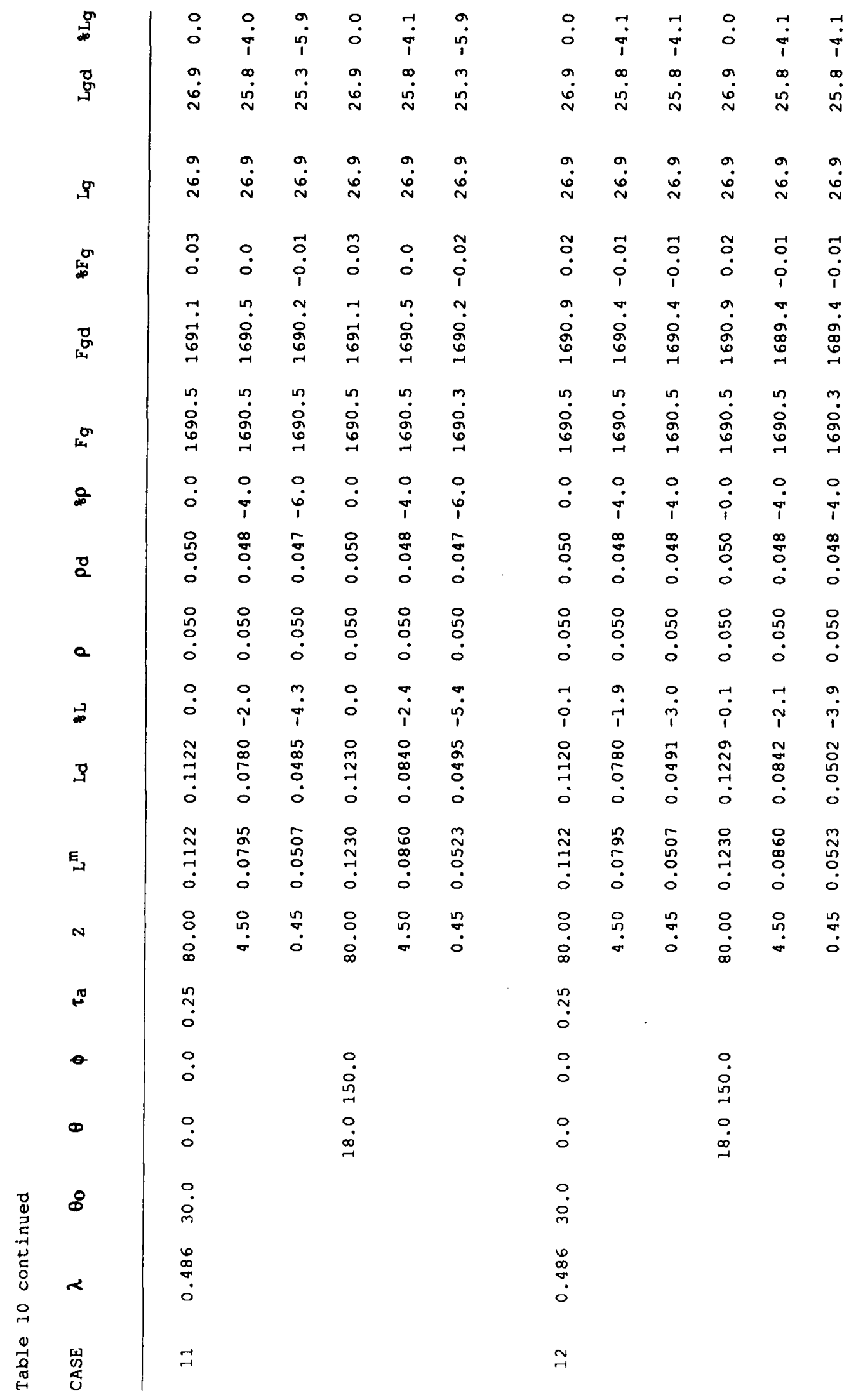




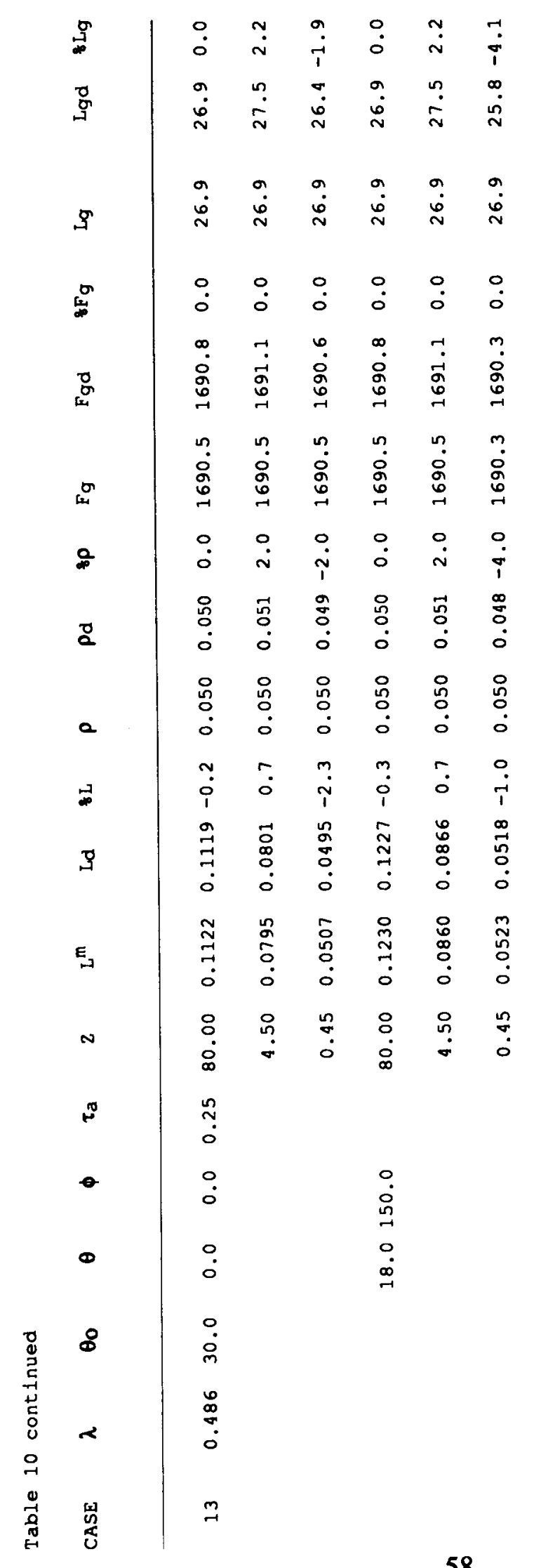




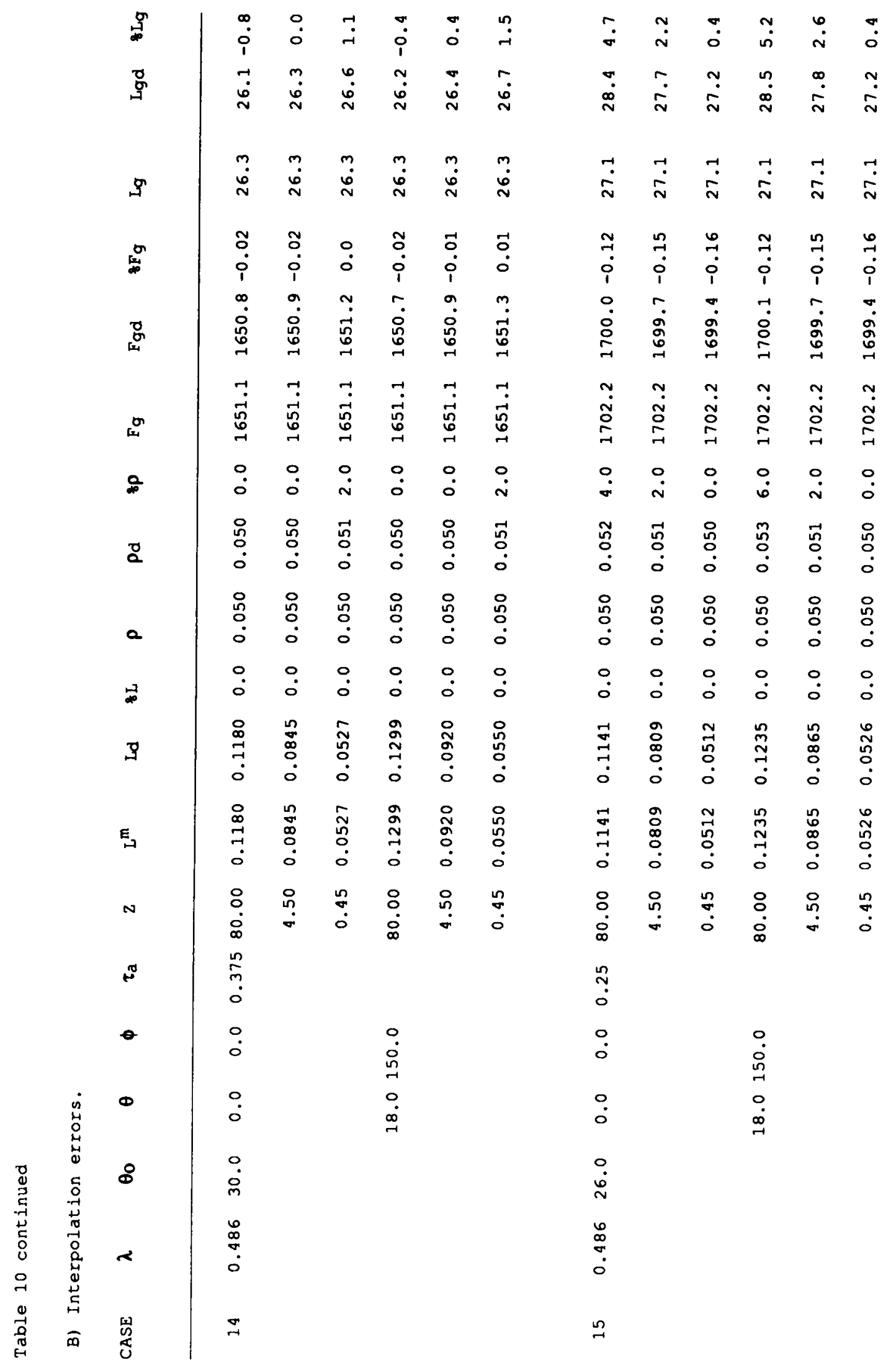




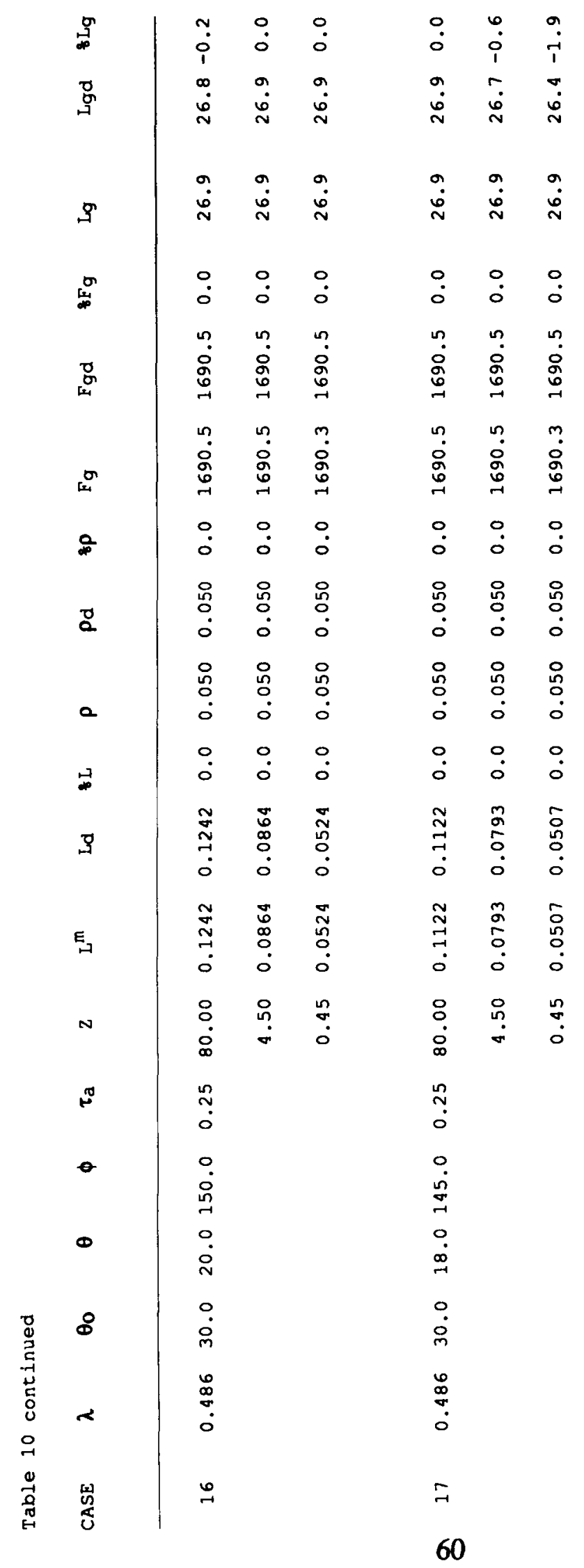




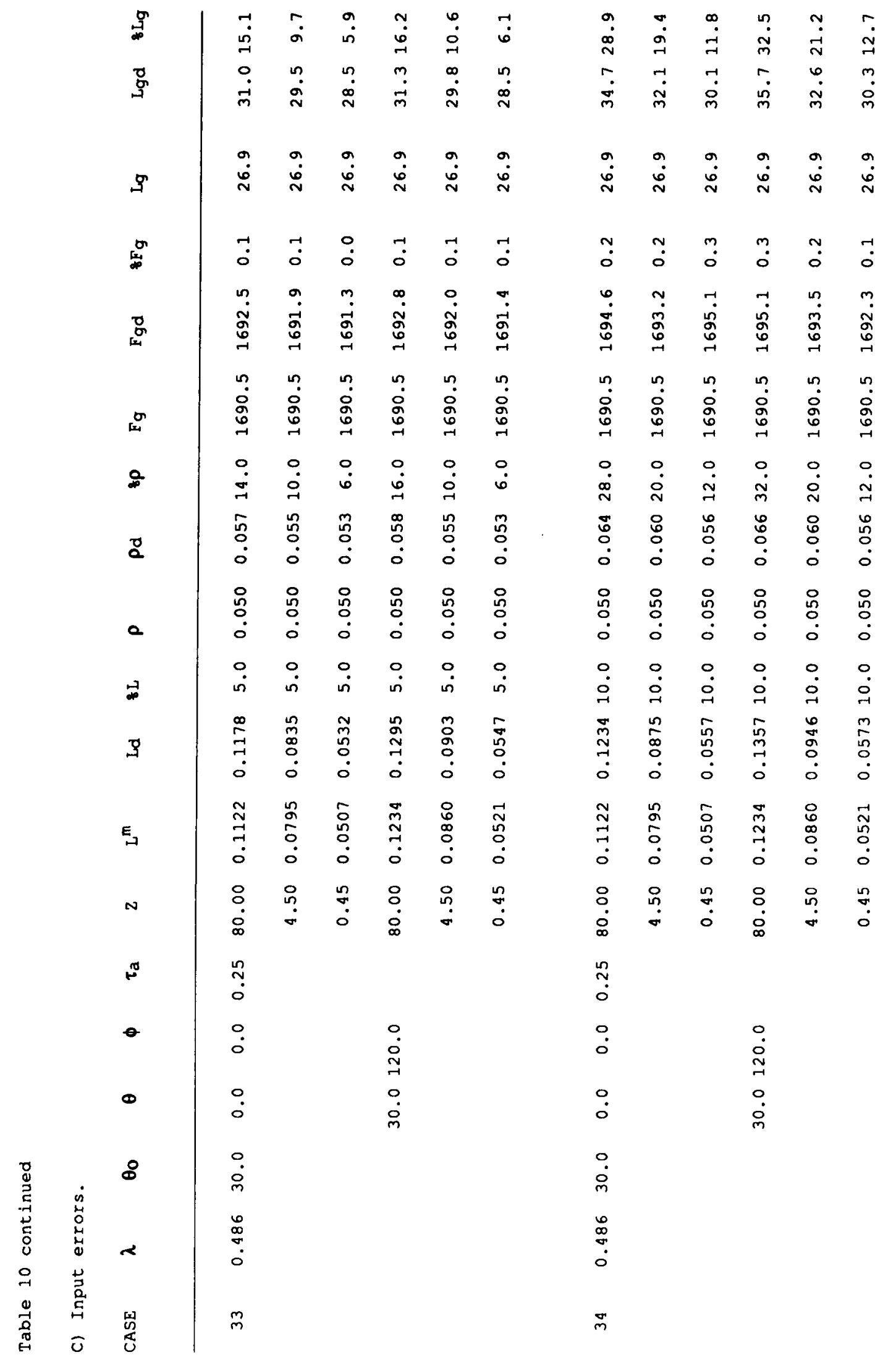




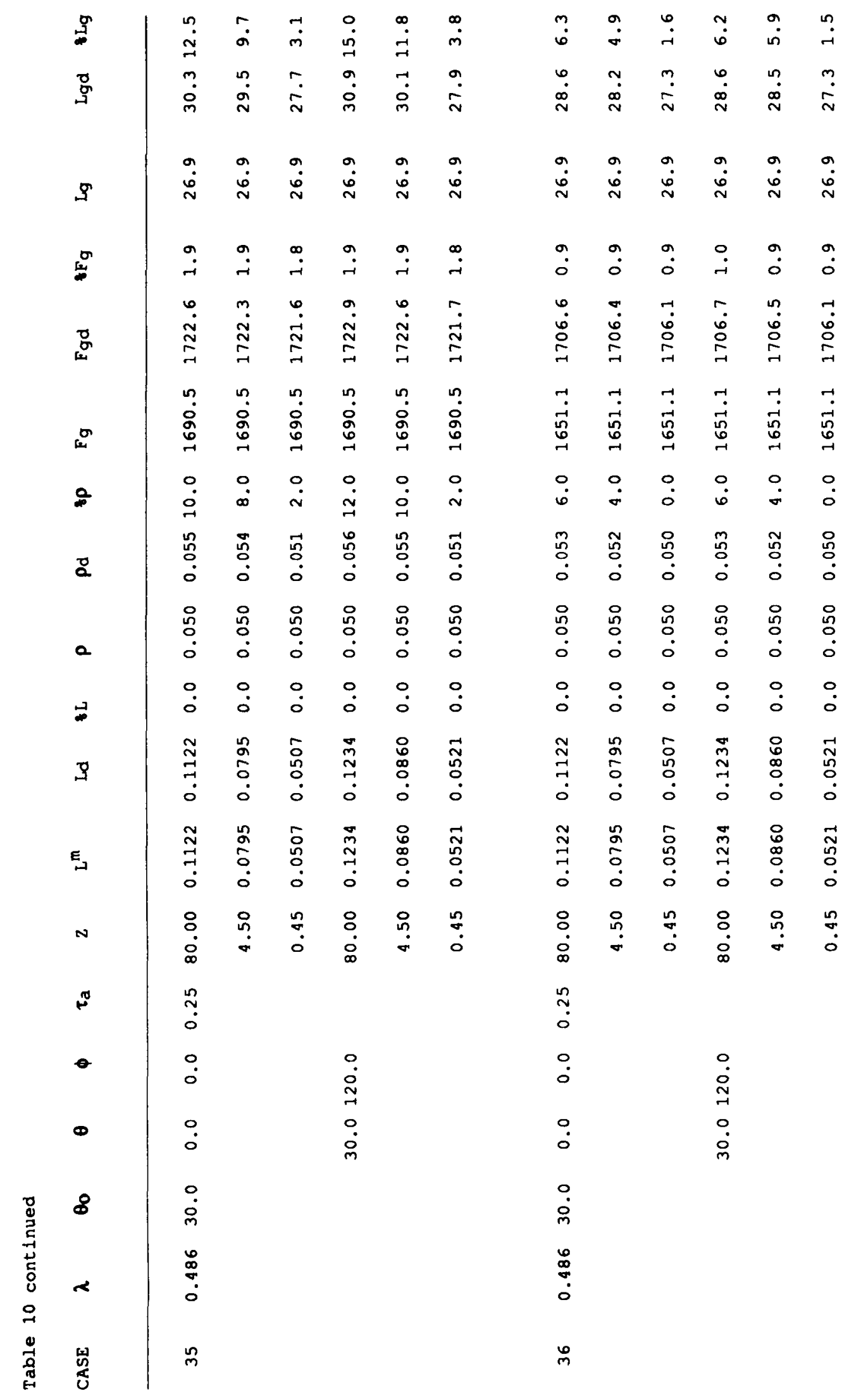




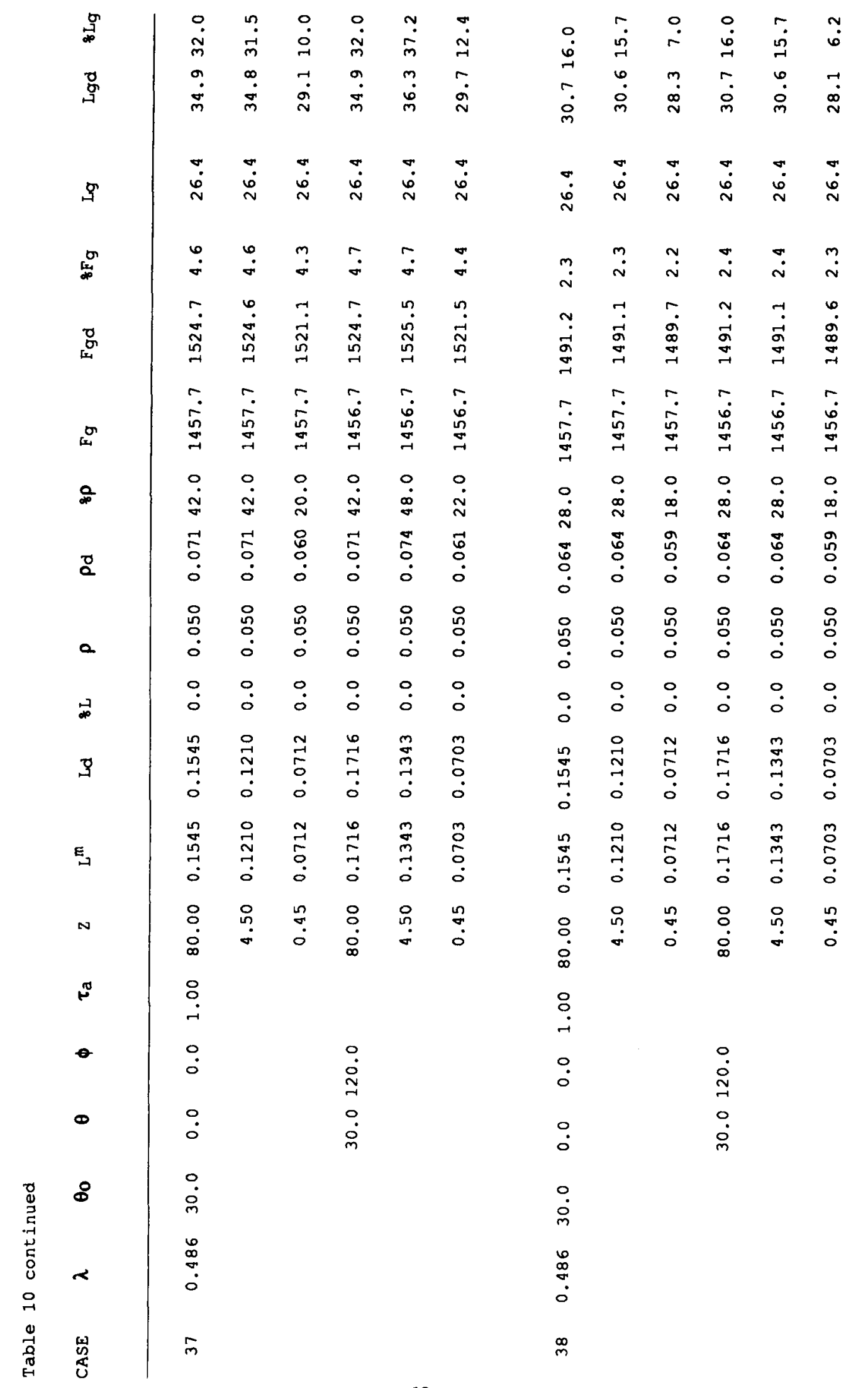




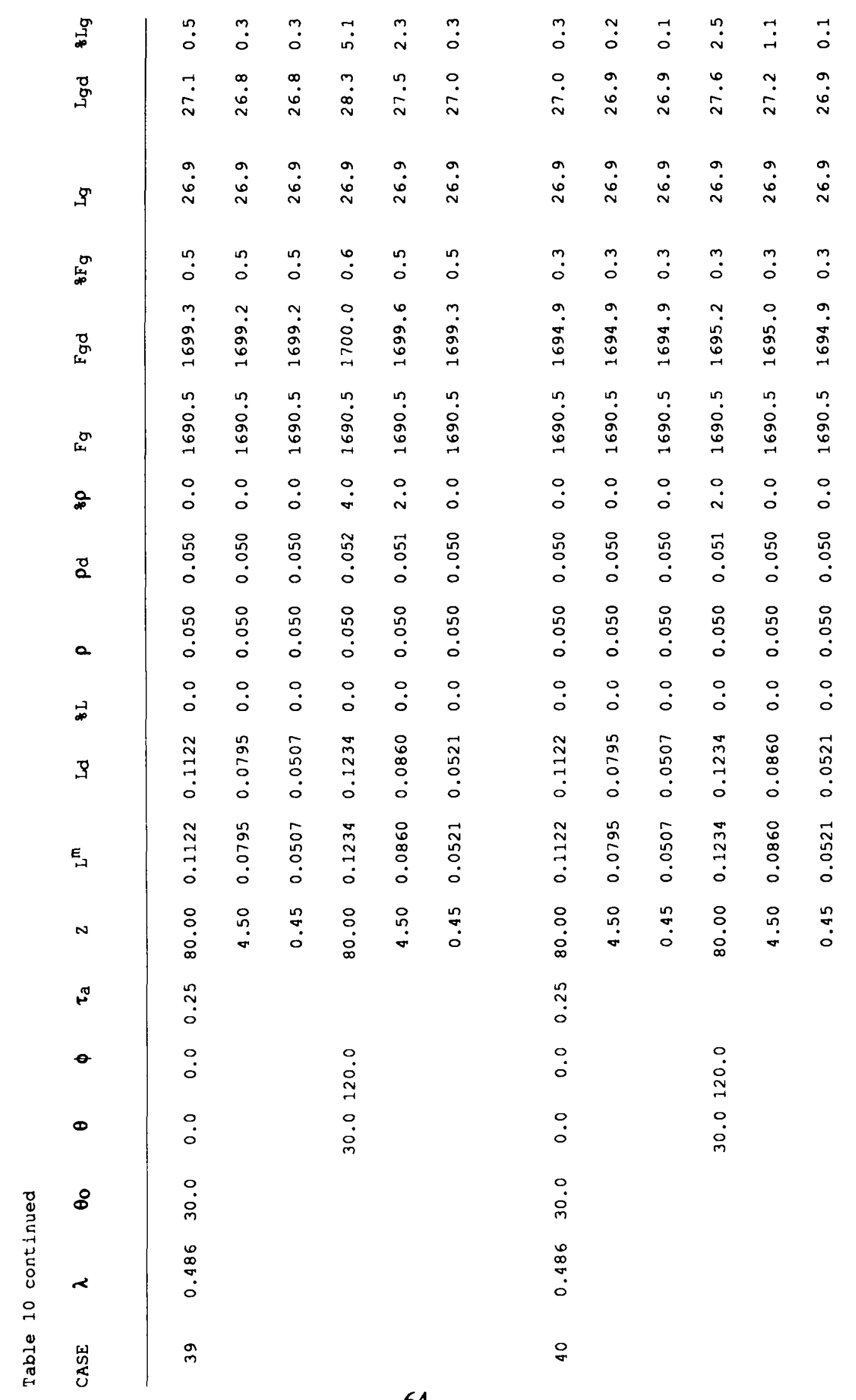




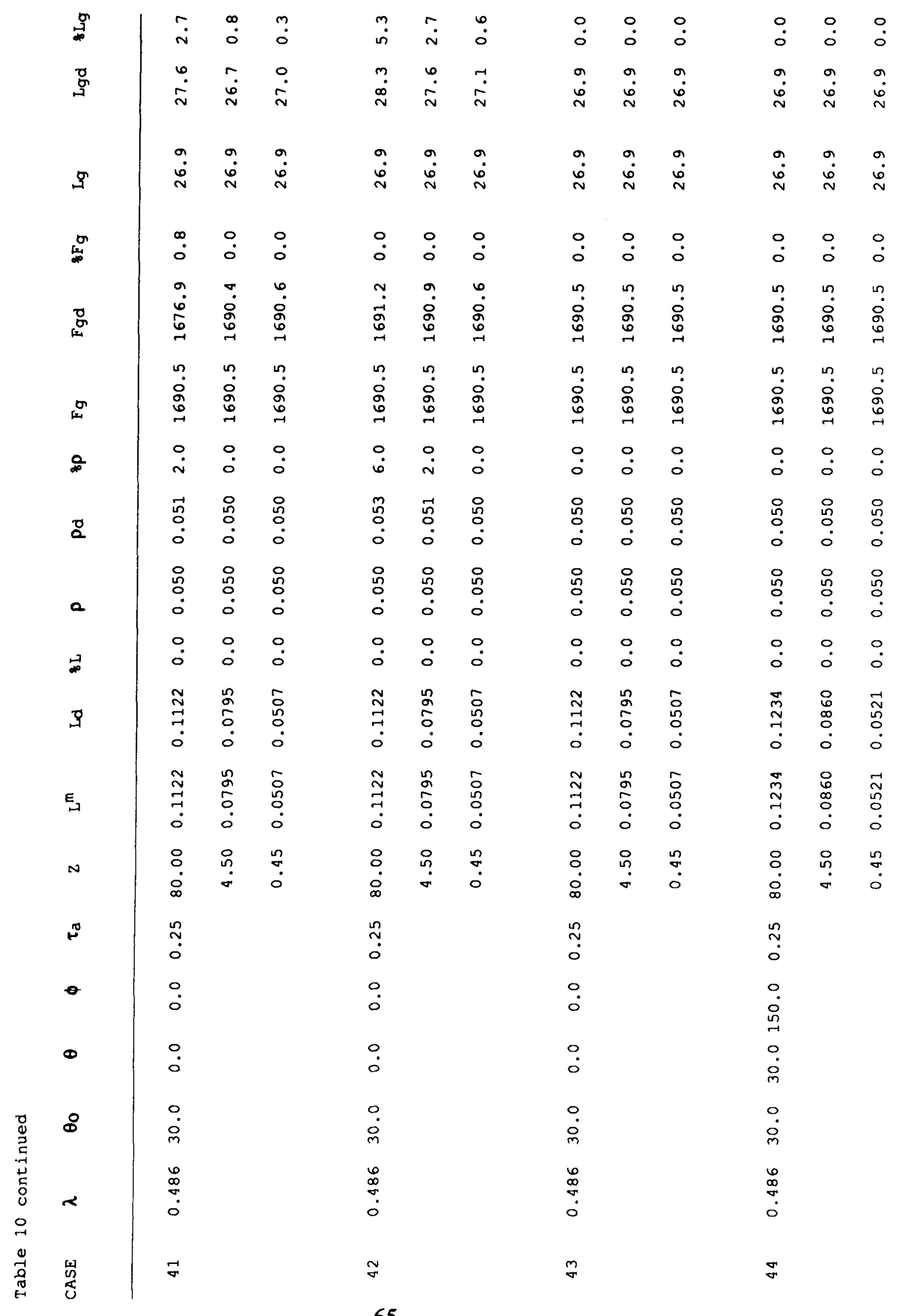


library of phase functions that were computed for 19 models of the accumulation mode. The size distribution is a single log-normal aerosol size distribution with an index of refraction of $n=1.349-0.008 i$, geometric mean mass radius $r_{m}=0.6 \mu \mathrm{m}$, and standard deviation of the logarithm of the radius $\sigma=0.61$. This phase function is compared with the phase function used in the algorithm in Figure 5 along. The second phase function used in the sensitivity analysis is chosen assuming a power law aerosol size distribution. The power chosen is $v=4$ where

$$
\frac{\mathrm{dn}}{\mathrm{d} \ln \mathrm{r}} \sim \mathrm{r}^{\mathrm{v}}
$$

and the index of refraction is $n=1.53-10^{-7} \mathrm{i}$. This phase function is also shown in Figure 5. Chayanova and Shifrin (1966) found this power law most closely matched the model number 4 (the surface visibility is $20 \mathrm{~km}$ ) aerosol phase function measured by Barteneva (1960). These two models are designated as cases 1 and 2 in Tables 8-10. Figure 5 shows that the bimodal log-normal phase function used in the algorithm lies between the two phase functions used in the sensitivity study for scattering angles greater than about $50^{\circ}$. Therefore, these two phase functions are chosen to represent extreme experimental conditions where the true aerosol scattering in the backward direction does not match the scattering assumed in the model.

Both of the phase functions used in the sensitivity analysis produced errors in the derived surface reflectance of approximately $\pm 20-30 \%$. The phase function derived using the single mode log-normal aerosol size distribution produced surface reflectance values too small, while the phase function derived using the power size distribution produced surface reflectance values too large. It should be noted that the two phase functions were chosen to represent the possible extremes in the scattering phase function (for large scattering angles) so that the errors associated with uncertainties in the phase function should usually be smaller.

Large negative reflectance errors (case 1) indicate that the algorithm will return negative reflectances, if the actual reflectance is weak. The large negative percentage reflectance error corresponds to an error magnitude of $\Delta \rho=-0.012$. If the simulation surface reflectance was less than +0.012 , the algorithm would return a negative reflectance.

The large errors associated with these uncertainties in the aerosol single scattering phase function indicate that the algorithm in its present form is limited to applications where the aerosol scattering phase function closely matches the function used in the algorithm. 


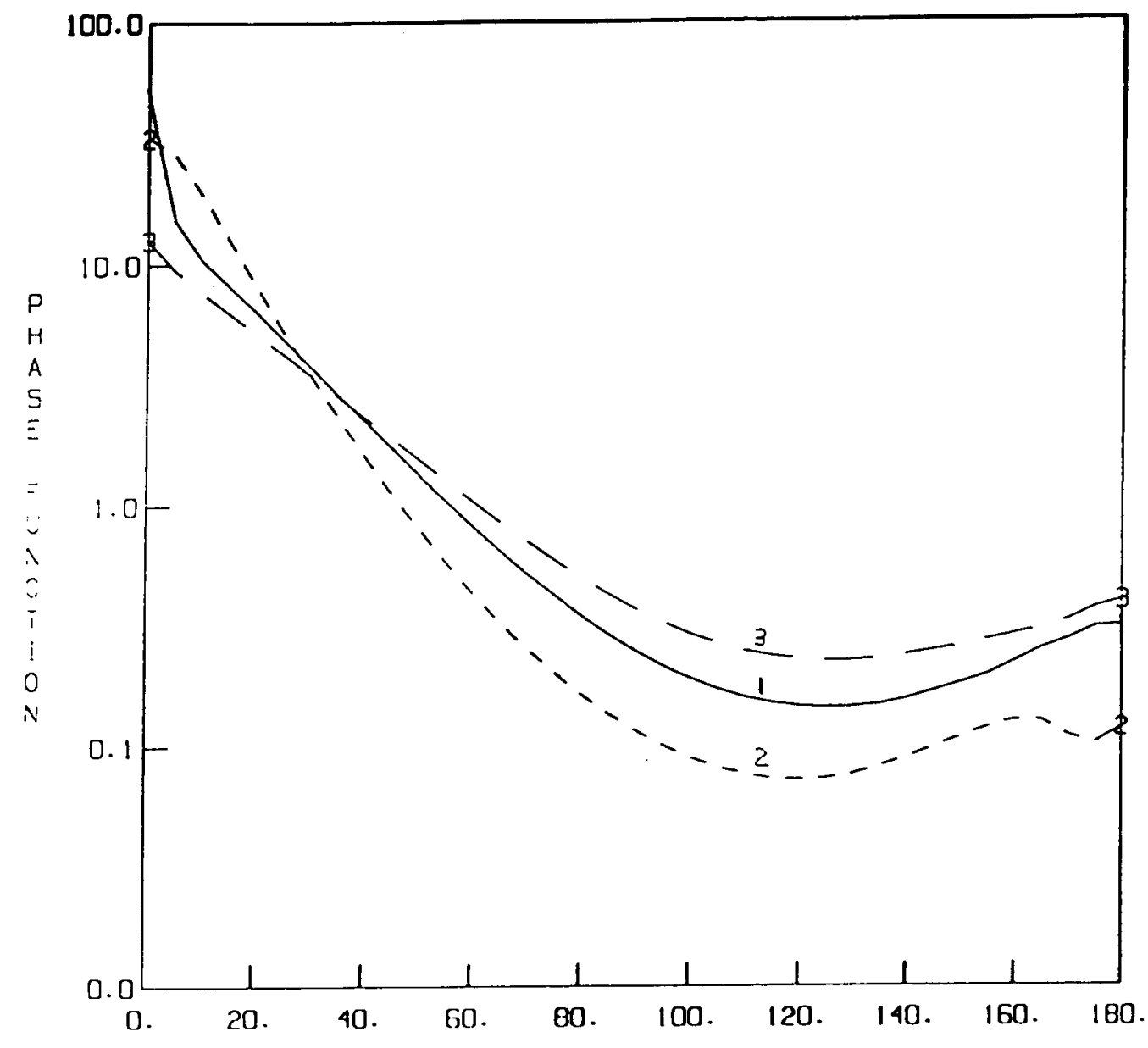

SCATIERING ANGLE (DEGREES)

Figure 5. Aerosol single scattering phase functions derived from: 1) bimodal log-normal aerosol size distribution used in the unperturbed model ( $\longrightarrow$, 2) single log-normal aerosol size distribution with an index of refraction $n=1.349-0.008 \mathrm{i}$, geometric mean mass radius $r_{m}=0.6 \mu \mathrm{m}$, standard deviation of the logarithm of the radius $\sigma=0.61(--)$, and 3) power law aerosol size distribution with $v=4$ and an index of refraction $\mathrm{n}=1.53-10^{-7} \mathrm{i}(--)$. 
However, the algorithm could be easily modified for use with other aerosol size distributions by replacing the look-up tables of path radiance, downward flux, transmission, and atmospheric backscattering ratio with values generated for a more appropriate aerosol size distribution. It is not necessary for these values to be generated by the same Dave (1972 a,b,c,d) radiative transfer code used to derive the values used here as long as the values tabulated are defined as in eq. (6-8).

\subsubsection{Polarization}

The algorithm which performs the atmospheric corrections uses tabulated radiances and fluxes computed with a Dave radiative transfer code. This code is based upon the scalar form of the radiative transfer equation, where the assumption is that the light scattered by the atmosphere and the earth's surface is unpolarized. If the atmospheric optical thickness is small this assumption is satisfactory, since the primary source of the light scattered by the atmosphere is the direct, unpolarized sunlight. The polarization errors are caused by second and higher order scattering of light that is polarized, and increase with optical thickness and decreasing wavelength. Light scattered by the surface, and especially by the atmosphere, is polarized.

Therefore, sensitivity tests are performed to estimate surface reflectance errors caused by neglect of polarization. In these tests, polarization is accounted for by another Dave code, similar in all other aspects to the scalar code. These sensitivity tests are performed for three wavelengths (cases 3,4,5): $0.486 \mu \mathrm{m}$ (TM band 1), $0.639 \mu \mathrm{m}$ (AVHRR band 1), and $0.845 \mu \mathrm{m}$ (AVHRR band 2). Errors in derived surface reflectance associated with the assumption of unpolarized light are less than $3 \%$ for $\lambda \geq 0.639 \mu \mathrm{m}$ (cases 4 and 5), but increase to approximately $10 \%$ for $\lambda=0.486 \mu \mathrm{m}$ (TM band 1 ). Although the results are not shown in the tables, the errors associated with the assumption of unpolarized light generally decrease with decreasing aerosol optical thickness because less multiple scattering occurs.

\subsubsection{Water Vapor and Ozone Absorption}

Another potential source of error which is examined is the effect of using an incorrect value of the gaseous absorption. Since most of the gaseous absorption in the Landsat TM and NOAA AVHRR visible and near IR bands is contributed by either water vapor or ozone, the sensitivity tests are run at those wavelengths where absorption by these 
constituents is the largest. For water vapor this occurs for AVHRR band 2 while for ozone this occurs for TM band 2 .

Since the amount of an absorbing gas is variable, the algorithm uses a weighted average of the gaseous absorption values computed for the tropical, mid-latitude summer, and mid-latitude winter models given in the LOWTRAN code. Most of the weight is given to the mid-latitude summer profile (see eq. 16). In the case of AVHRR band 2, the algorithm uses a water vapor gaseous absorption optical thickness of $\tau_{\mathrm{g}}=0.0933$. The gaseous absorption optical thicknesses computed using the mid-latitude winter and tropical profiles are used for the sensitivity studies. Therefore, two tests are made to estimate the uncertainty due to water vapor absorption; the first test uses the mid-latitude winter value of $\tau_{\mathrm{g}}=0.0486$ (case 6) while the second test uses the tropical value of $\tau_{\mathrm{g}}=0.1235$ (case 7).

A change in the total amount of water vapor between the algorithm and mid-latitude winter profiles (case 6) causes errors as large as $11 \%$ in the derived surface reflectance for AVHRR band 2. Since the difference in the total water vapor amounts between the algorithm and tropical profiles is smaller than the difference between the algorithm and midlatitude winter profiles, the magnitude of the error that results from using the tropical profile is less--7\% (case 7). These errors can be reduced significantly by applying the water vapor correction given in Section 3.3.

A second set of tests is conducted to determine the sensitivity of the model to changes in ozone absorption. Since TM band 2 has the largest ozone absorption, the ozone absorption sensitivity tests are run at this wavelength. As in the case of water vapor absorption discussed above, the algorithm uses a weighted average of the mid-latitude winter, mid-latitude summer, and tropical profiles computed using the LOWTRAN code to derive a value of ozone absorption optical thickness of $\tau_{g}=0.032$ for TM band 2 . The first of two sensitivity tests are run using the mid-latitude winter ozone absorption optical thickness $\tau_{\mathrm{g}}=0.039$ (case 8 ) while the second test is run using the tropical value of $\tau_{g}=0.024$ (case 9). The magnitude of errors in the the derived surface reflectance in TM band 2 caused by variations in mid-latitude winter and tropical profiles to the algorithm ozone amounts is $2-4 \%$ (cases 8 and 9 ). 


\subsubsection{Aerosol Absorption}

The sensitivity of the correction algorithm to aerosol absorption is tested by changing the aerosol single scattering albedo $\omega_{0}$, which is the ratio of aerosol scattering to extinction. The algorithm uses values of $\omega_{0}$ derived for the 70\%-relative-humidity, rural model of Shettle and Fenn (1979); in this model the aerosol single scattering albedo varies from 0.95 at $\lambda=0.486 \mu \mathrm{m}$ to 0.86 at $\lambda=2.550 \mu \mathrm{m}$. Values of the single scattering albedo for the visible spectrum, reported by Waggoner et al. (1981), range from $0.54 \leq \omega_{0} \leq 0.61$ for urban industrial areas, $0.73 \leq \omega_{0} \leq 0.87$ for urban residential areas, and $0.89 \leq \omega_{0} \leq 1.00$ for rural areas. These values agree with the values used by Shettle and Fenn. In the sensitivity test (case 10 ), a value of $\omega_{0}=0.84$ at $0.486 \mu \mathrm{m}$ is based upon the average measured values in residential urban areas of Michigan and Missouri (Waggoner et. al., 1981). Since the algorithm is designed to correct radiances measured over rural sites, this should represent a rather extreme (but possible) departure from the usual case.

The derived surface reflectance is somewhat sensitive to changes in aerosol absorption (case 10). This sensitivity appears to depend strongly on geometry, as the resulting errors in the derived reflectance vary between -10 to $0 \%$ for the case when the single scattering albedo decreased from 0.95 to 0.84 .

Another study of the effect of aerosol absorption error on the derived surface reflectance is given out of sequence (case 10a ), because the unperturbed model is different. The emphasis is on a large solar zenith angle $\left(\theta_{0}=64^{\circ}\right)$, long path through the atmosphere $\left(\theta=56^{\circ}\right)$, and rather large aerosol optical thickness $\left(\tau_{\mathrm{a}}=0.35\right)$. Interpolations are made on all these variables plus the azimuth. Also, the simulated surface reflectance is high $(0.6)$. The error $(-0.11 \%)$ is significant. The error would be less with smaller optical thickness, however.

\subsubsection{Vertical Distribution of Aerosols}

The next sensitivity test deals with errors which result from uncertainty in the vertical distribution of aerosols. The altitude distribution of aerosols used in the algorithm is based on the 'average' distribution described by Braslau and Dave (1973) which is shown in Figure 4. The sensitivity of the results to this distribution is tested by using three different profiles which are constructed using the aerosol models described by Shettle and Fenn (1979). In these models, the atmosphere is divided into four regions: boundary layer (0 $2 \mathrm{~km})$, upper troposphere (2-9km), stratosphere $(9-30 \mathrm{~km})$, and upper atmosphere 
( $30-100 \mathrm{~km})$. All three of the models use the background aerosol models for the stratosphere and upper atmosphere regions; the perturbation models differ in the boundary layer and upper troposphere regions. The first model (case 11) uses the 50-km-visibility, rural model in the boundary layer and the 50-km-visibility, spring/summer model in the upper troposphere. The second model (case 12) uses the 23-km-visibility, rural model in the boundary layer and the 23-km-visibility, spring/summer model in the upper troposphere. The third model (case 13) uses the 10-km-visibility, rural model in the boundary layer and the 23-km-visibility, spring/summer model in the upper troposphere. The vertical distributions of aerosol corresponding to these three models are shown in Figure 4. These profiles are normalized to produce an optical thickness of $\tau_{\mathrm{a}}=0.25$ at $0.550 \mu \mathrm{m}$. Since the average visibility in the midwestern U.S. is about $20 \mathrm{~km}$ (Husar and Holloway, 1984), a maximum visibility of $50 \mathrm{~km}$ and a minimum visibility of $10 \mathrm{~km}$ are chosen to represent the extremes used for the construction of the altitude distribution of aerosols.

Uncertainty in the height distribution of aerosols has a negligible effect on the surface reflectance when measured from the top of the atmosphere, since the aerosol distribution is normalized such that the total aerosol optical thickness below the sensor remains the same (cases 11, 12 and 13). However, if a sensor is within the atmosphere, there will be small differences in the optical thickness of aerosols above and below the sensor, depending upon which aerosol distribution is used. The magnitude of the derived reflectance errors is less than $7 \%$ at aircraft heights (Table 10).

\subsubsection{Bidirectional Reflectance Errors}

The final model error concerns the assumption that the surface is Lambertian. Surfaces do not reflect light according to Lambert's Law as is assumed for the current atmospheric correction algorithm. Lee and Kaufman (1986) calculated the error in the derived surface reflectance for a model which also assumed Lambert reflection. Their study utilized actual surface bidirectional reflectances for pasture as measured by Kriebel (1977). The absolute errors in estimates of surface reflectance are a few hundredths when the solar zenith angle is small because the surface is nearly Lambertian. The errors are also small where the surface reflectance is weak. The derived surface reflectance errors become large (about 0.1 ), however, for moderate haze, when the surface reflectance is both high and strongly anisotropic. Errors in the derived surface reflectance and radiance, but not the irradiance, will not be significant if the surface reflectance is weak; however, the errors can be important for strong bidirectional reflectance. 


\subsection{Interpolation Errors}

The correction algorithm is based on a series of look-up tables relating surface reflectance to measured upward radiance for various aerosol optical thicknesses and geometries. As a result, the algorithm must interpolate to determine the reflectance corresponding to an arbitrary input radiance, aerosol optical thickness, gaseous absorption optical thickness, altitude, and geometry. (No extrapolation is permitted.) The simulations are chosen to show the largest interpolation errors. The interpolation errors are computed by comparing the reflectance errors derived from simulated radiances with those derived with the correction algorithm.

The first interpolation sensitivity test (case 14) is performed using the standard test input parameters described earlier $\left(\lambda=0.486 \mu \mathrm{m}, \theta_{O}=30^{\circ}, \theta=0^{\circ}, \phi=0^{\circ}\right)$, except with an aerosol optical thickness of $\tau_{a}=0.375$, which requires the algorithm to interpolate between $\tau_{a}=0.25$ and $\tau_{a}=0.50$. Note that the reflectance errors are deviations from the correct value of $\rho=0.05$ for cases 14-21 and 24-32; the unperturbed reflectance changes only for cases 22 and 23 . The next run (case 15) tests the interpolation on solar zenith angle. The solar zenith angle interpolation test is run using the standard test input parameters except with a solar zenith angle of $26^{\circ}$ which requires the algorithm to interpolate between $\theta_{o}=20^{\circ}$ and $\theta_{0}=30^{\circ}$. Similar tests are run for the observation zenith angle (case 16) and the azimuth angle (case 17). The observation zenith angle interpolation test was run using $\theta=20^{\circ}$, which requires the algorithm to interpolate between $\theta=18^{\circ}$ and $\theta=24^{\circ}$. The azimuth angle interpolation test was run using $\phi=145^{\circ}$ so that the algorithm interpolated between $\phi=140^{\circ}$ and $\phi=150^{\circ}$. Separate interpolations on $\tau_{\mathrm{a}}, \theta$, and $\phi$ result in errors less than $1 \%$ in the derived surface reflectance, while the interpolation on $\theta_{o}$ can result in an error as large as $4 \%$.

Errors associated with interpolation on wavelength are shown in cases $18-20$. The input wavelengths are $0.5,0.6$ and $0.775 \mu \mathrm{m}$. In these cases, the error in derived surface reflectance is at most $6 \%$.

Since the algorithm may also interpolate on gaseous absorption, sensitivity tests are also made to determine the uncertainty involved with this interpolation. In cases 21-23 the algorithm uses the input gaseous absorption value $\tau_{\mathrm{g}}$ computed using the LOWTRAN 6 code and the radiances associated with TM band $4(0.840 \mu \mathrm{m})$ (which has a narrow bandwidth and relatively small gaseous absorption) to determine the surface reflectance 
seen by the AVHRR band 2 (which has a wide bandwidth and relatively large gaseous absorption). These tests show the algorithm underestimates the surface reflectance by only about $1-2 \%$.

Sensitivity tests are also made to determine the errors associated with adjustments to the look-up tables corresponding to different input surface heights. As discussed in section 3.5, the algorithm makes the adjustment by changing the wavelength slightly (eq. 20). Cases 24 and 25 show that this adjustment results in rather large errors in the derived surface reflectance of $-8 \%$.

Errors associated with interpolation on the measurement altitude $\mathrm{Z}$ are studied. The radiative transfer computations are tabulated at three altitudes: $0.45 \mathrm{~km}, 4.5 \mathrm{~km}$, and 80 $\mathrm{km}$. In cases 26 to 28 input observation altitudes of $Z=0.23 \mathrm{~km}, 2.96 \mathrm{~km}$, and $6.5 \mathrm{~km}$ are used. The derived surface reflectance errors are as large as $8 \%$.

Finally, errors associated with interpolation for large solar and viewing zenith angles are given. Interpolations are made with respect to $\tau_{\mathrm{a}}, \theta_{0}, \theta$, and $\phi$; the surface reflectance $\rho=0.05$ (cases $29-32$ ). Case 29 shows that the error is appreciable for a rather large optical thickness. This large error depends on the nonlinear change in radiance as the azimuth increases from $10^{\circ}$ to $20^{\circ}$. If the same test is made, except that the azimuth is $165^{\circ}$, the error reduces to $8 \%$ (case 30 ). When the optical thickness decreases to $\tau_{\mathrm{a}}=0.1$ (case 31), however, the error has a large negative value. The derived value is $\rho=0.034$, compared with the simulation value of $\rho=0.050$. Again, if the azimuth is changed from near-forward (case 31) to near-backward (case 32), the magnitude of the error decreases to $6 \%$.

\subsection{Input Errors}

A third set of sensitivity tests is performed to estimate the errors in the derived surface reflectance resulting from errors or uncertainties in the input data. Each test is performed with the algorithm model, except that an incorrect value of one of the input parameters is used.

The first test introduces a 5\% error into the input radiance (case 33). As would be expected, the algorithm is very sensitive to such an error. If the input radiance error increases to $10 \%$ (case 34 in Tables 8 and 10), the reflectance error doubles to $28 \%$. The relative errors in the derived surface reflectance can be as large as two to three times the relative errors in the input radiance. 
Errors in the input optical thickness occur because of measurement errors, and the optical thickness is not measured at the same time and place of the remote measurement. Tests are made with an error in the input aerosol optical thickness of $\Delta \tau_{\mathrm{a}}=0.05$ for the case where the correct input is $\tau_{\mathrm{a}}=0.25$ (case 36), and for $\Delta \tau_{\mathrm{a}}=0.1$ when $\tau_{\mathrm{a}}=1.0$ (case 38). The derived surface reflectance errors caused by optical thickness errors are largest when the surface reflectance is weak. Hence, the errors are computed for visible reflectance of visible light from vegetation $(p=0.05)$. The resulting surface reflectance error of 0.003 is insensitive to errors of 0.05 for moderate aerosol optical thickness (case 36). For $\tau_{\mathrm{a}}=1.0$ and larger aerosol optical thickness error of 0.1 , the error in the derived surface reflectance increases to $\Delta \rho=0.014$ (case 38).

The solar zenith angle test is run by introducing an error of $\Delta \theta_{0}=2^{\circ}$ (case 40) when the correct input is $\theta_{0}=30^{\circ}$. Similarly, the sensitivity of the results to errors in the input observation zenith angle is tested by introducing an error of $\Delta \theta=2^{\circ}$ (case 41) when the correct input is $\theta=0^{\circ}$. Finally, the sensitivity to errors in the input azimuth angle is tested by introducing an error of $\Delta \phi=2^{\circ}$ for the case when the correct input is $\phi=0^{\circ}$ (case 44). Errors in the input values of solar zenith, observation zenith, and azimuth angles generally result in negligible errors of less than $2 \%$ in the derived surface reflectance.

\section{Z.e Conclusion}

An algorithm is developed to account for atmospheric effects when deriving surface reflectance properties from visible and near-infrared radiances measured by aircraft or satellite over rural areas. The radiance that would be measured for a given surface reflectance can be derived, also. The algorithm uses a tabulated set of radiances computed for various wavelengths, solar and observation angles, and aerosol optical thicknesses. All aerosol parameters have been assumed, except for the aerosol optical thickness, which is an input value. Since the algorithm performs essentially interpolations, it is fast; therefore, it is well suited for reducing observations in many wavelengths. Otherwise, the effect of the atmosphere requires many radiative transfer computations.

Large errors in derived parameters, rather than rms errors are estimated. Among the largest model errors are those caused by uncertainties in the aerosol scattering phase function; in this case surface reflectance and radiance errors reach $\pm 20-30 \%$. Thus, in its current configuration, the algorithm is suitable for only a rural, bimodal log-normal aerosol size distribution. However, the algorithm could be easily modified for use with other 
aerosol size distributions by replacing the radiance look-up tables with values generated for a more appropriate aerosol size distribution.

Errors in the derived surface reflectance can be large when either the slant path through the atmosphere of sunlight or light reflected from the ground is long.The uncertainty in the amount of water vapor causes an error of 5\% in the reflectance for AVHRR band 2. This error can be reduced significantly by using measurements of the total amount of water vapor at the time of measurement. The mesh for the tabulated radiation parameters is fine enough so that linear interpolation results in small reflectance errors $(<4 \%)$.

Of the errors in the input parameters required by the correction algorithm, errors in the measured radiance can result in large errors in the derived radiance and reflectance but not irradiance. Absolute measured radiance errors of 5-10\% are expected. Therefore, the derived surface radiances and reflectances will deviate by at least 5-10\% from the correct values even without any errors in the atmospheric correction algorithm. Large errors in the derived surface reflectance can also result from errors in the input values of aerosol optical thickness. Optical thickness errors should be less than 0.05 so that the corresponding surface reflectance errors are less than $10 \%$ for a dark surface $(\rho=0.05)$.

Acknowledgement: We appreciate Mr. Brian Markham's early efforts to use the tables, and thereby bring to our attention places to improve their accuracy.

\subsection{References}

Ahmad, Z. and R.S. Fraser, 1982: An iterative radiative transfer code for oceanatmosphere system, J. Atmos. Sci., 39, 656-665.

Barteneva, C.D., 1960: Scattering functions of light in the atmospheric boundary layer., Izv. Geophys. Ser., 1852-1865.

Bohren, C.F. and D.R. Huffman, 1983: Absorption and scattering of light by small particles., Wiley, New York.

Braslau, N. and J.V. Dave, 1973: Effect of aerosols on the transfer of solar energy through realistic model atmospheres. Part I: Non-absorbing aerosols., J. Appl. Meteor.,12, 601-615.

Carlson T.N., 1979: Atmospheric turbidities in Saharan dust outbreaks as determined by analysis of satellite brightness data, Mon. Wea. Rev., 107, 322-335. 
Chandrasekhar, S., 1960: Radiative Transfer, Dover, New York.

Chayanova, E.A. and K.S. Shifrin, 1966: The scattering indicatrix of the atmospheric boundary layer., Izv., Atm. and Oceanic Phys., 4, No. 2, 233-235.

Dave, J.V., 1972a: Development of programs for computing characteristics of ultraviolet radiation - Technical Report - Scalar Case, Program I, FSC-72-0009, IBM Federal Systems Division, Gaithersburg, Maryland.

1972b: Development of programs for computing characteristics of ultraviolet radiation - Technical Report - Scalar Case, Program II, FSC-72-0011, IBM Federal Systems Division, Gaithersburg, Maryland.

-ato 1972c: Development of programs for computing characteristics of ultraviolet radiation - Technical Report - Scalar Case, Program III, FSC-72-0012, IBM Federal Systems Division, Gaithersburg, Maryland.

-.------, 1972d: Development of programs for computing characteristics of ultraviolet radiation - Technical Report - Scalar Case, Program IV, FSC-72-0013, IBM Federal Systems Division, Gaithersburg, Maryland.

Ferrare, R.A., R.S. Fraser and Y.J. Kaufman 1988: Satellite remote sensing of large scale air pollution - measurements of forest fires smoke, submitted to J. Geoph. Res.

Fraser, R.S., Y.J. Kaufman, and R.L. Mahoney, 1984: Satellite measurements of aerosol mass and transport, Atmos. Environ., 18, 2577-2584.

Fraser, R.S. and Y.J. Kaufman, 1985: The relative importance of aerosol scattering and absorption in remote sensing., IEEE Trans. Geosc. Remote Sensing, GE-23, No. $5,625-633$.

Gordon, H.R., D.K. Clark, J.W. Brown, O.B. Brown, R.H. Evans, and W.W. Broenkow, 1983: Phytoplankton pigment concentration in the middle Atlantic bight: Comparison of ship determination and CZCS estimates, Appl. Optics, 22, 20-36.

Griggs, M., 1975: Measurements of atmospheric aerosol optical thickness over water using ERTS-1 data, J. Air Pollut. Control Ass., 25, 622-626.

Hansen, J.E. and L.D. Travis, 1974: Light scattering in planetary atmospheres., Space Sci. Rev., 16, No. 4, 527-610. 
Herman, B.M., R.S. Browning, and J. DeLuisi, 1975; Determination of the effective imaginary term of the complex index of refraction of atmospheric dust by remote sensing: The diffuse-direct radiation method., J. Atmos. Sci., 32, 918-925.

Holben B.N., 1986: Characteristics of maximum value composite images for temporal AVHRR data, Int. J. Rem. Sens., 7, 1417-1437.

Husar, R.B. and J.M. Holloway, 1984: Properties and climate of atmospheric haze., Hygroscopic Aerosols, (L.H. Ruhnke and A. Deepak, eds.), A. Deepak, Hampton, VA, 129-170.

Kaufman, Y.J., 1987: Satellite sensing of aerosol absorption, J. Geoph. Res., 92, 43074317.

Kaufman, Y.J. and R.S. Fraser, 1983: Light extinction by aerosols during summer air pollution, J. Appl. Meteor., 22,1694-1706.

Kaufman, Y.J., R.S. Fraser and R.A. Ferrare, 1988: Satellite remote sensing of large scale air pollution - method, submitted to J. Geoph. Res.

Kaufman Y.J. and C. Sendra, 1988: Automatic atmospheric correction, accepted to Int. J. Rem. Sens.

Kidwell, C.D, 1985: NOAA Polar Orbiter Data User's Guide, NOAA-NESDIS, Washington, D.C., 20233

King, M. D. 1979: Determination of the ground albedo and the index of absorption of atmospheric particulates by remote sensing. Part II: application, J. Atmos Sci., 36, 1072-1083.

King, M. D. and B. M. Herman, 1979: Determination of the ground albedo and the index of absorption of atmospheric particulates by remote sensing. Part I: theory, J. Atmos Sci., 36, 163-173.

King M.D., D.M. Byrne, B.M. Herman and J.A. Reagan, 1978: Aerosol size distribution obtained by inversion of optical depth measurements, J. Atmos. Sci., 35, 21532167.

Kniezys, F.X., E.P. Shettle, W.O. Gallery, J.H. Chetwynd, L.W. Abreu, J.E.A. Selby, S.A. Clough, R.W. Fenn, 1983: Atmospheric transmittance/radiance: computer code LOWTRAN 6, AFGL-TR-83-0187, Air Force Geophysics Lab, Hanscom AFB, MA. 
Koepke, P. and H. Quenzel, 1979: Turbidity of the atmosphere determined from satellite calculation of optimum viewing geometry, J. Geoph. Res., 84, 7847-7855.

Kriebel, K.T., 1977: Reflection properties of vegetated surfaces: tables of measured spectral biconical reflectance factors, Muenchener Universitaets-Schriften, Meteorologisches Institut, Wissenschaftl. Mitteiling 29, 1977.

Lee, T. and Y.J. Kaufman, 1986: The effect of surface nonlambertianity on remote sensing., IEEE Trans. Geosc. Remote Sensing, GE-24, No. 5, 699-708.

Markham, B. and J.L. Barker, 1985: Spectral characterization of the Landsat TM sensors, Lansdat-4 Science Characterization - Early Results, 2, NASA Conf. Pub. 2355, 235276.

McClatchey, R.A., R.W. Fenn, J.E.A. Selby, F.E. Volz, J.S. Garing, 1971: Optical properties of the atmosphere., AFCRL-71-0279, Air Force Cambridge Research Lab, Hanscom AFB, MA.

Mekler Yu., H. Quenzel, G. Ohring, and I. Marcus, 1977: Relative atmospheric aerosol content from ERTS observations, J. Geoph. Res., 82, 967-972.

Neckel, H. and D. Labs, 1984: The solar radiation between 3300 and $12500 \AA$, Solar Phys., 90, 205-258.

Nilsson, B., 1979: Meteorological influence on aerosol extinction in the $0.2-40 \mu \mathrm{m}$ wavelength range, Appl. Opt., 18, 3457-3473.

Patterson, E.M. and G.W. Grams, 1984: Determination of aerosol absorption and scattering in the free troposphere, IRS 184: Current Problems in Atmospheric Radiation, Proceedings of the International Radiation Symposium, Perugia, Italy, 21-28 Aug. 1984, Deepak, Hampton, VA.

Peterson, J. T., E. C. Flowers, G. J. Berri, C. L. Reynolds, J. H. Rudisil, 1981:

Atmospheric turbidity over central North Carolina, J. Appl. Meteor., 20, 229-241.

Reagan, J.A., D.M. Byrne, M.D. King, J.D. Spinhirne, and B.M. Herman, 1980: Determination of the complex refractive index of atmospheric particulates from bistatic-monostatic lidar and solar radiometer measurements., J. Geophys. Res., 85, 1591-1599. 
Sellers, P.J., F.G. Hall, G. Asrar, D.E. Strebel, and R.E. Murphy, 1988: The First ISLSCP Field Experiment (FIFE)., Bull. Amer. Meteor. Soc, 69, No. 1, 22-27.

Shettle, E.P. and R.W. Fenn, 1979: Models for the aerosols of the lower atmosphere and the effects of humidity variations on their optical properties., AFGL-TR-79-0214, Air Force Geophysics Lab, Hanscom AFB, MA.

Spinhirne, J.D., J.A. Reagan, and B.M. Herman, 1980; Vertical distribution of aerosol extinction cross section and inference of aerosol imaginary index in the troposphere by lidar technique, J. Appl. Meteor., 19, 426-438.

Takayama, Y., and T. Takashima,1986: Aerosol optical thickness of yellow sand over the yellow sea derived from NOAA satellite data, Atmos. Environ., 20, 631-638.

Waggoner, A.P., R.E. Weiss, N.C. Ahlquist, D.S. Covert, S. Will, and R.C. Charlson, 1981: Optical characteristics of aerosols., Atmos. Environ., 15, No. 11, 1891-1909.

\subsection{FORTRAN Listing}

The FORTRAN code for the atmospheric correction algorithm is given in the pages which follow. The line numbers are listed to the right of each line. 


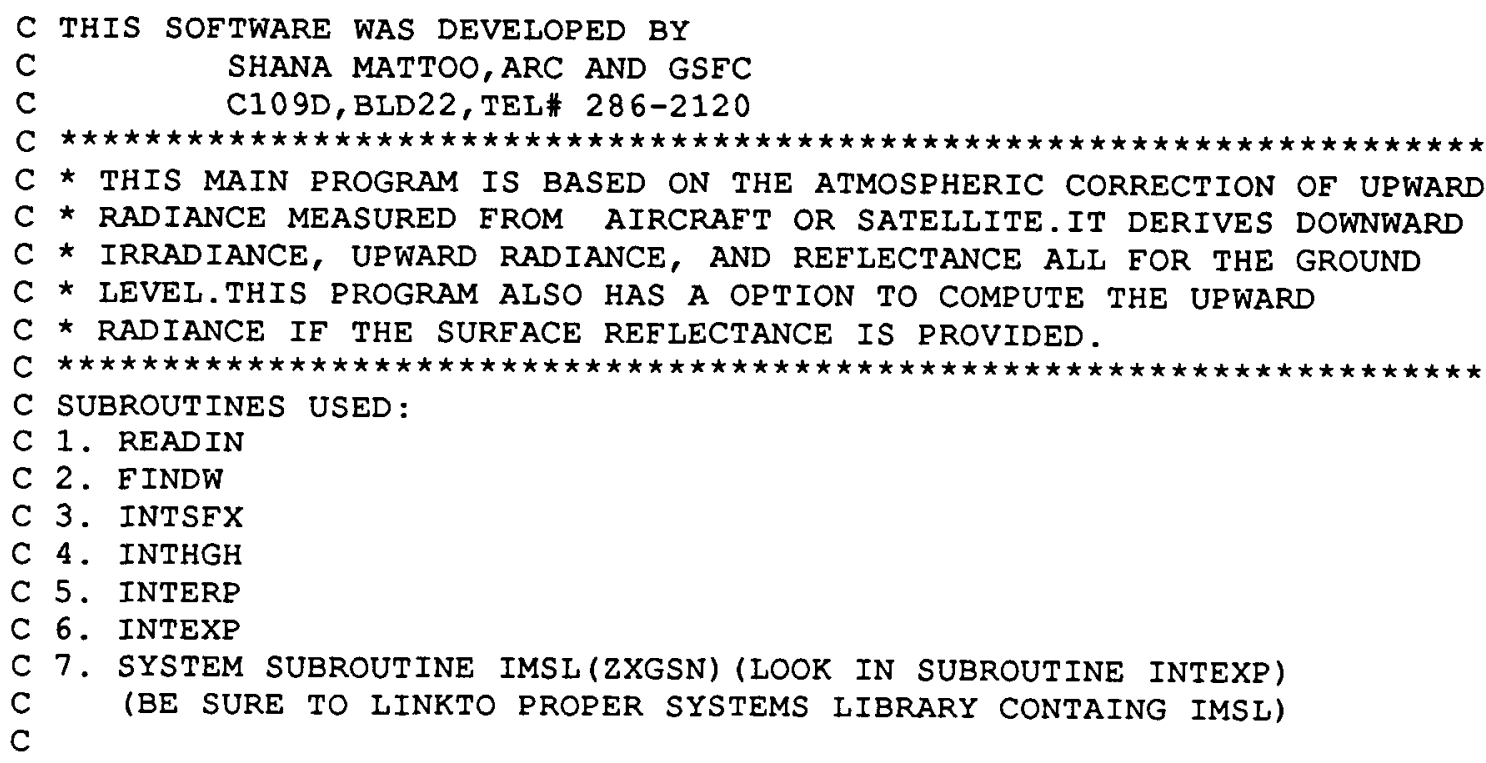

REAL * 4 MWAV, MTAU, MINT, MTHETO, MTHET, MPHI, MHGHT, RHOS, MRHO, SBARN REAL *4 HGHT (3), THE (13), INT $(9,4,13,19), \operatorname{WAV}, \operatorname{OPTH}(4), \operatorname{FDOWN}(9,4)$

$\operatorname{REAL} \star 4 \operatorname{SBAR}(4), \operatorname{PIT}(13,4), \operatorname{THETO}(9), \operatorname{NEW}(30), \mathrm{YY}(1), \operatorname{NEWN}(30)$

$\operatorname{REAL} \star 4 \operatorname{SBARW}(2,4), \operatorname{PITW}(2,13,4,3), \operatorname{FDOWNW}(2,9,4)$

REAL *4 INTW $(2,9,4,3,13,19), \operatorname{INTWH}(2,9,4,13,19), \operatorname{PITWH}(2,13,4)$

REAL *4 NEWINT $(4,13,19), \operatorname{NFDOWN}(4), \operatorname{NEWNEW}(4,13), \operatorname{FINT}(4), \mathrm{FT}(4)$

REAL *4 F, AIRR, ARAD, PHI (19)

REAL * 4 FOIRR (100), WAVE (100), R(365)

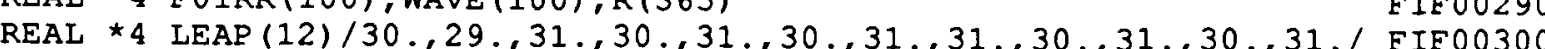

$\operatorname{REAL} \star 4$ NLEAP $(12) / 30,28,31,30,31,30,31,31,30,31,30,31, / F I F 00310$

REAL * 4 WAVEN $(8) / .486, .587, .639, .663, .837, .845,1.663,2.189 / \quad$ FIFOO320

REAL *4 TAUGH (8)/.0070,.0320,.0247,.0174,.0021,.0152,.0077,.0091/ FIF00330

REAL *4 TAUGL (8) /.0130,.0142,.0208,.0218,.0628,.1156,.1380,.0930/FIF00340 CHARACTER * 1 LINE (132)

CHARACTER * 1 LINE2 $(80)$

CHARACTER * $1 \mathrm{LL}(30)$

INTEGER ANGLE (19)

$\mathrm{C}$

C DEFINE PI

$P I=A R C O S(-1.00)$

$\mathrm{C}$

$\mathrm{C}$

$\star$ CALI SUBROUTINE READIN

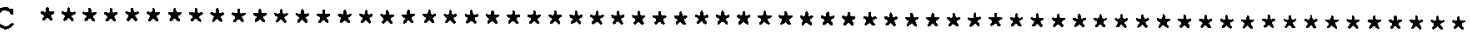

C SUBROUTINE READIN READS THE INPUT DATA AND WRITES IT ON UNIT 6, TO

C PERFORM A CHECK ON INPUT DATA.

C

CALL READIN

$\mathrm{C}$

C LINE2 READS THE TITLE FOR THE VALUES OF FOLLOWING INPUT QUANTITIES.

C READ THE IOPT, MOPT AND NOPT. IOPT IS OPTION FOR UNITS OF RADIANCE.

C IF OPTION IS 1, UNITS SHOULD BE IN REFLECTANCE UNITS; IF IOPT=2

C THE UNITS OF REFLECTANCE SHOULD BE IN ABSOLUTE UNITS.IF MOPT IS 1

C THE DAY, MONTH AND YEAR FOR WHICH DATA IS MEASURED SHOULD BE

C GIVEN; AND IF MOPT IS 2 THE DAY OF THE YEAR AND THE YEAR SHOULD BE

C GIVEN . NOPT IS OPTION FOR COMPUTING SURFACE REFLECTANCE OR RADIANCE.

C GIVEN . NOPT IS OPTION FOR COMPUTING SURFACE REFLECTANCE OR RADIANCE. FIFOO570
C IF NOPT IS 1 SURFACE REFLECTANCE IS COMPUTED AND IF NOPT IS 2 RADIANCEFIFOO580

C IS COMPUTED.
FIF00010

FIF 00020

F00030

ITO0050

FIF00060

E00070

FIF00100

IF00110

FIF00130

FIF00140

FIF00170

FIF00180

FIF00210

EIFO0220

EIF00250

FIF00260

EIF00270

FIF00280

FIE00350

FIF00360

FIF00370

FIF00380

EIF00390

FIF00400

FIF00410

FIF00420

FIF00430

FIF00440

FIE00450

FIF00460

FIE00470

FIE00480

EIF00490

FIF00500

FIF00510

FIF00520

FIF00530

EIF00540

FIE00550

FIF00560

FIF00590

FIF00600 
$\operatorname{READ}(5,1003)$ LINE2

FIF00610

READ $(5,9)$ IOPT, MOPT, NOPT

FIF00620

FIF00630

C

C IINE2 READS THE TITLE FOR THE VALUES OF FOLLOWING INPUT QUANTITIES:

FIF00640

C INUM THE NUMBER OF DATA POINTS TO BE PROCESSED, MONTH, DAY, YEAR AND

FIF00650

C TIME ZONE FOR WHICH MEASURED DATA ARE PROVIDED.

C

$\operatorname{READ}(5,1003)$ LINE2

IF (MOPT .EQ . 1) READ $(5,10)$ INUM, IMONTH, IDAY, IYEAR, LL

IF (MOPT .EQ. 2) READ $(5,10)$ INUM, IDAY, IYEAR, LI

$\operatorname{READ}(5,1003)$ LINE2

C

C WRITE THE LABELS FOR THE OUTPUT.

C

WRITE $(56,1108)$

WRITE $(56,1109)$

IF (MOPT .EQ.1) WRITE $(6,11)$ IMONTH, IDAY, IYEAR, LL

IF (MOPT .EQ.1) WRITE $(56,11)$ IMONTH, IDAY, IYEAR, LL

IE (MOPT .EQ.2) WRITE $(6,21)$ IDAY, IYEAR, LL

IF (MOPT .EQ.2) WRITE $(56,21)$ IDAY, I YEAR, LL

WRITE $(6,12)$

$\operatorname{WRITE}(56,22)$

C

CREAD LABS AND NECKEL DATA FOR SOLAR FLUX

$\mathrm{C}$

DO $121 \mathrm{IJ}=1,4$

$121 \operatorname{READ}(20,1003)$ LINE

$I K=1$

DO 122 IJ $=1,20$

READ $(20,23)$ WAVE (IK), FOIRR (IK), WAVE (IK+1), FOIRR (IK+1), WAVE (IK+2), 1

$I K=I K+3$

FOIRR (IK+2)

122

CONTINUE

$I K=I K-1$

C

C START OF LOOP FOR THE NUMBER OF THE DATA POINTS TO BE PROCESSED

C LFILE IS USED TO SET THE VALUE FOR THE FILE NUMBER NFILE TO READ

C THE LOOK-UP TABLE FOR CHOSEN WAVELENGTH.

C

LEILE $=6$

2000 DO 999 NUM=1, INUM

IF (NUM .GT.1) REWIND NFILEI

IF (NUM .GT.1) REWIND NFILE2

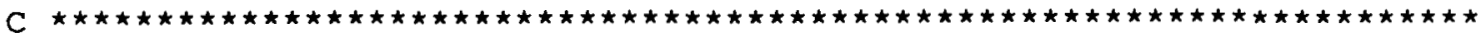

C $\star$ READ MEASURED PARAMETERS

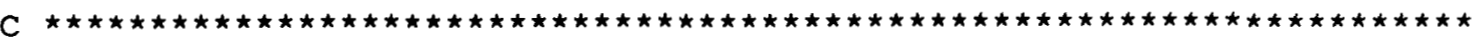

C TIME IN CDT (MTIME IN HOURS AND MINUTES), WAVELENGTH (MWAV IN

C MICROMETERS), OPTICAL THICKNESS (MTAU) FOR MWAV, SOLAR ZENITH ANGLE

C MTHETO IN DEGREES), OBSERVATION SCAN ANGLE (MTHET IN DEGREES),

C OBSERVATION AZIMUTH ANGLE (MPHI IN DEGREES), OBSERVATION HEIGHT (MHGHT

C IN KILOMETERS), INTENSITY (MINT IN REFLECTANCE OR ABSOLUTE UNITS) IF

C NOPT IS 1; AND SURFACE REFLECTANCE (MRHO) IF NOPT IS 2 .

C TAUGHW (ABSORPTION FOR CARBONDIOXIDE AND OZONE), TAUGLW (ABSORPTION

C FOR WATER) FOR MEASURED WAVELENGTH, HEIGHT FROM THE SURFACE ABOVE SEA-

C LEVEL (SHGHT IN KILOMETERS). (LOOK DOCUMENTATION PAGE 19)

C

IF (NOPT.EQ.1)

IREAD $(5,13)$ MTIME, MWAV, MTAU, MTHETO, MTHET, MPHI, MHGHT, MINT, TAUGLW,

1 TAUGHW, SHGHT

FIF 00660

FIF 00670

FIF 00680

FIF00690

FIF00700

FIF 00710

EIF00720

FIF 00730

FIF00740

FIF00750

FIF 00760

FIF 00770

FIF 00780

FIF00790

FIF00800

FIF 00810

FIF 00820

FIF 00830

FIF00840

FIF00850

FIF00860

EIF00870

FIF 00880

FIF 00890

FIF00900

FIF 00910

EIF00920

FIF00930

EIF 00940

FIF00950

FIF00960

FIF 00970

FIF 00980

FIF00990

FIF01000

FIF01010

FIF 01020

FIF 01030

EIF01040

FIF01050

FIF01060

EIF01070

FIF 01080

FIF01090

FIF0 1100

FIF01110

FIF 01120

FIF 01130

FIF01140

FIF01150

FIF 01160

FIF 01170

FIF 01180

FIF01190

FIF 01200 
IF (NOPT .EQ .2)

IREAD $(5,13)$ MT IME, MWAV, MTAU, MTHETO, MTHET, MPHI, MHGHT, MRHO, TAUGLW,

FIF 01210

1 TAUGHW, SHGHT

C

C IF TAUGLW (ABSORPTION FOR WATER) IS 0.0 THE DEFAULT VALUE IS COMPUTED

FIF 01220

FIF01230

FIF 01240

C OUT OF RANGE NO EXTRAPOLATION IS ALLOWED, THE PROGRAM SENDS CONTROL TO

C PROCESS NEW DATA POINT.

C

IF (TAUGLW .GT .0.0) THEN

GO TO 360

ELSE

CALL INTERP $(1,8$, MWAV, WAVEN, TAUGL, YY, IJK, NUM, LOPT)

IF (LOPT .EQ.0) THEN

WRITE $(6,24)$ MWAV, NUM

FIF01260

GO TO 999

ELSE

TAUGLW $=Y Y(1)$

ENDIF

FIF01270

FIF 01280

FIF01290

FIF 01300

FIF01310

FIF 01320

FIF 01330

FIF01340

FIF01350

FIF 01360

FIF01370

FIF 01380

FIF 01390

ENDIF

FIF01400

C

C IF TAUGHW (ABSORPTION FOR GASES) IS 0.0 THE DEFAULT VALUE IS COMPUTED

FIF 01410

C BY INTERPOLATING LINEARLY FOR THE MEASURED WAVELENGTH MWAV. IF MWAV IS FIF01430

C OUT OF RANGE NO EXTRAPOLATION IS ALLOWED, THE PROGRAM SENDS CONTROL TO

C PROCESS NEW DATA POINT.

C

360

CONT INUE

IF (TAUGHW .GT.0.0) THEN

GO TO 350

ELSE

CALL INTERP ( 1,8, MWAV, WAVEN, TAUGH, YY, IJK, NUM, LOPT)

IF (LOPT .EQ.0) THEN

WRITE $(6,25)$ MWAV, NUM

GO TO 999

ELSE

TAUGHW $=Y Y(1)$

ENDIF

ENDIF

350 CONTINUE

FIF 01440

FIF 01450

FIF01460

FIF01470

FIF01480

FIF 01490

FIF01500

FIF01510

FIF01520

FIF01530

FIF01540

FIF01550

FIF01560

FIF01570

FIF 01580

EIF01590

FIF 01600

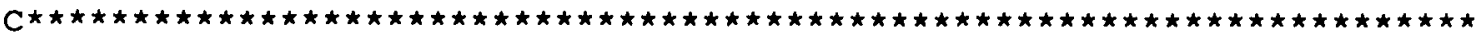

C* CALL TO SUBROUTINE FINDW

FIF 01610

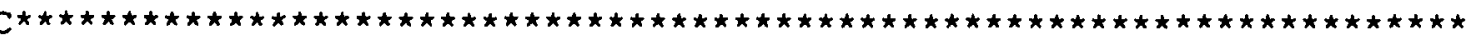

C SUBROUTINE EINDW PICKS TWO WAVELENGTHS WAV1 AND WAV2 BETWEEN WHICH

FIF01620

FIF 01630

FIF01640

C MEASURED WAVELENGTH MWAV LIES AND SETS FILE NUMBERS NFILE1 AND NFILE2

C TO READ THE REQUIRED DATA SET FOR THE TWO WAVELENGTHS FROM LOOK-UP

FIF 01650

C TABLE.THE MWAV SHOULD BE IN RANGE OF $0.486-2.189$ UM, NO EXTRAPOLAT-

C ION IS ALLOWED.

C

CALL FINDW (MWAV, II, NUM, KOPT, IMM, WAV1, WAV2)

IF (KOPT.EQ.O) GO TO 999

NFILE 1 = LFILE+II

NFILE2 = LFILE+IMM

FIF01660

FIF 01670

FIF 01680

FIF01690

FIF01700

FIF 01710

FIF 01720

FIF 01730

$C$

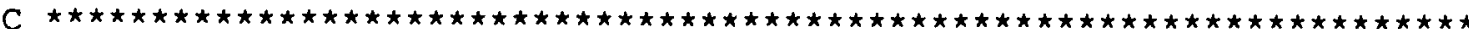

C $\star$ CALL TO SUBROUTINE INTSEX

FIF 01740

FIF 01750

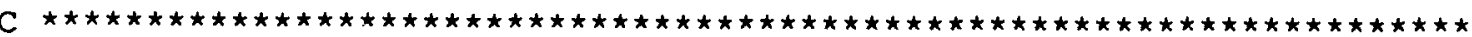

C SUBROUTINE INTSFX INTERPOLATES TO COMPUTE THE VALUES OF $R$ FOR

FIF 01760

FIF 01770

FIF 01780

FIF 01790

365 DAYS. THESE VALUES WILL BE USED TO COMPUTE THE CORRECTED VALUES

C OF SOLAR FLUX FOR THE DAY MONTH AND YEAR FOR WHICH MEASURED DATA

FIF01800

C IS GIVEN. R IS SUN-EARTH DISTANCE .

FIF01810 
C

C COMPUTE SOLAR FLUX FOR THE MEASURED WAVELENGTH MWAV FROM LABS AND

C NECKEL DATA BY INTERPOLATION

C

\section{$I J K=0$}

LNUM $=0$

CALI INTERP ( 1 , IK, MWAV, WAVE, FOIRR, YY, IJK, LNUM, LOPT)

FIF 01860

FIF01870

FIF 01880

FIF01890

FIF 01900

FIF01910

FIF01920

FIF01930

FIF01940

FIF01950

FIF01960

FIF01970

FIF01980

FIF01990

FIF 02000

FIF02010

FIF02020

FIF02030

FIF02040

FIF02050

FIF02060

FIF02070

FIF02080

EIF02090

FIF 02100

C

C COMPUTE CORRECTED SOLAR FLUX FOR THE DAY OF YEAR FOR WHICH

C MEASUREMENT ARE MADE. (SEE DOCUMENTATION EQ.6)

FIF02110

FIF02120

FIF02130

FIF02140

C $\quad R(I Q)=1$.

$F F L U X=Y Y(1) /(R(I Q) \star R(I Q))$

C

C

C COMPUTE THE OBSERVATION ZENITH ANGLE FOR THE SCAN ANGLE OF

C THE SATELLITE OR AIRCRAFT(SEE DOCUMENTATION EQ.9)

C RAD $=$ RADIUS OF EARTH

C

DEGRAD $=$ ARCOS $(-1) /$.180 .

RADDEG $=180 . / \operatorname{ARCOS}(-1$.

$R A D=6370$.

MTHET $=A S I N((1 .+($ MHGHT $/ R A D)) \star(S I N(M T H E T \star D E G R A D))) \star R A D D E G$

$\mathrm{C}$

C IF IOPT EQ 1 CONVERT MEASURED RADIANCE TO ABSOULTE UNITS.

C IF IOPT IS 2 CONVERT MEASURED RADIANCE FROM ABSOLUTE UNITS TO

C REFLECTANCE UNITS.

C

AMU $0=\operatorname{COS}($ MTHET 0 *DEGRAD)

IF (IOPT .EQ.1 . AND. NOPT.EQ.1 ) AMINT $=(M I N T \star F F L U X \star A M U O) / P I$ IF (IOPT .EQ.2 . AND. NOPT.EQ.1) AMINT=MINT

IF (IOPT .EQ.2 .AND. NOPT.EQ.1) MINT $=(M I N T \star P I) /\left(F F L U{ }^{\star} A M U 0\right)$

FIF02150

FIF 02160

FIF 02170

FIF02180

FIF02190

FIF02200

FIF 02210

FIF02220

FIF 02230

FIF02240

FIF02250

FIF02260

FIF 02270

FIF 02280

FIF 02290

FIF 02300

FIF02310

FIF02320

FIF02330

FIF02340 

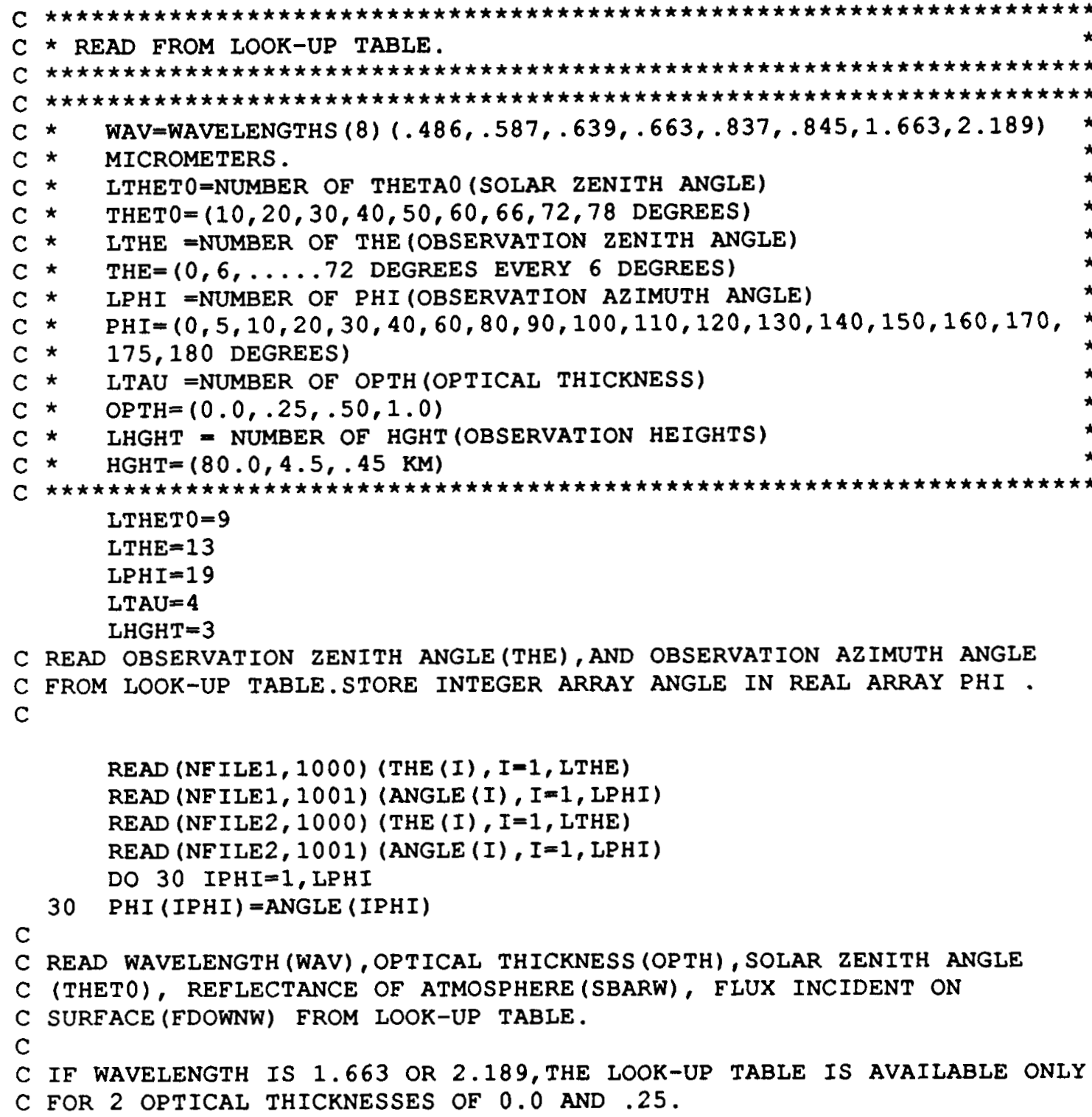
C
C

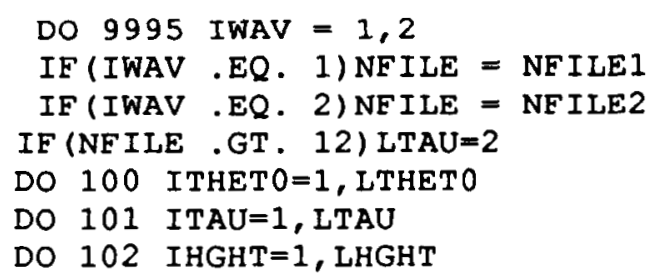

C READ ATMOSPHERIC RADIANCE (INTW) AS FUNCTION OF SOLAR ZENITH ANGLE, C OPTICAL THICKNESS, HEIGHT, OBSERVATION ZENITH ANGLE, AND OBSERVATION C AZIMUTH ANGLE FROM LOOK-UP TABLE.

C

DO 103 ITHE $=1$, LTHE

READ (NFILE, 1004) (INTW (IWAV, ITHET0, ITAU, IHGHT, ITHE, IPHI), IPHI=1, 10 ) READ (NFILE, 1004) (INTW (IWAV, ITHET0, ITAU, IHGHT, ITHE, IPHI), $1 \mathrm{IPHI}=11,19)$

103 CONTINUE
FIF02350

EIE02360

FIF 02370

FIF 02380

FIF02390

FIF02400

FIF02410

FIF02420

FIF02430

FIF02440

FIF02450

FIF02460

FIF02470

FIF02480

FIF02490

FIF02500

FIF02510

FIF02520

FIF02530

FIF02540

EIF02550

FIF02560

FIF 02570

FIF02580

FIF 02590

FIF02600

EIF02610

FIF02620

FIF02630

FIF02640

FIE02650

FIF02660

FIF02670

FIF02680

FIF02690

FIF 02700

FIF02710

FIF02720

FIF0 2730

FIF02740

FIF02750

EIF 02760

FIF02770

FIF02780

FIF02790

EIF02800

FIF02810

FIF02820

FIF02830

FIF02840

FIF02850

FIF02860

FIF02870

FIF 02880

FIF02890

FIF02900

FIF02910

) FIF0 2920

FIF02930

FIF02940

FIF02950 
C

C READ TRANSMISSION FROM SURFACE (PITW) AS FUNCTION OF OBSERVATION

C ZENITH ANGLE, OPTICAL THICKNESS, AND HEIGHT.

C

READ (NE ILE, 1005) (P ITW (IWAV, ITHE, ITAU, IHGHT), ITHE=1, LTHE)

102 CONTINUE

101 CONTINUE

100 CONTINUE

9995 CONTINUE
FIF02960

FIF02970

FIF02980

FIF02990

FIF0 3000

FIE03010

EIF03020

EIF03030

EIF03040

EIF03050

EIF03060

EIF03070

EIF03080

EIF03090

EIF0 3100

EIF03110

EIF03120

EIF03130

FIF03140

FIF 03150

FIF0 3160

FIF03170

FIF03180

FIF03190

FIF03200

FIF03210

FIF03220

FIE0 3230

FIF 03240

FIF0 3250

FIF 03260

FIF0 3270

FIF0 3280

FIF 03290

FIF0 3300

FIF03310

FIF0 3320

FIF0 3330

FIF0 3340

EIF03350

FIF03360

FIF03370

EIF03380

FIF0 3390

FIE0 3400

FIF03410

FIF0 3420

FIF03430

FIF03440

FIF03450

EIF03460

FIF03470

FIF03480

FIF03490

FIF03500

FIF03510

FIF03520

FIF 03530

EIF03540 
DO 908 ITHET0=1, LTHET0

FIF03550

AMUTHO $=\operatorname{COS}($ THETO $($ ITHETO $) \star$ DEGRAD $)$

FIF03560

THDOWN=EXP (-DELTAH/ AMUTHO)

FIF 03570

TLDOWN=EXP (-DELTAL/AMUTHO)

FIF 03580

DO 908 ITAU $=1$, LTAU

908 FDOWN (ITHETO, ITAU) = FDOWN (ITHETO, ITAU) ${ }^{*}$ THDOWN ${ }^{2}$ TLDOWN

FIF 03590

DO 909 ITAU $=1$, LTAU

$909 \operatorname{SBAR}(I T A U)=\operatorname{SBAR}(I T A U)$ * $\operatorname{EXP}(-D E L T A L$ * 2)

DO 910 ITAU $=1$, LTAU

DO 910 ITHE $=1$, LTHE

AMUTH $=\operatorname{COS}($ THE (ITHE) $\star$ DEGRAD $)$

THUP $=$ EXP (-DELTAH / AMUTH)

TLUP $=$ EXP (-DELTAL/AMUTH)

910 PIT (ITHE, ITAU) =PIT (ITHE, ITAU) * THUP *TLUP

DO 912 ITAU $=1$, LTAU

DO 912 ITHET0 $=1$, LTHETO

AMUTHO $=\operatorname{COS}($ THETO (ITHETO) $\star$ DEGRAD)

DO 912 ITHE=1, ITHE

AMUTH $=\operatorname{COS}($ THE $(I T H E) *$ DEGRAD $)$

DO 912 IPHI=1, LPHI

912 INT (ITHETO, ITAU, ITHE, IPHI) =INT (ITHETO, ITAU, ITHE, IPHI) *

FIF 03600

FIF 03610

FIF 03620

FIF 03630

FIF 03640

FIF03650

FIF03660

FIF03670

FIF03680

FIF03690

FIF03700

FIF03710

EIF03720

FIF 03730

FIF 03740

FIF 03750

FIF 03760

FIF 03770

FIF 03780

FIE0 03790

FIF 03800

$C \star$ INTERPOLATION OF ATMOSPHERIC RADIANCE AND FLUX INCIDENT ON GROUND*

$C \star$ ON MEASURED SOLAR ZENITH ANGLE.

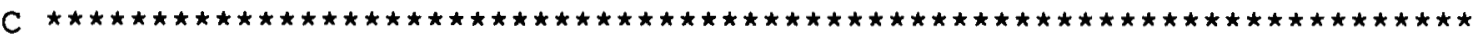

C INT (THETO, OPTH, HGHT, THE, PHI) IS INTERPOLATED FOR

C MEASURED MTHETO TO GET NEW VARAIBLE NEWINT (TAU, THE, PHI) .

C FDOWN (THETO, TAU) IS INTERPOLATED FOR MEASURED MTHETO TO

C GET NEW VARIABLE NFDOWN(TAU).

C

701 CONTINUE

DO $240 \quad I=1,30$

NEW $(I)=0.0$

240 NEWN $(I)=0.0$

DO 104 ITAU $=1$, LTAU

DO 105 ITHE $=1$, LTHE

DO 106 IPHI $=1$, LPHI

DO 107 ITHETO=1, LTHETO

NEW ( ITHETO) =INT ( ITHET 0, ITAU, ITHE, IPHI)

NEWN ( ITHET 0$)=$ FDOWN (ITHET 0, ITAU)

107 CONTINUE

$I J K=1$

C

C CALL SUBROUTINE INTERP TO INTERPOLATE INT.

C IF MTHETO IS OUT OF RANGE OF VALUES OF THETO SUBROUTINE INTERP

C RETURNS THE VALUE OF LOPT $=0$ AND THE NEW DATA POINT WILL BE READ.

C

CALL INTERP (1, LTHETO, MTHETO, THET0, NEW, YY, IJK, NUM, LOPT)

IF (LOPT.EQ.O) GO TO 999

NEWINT (ITAU, ITHE, IPHI) $=Y Y(1)$

$I J K=I J K+1$

$\mathrm{C}$

C CALL SUBROUTINE INTERP TO INTERPOLATE FDOWN.

C IF MTHETO IS OUT OF RANGE OF VALUES OF THETO SUBROUTINE INTERP

C RETURNS THE VALUE OF LOPT $=0$ AND THE NEW DATA POINT WILL BE READ.

EIF03810

FIF0 3820

FIF0 3830

FIF03840

FIF0 3850

FIF0 3860

FIF0 03870

FIF0 3880

FIF 03890

FIF0 03900

FIF0 3910

FIF03920

FIF03930

FIF03940

FIF 03950

EIF03960

FIF 03970

FIF03980

FIF 03990

FIF 04000

FIF0 4010

FIF0 4020

FIF 04030

FIF 04040

FIF 04050

FIF 04060

FIF 04070

FIF 04080

FIF0 4090

FIF0 4100

FIF 04110

FIF 04120

FIF 04130 
CALL INTERP (1, LTHET0, MTHET0, THET0, NEWN, YY, IJK, NUM, LOPT)

FIF0 4140

IF (LOPT.EQ.O) GO TO 999

FIFO 4150

NFDOWN $(I T A U)=Y Y(1)$

106 CONTINUE

105 CONTINUE

104 CONTINUE

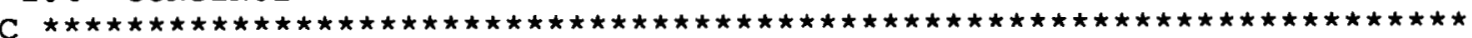

$C \star$ INTERPOLATION OF THE ATMOSPHERIC RADIANCE ON MEASURED AZIMUTH *

$C \star$ ANGLE.

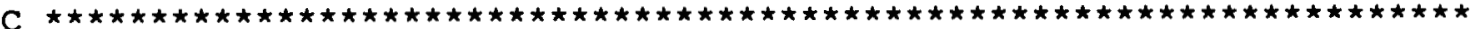

C NEWINT (TAU, THETA, PHI) IS INTERPOLATED FOR MEASURED MPHI

C TO GET NEW VARAIABLE NEWNEW (TAU, THETA).

$\mathrm{C}$

DO $241 I=1,30$

$\operatorname{NEW}(I)=0.0$

$241 \operatorname{NEWN}(I)=0.0$

DO 108 ITAU $=1$, LTAU

DO 109 ITHE=1, LTHE

DO 110 IPHI $=1$, LPHI

NEW $($ IPHI $)=$ NEWINT (ITAU, ITHE, IPHI)

110 CONTINUE

$\mathrm{IJK}=3$

C

C CALL SUBROUTINE INTERP TO INTERPOLATE ON PHI.

C IF MPHI IS OUT OF RANGE OF VALUES OF PHI SUBROUTINE INTERP

C RETURNS THE VALUE OF LOPT $=0$ AND THE NEW DATA POINT WILI BE READ.

C

CALL INTERP ( 1, LPHI, MPHI, PHI, NEW, YY, IJK, NUM, LOPT)

IF (LOPT.EQ.0) GO TO 999

NEWNEW ( ITAU, ITHE) $=Y Y(1)$

109 CONTINUE

108 CONTINUE

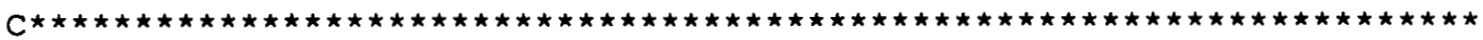

C* INTERPOLATION OF ATMOSPHERIC RADIANCE AND TRANSMISSION/PI FROM *

C* SURFACE ON MEASURED OBSERVATION ZENITH ANGLE.

FIF04160

FIF0 4170

EIF0 4180

FIF0 4190

FIF0 4200

FIFO 4210

FIF0 4220

FIF0 4230

FIF0 4240

FIF0 4250

FIF0 4260

FIF0 4270

FIF0 4280

FIF04290

FIF04300

FIF0 4310

EIF 04320

FIF 04330

FIF 04340

EIE0 4350

FIF0 4360

FIF0 4370

FIF 04380

FIF0 4390

FIF0 4400

FIF0 4410

FIF0 4420

FIE0 4430

FIF0 4440

FIF0 4450

FIF0 4460

C NEWNEW (OPTH, THE) IS INTERPOLATED FOR MEASURED THETA(MTHET)

C TO GET NEW VARAIABLE FINT (TAU). TRANSMISSION FACTOR PIT IS

C INTERPOLATED TO GET FT (TAU).

C

DO $242 I=1,30$

$\operatorname{NEW}(I)=0.0$

$242 \operatorname{NEWN}(I)=0.0$

DO 111 ITAU =1, LTAU

DO 112 ITHE=1, LTHE

NEW (ITHE) =NEWNEW (ITAU, ITHE)

NEWN (ITHE) $=$ PIT (ITHE, ITAU)

112 CONTINUE

$\mathrm{IJK}=4$

C

C CALL SUBROUTINE INTERP TO INTERPOLATE RADIANCE ON MTHET.

C IF MTHET IS OUT OF RANGE OF VALUES OF THE SUBROUTINE INTERP

C RETURNS THE VALUE OF LOPT $=0$ AND THE NEW DATA POINT WILL BE READ

C

CALL INTERP (1, LTHE, MTHET, THE, NEW, YY, I JK, NUM, LOPT)

IE (LOPT.EQ.0) GO TO 999

$\operatorname{FINT}(I T A U)=Y Y(1)$

C

$I J K=5$

FIF04470

FIF0 4480

FIF 04490

FIF0 4500

FIF 04510

FIF0 4520

FIF 04530

FIF04540

FIF0 4550

FIF 04560

EIF0 4570

FIF 04580

FIF0 4590

FIF0 4600

FIF0 4610

FIF0 4620

FIF 04630

FIF0 4640

FIF 04650

FIF 04660

FIF04670

FIF 04680

FIF0 4690

FIF0 4700

FIF 04710

FIF 04720 
C CALL SUBROUTINE INTERP TO INTERPOLATE PIT ON MTHET.

C IF MTHET IS OUT OF RANGE OF VALUES OF THE SUBROUTINE INTERP

C RETURNS THE VALUE OF LOPT $=0$ AND THE NEW DATA POINT WILI BE READ.

C

CALI INTERP (1, LTHE, MTHET, THE, NEWN, YY, IJK, NUM, LOPT)

IF (LOPT.EQ.0) GO TO 999

$\mathrm{FT}(\operatorname{ITAU})=\mathrm{YY}(1)$

111 CONTINUE

FIF0 4730

FIF 04740

FIF0 4750

FIF 04760

FIE 04770

FIF 04780

FIF0 4790

EIF04800

EIE0 4810

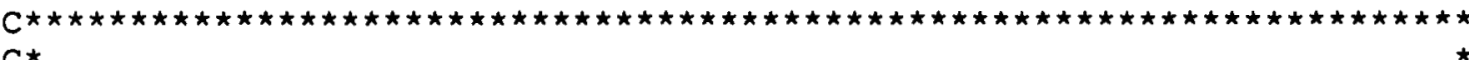

FIF04820

C* INTERPOLATE RADIANCE (FINT)， FLUXDOWN (NFDOWN)，TRANSMISSION (FT) AND*

C* SBAR(SBAR) ON MEASURED OPTICAL THICKNESS (MTAU) .

$C \star$

FIF 04830

*

C CALL SUBROUTINE INTEXP WHICH PERFORMES EXPONANTIAL INTERPOLATION,

IF0 4840

FIF 04850

FIF 04860

EIF 04870

C IE VALUE OF IGNORE RETURNED FROM SUBROUTINE INTEXP IS 1 IINEAR INTER-

C POLATION IS PERFORMED USING SUBROUTINE INTERP.

C

CALL INTEXP (OPTH, FINT, MTAU, YY, LTAU, IGNORE)

$\mathrm{C}$

C IF MTAU IS OUT OF RANGE OF VALUES OF OPTH SUBROUTINE INTERP

C RETURNS THE VALUE OF LOPT $=0$ AND THE NEW DATA POINT WILL BE READ

C

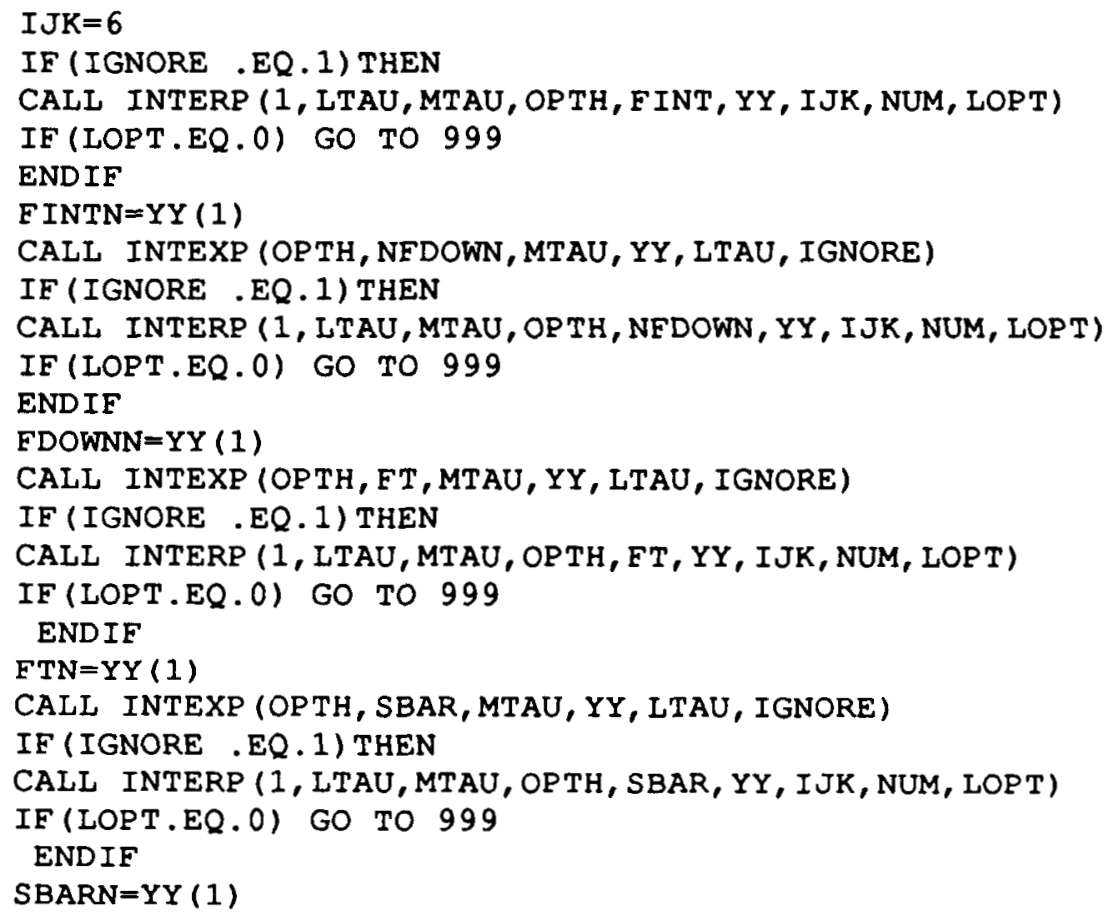


$A I R R=(F D O W N N \star F F L U X * A M U O) /(1 .-S B A R N \star R H O S)$

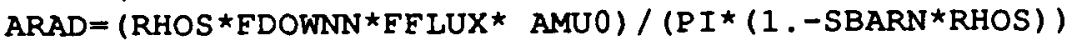$$
\text { C }
$$$$
\text { *WRITE OUTPUT, ALL MEASURED PARAMETERS WHICH ENTER AS INPUT; AND }
$$

IAIRR, ARAD, RHOS

WRITE (56, 1107 ) MTIME, MWAV, MTAU, MTHET0, MTHET, MPHI, MHGHT, AMINT,

IMINT, FINTN, FDOWNN, FTN, SBARN

GO TO 9987

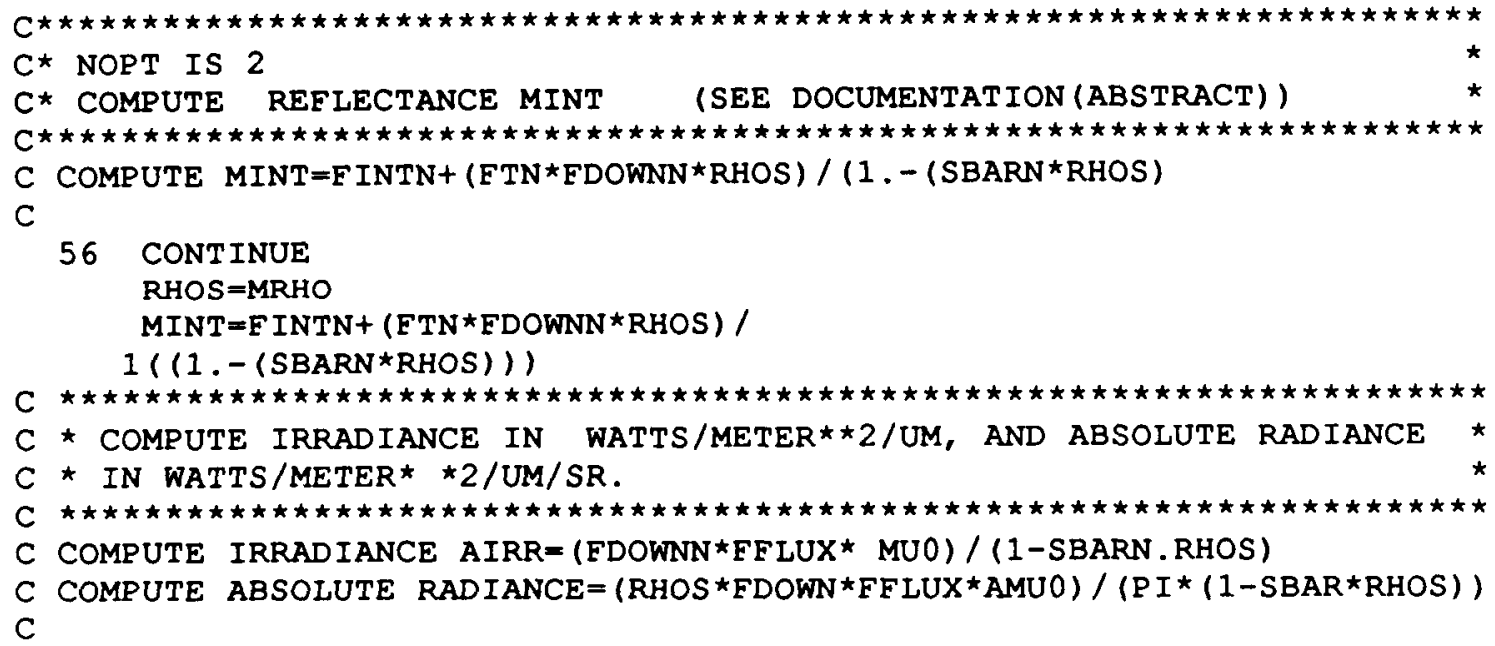

* FIF05420

EIF05430

FIF0 5440

FIE05450

FIF05460

FIF0 5470

FIF0 5480

FIF0 5490

FIF05500

FIF05510

FIF0 5520

FIF0 5530

FIF0 5540

EIF 05550

FIF0 5560

FIF0 5570

FIF 05580

FIF05590

FIF0 5600

FIE05610

FIE0 5620

FIE 05630

FIF0 5640

FIF0 5650

$A I R R=(F D O W N N \star F F L U X * A M U O) /(1 .-S B A R N * R H O S)$

FIF 05660

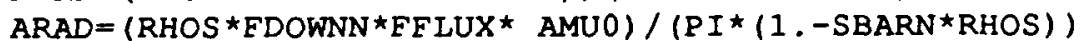

FIF0 0670

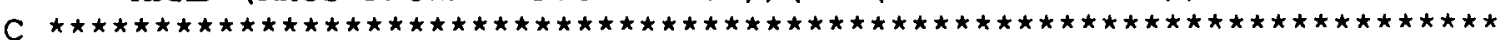

C *WRITE OUTPUT, ALL MEASURED PARAMETERS WHICH ENTER AS INPUT; AND

FIF0 5680

$C$ *COMPUTED IRRADIANCE AIRR, ABSOLUTE RADIANCE ARAD, AND SURFACE

* FIF05690

C $\star$ REFLECTANCE AT GROUND LEVEL.

* FIF05700

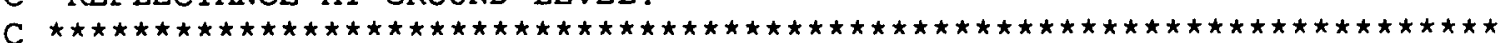

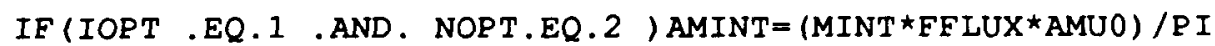

IF (IOPT .EQ.2 .AND. NOPT.EQ.2) AMINT=MINT

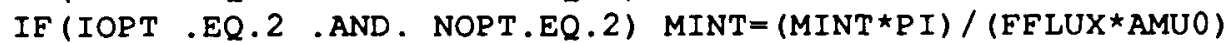

WRITE (6, 1006$)$ MT IME, MWAV, MTAU, MTHET0, MTHET, MPHI, MHGHT, AMINT, MINT,

IAIRR, ARAD, RHOS

WRITE (56, 1107) MT IME, MWAV, MTAU, MTHET0, MTHET, MPHI, MHGHT, AMINT,

IMINT, EINTN, EDOWNN, FTN, SBARN

9987 CONTINUE

999 CONTINUE

WRITE $(6,1007)$

STOP

9 FORMAT (3I5)

10 FORMAT $(4 I 5,30 A 1)$

11 FORMAT $\left(/,,^{\prime}\right.$ DATE ', I3,', I3,'/,,I5,' TIME ZONE',30A1)

* FIF05710

FIF0 0520

EIF 05730

FIF0 05740

FIE 05750

FIF 05760

FIF 05770

FIF 05780

FIF05790

FIF0 5800

FIF05810

FIF05820

EIF0 5830

EIF05840

FIF 05850

FIF0 0860 


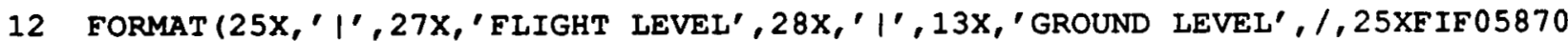
$1,1^{\prime}, 67 \mathrm{X}, \mathrm{\prime}^{\prime}, 1,25 \mathrm{X}, \mathrm{I}^{\prime}, 67 \mathrm{X}, \mathrm{\prime}^{\prime}, 1$,

1' TIME', 2X, 'WAVELENGTH', 2X, 'OPTICAL', 2X, 'SOLAR', 2X, FIE05880

$1^{\prime}, \prime, 2 \mathrm{X}$, 'DOWNWARD', 5X, 'UPWARD', $/, 18 \mathrm{X}$, ' THICKNESS', $1 \mathrm{X}$,

EIF05890

I'ZENITH', $3 \mathrm{X}$, 'ZENITH', $7 \mathrm{X}$, 'AZIMUTH',

$16 \mathrm{X}$, 'HEIGHT', 5X, 'RADIANCE', 2X, 'RADIANCE', 1X,' 1 ', 3X,

FIF05910

FIF0 5920

1 'IRRADIANCE' , 3X, 'RADIANCE', 2X, 'REFLECTANCE' , /, 25X, ' 1 ', 3X, 'ANGLE'

FIF05930

$14 \mathrm{X},{ }^{\prime}$ ANGLE' , 8X, 'ANGLE', 23X, 'RADIANCE*PI/FO/U0', 10X, ' W/M**2/UM/SR'

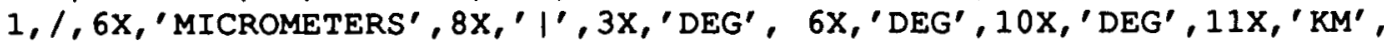

$14 \mathrm{X},{ }^{\prime} \mathrm{W} / \mathrm{M} * \star 2 / U \mathrm{M} / \mathrm{SR}^{\prime}, 10 \mathrm{X}, \mathrm{\prime}^{\prime} \mathrm{I}^{\prime}, 5 \mathrm{X},{ }^{\prime} \mathrm{W} / \mathrm{M} \star \star 2 / \mathrm{UM}^{\prime}, /, 25 \mathrm{X}, \mathrm{I}^{\prime}, 67 \mathrm{X}, \mathrm{I}^{\prime}, / 25 \mathrm{X}$,

$\left.1^{\prime} 1^{\prime}, 67 x_{1}^{\prime} 1^{\prime}\right)$

13 FORMAT (I5, 1X, F6.3,F6.3, 4F7.2, F10.5, 3F8.4)

21 FORMAT (/,' JULIAN DATE ', I3,'/',I5,' TIME ZONE', 30A1)

22 FORMAT (' TIME', $2 \mathrm{X}$, 'WAVELENGTH', $2 \mathrm{X}$, 'OPTICAL', $2 \mathrm{X}$, ' SOLAR', $2 \mathrm{X}$,

IF05940

FIF05950

FIF05960

FIF05970

FIF05980

FIF05990

FIF0 6000

1' OBSERVATION' , 2X,' OBSERVATION', 2X,' OBSERVATION' , 12X, ' RELATIVE' , 5X, FIF06020

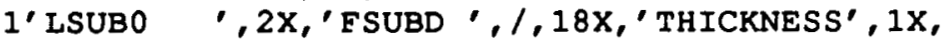

1'ZENITH', 3X,'ZENITH', 7X,'AZIMUTH',

$16 \mathrm{X}$, 'HEIGHT' , 5X, ' RADIANCE', 2X,' RADIANCE', $2 \mathrm{X}$,

1 'SUPERPRIME' , 1X,'SUPERPRIME', 2X,'T ', 2X, 's', /,29X,' ANGLE',

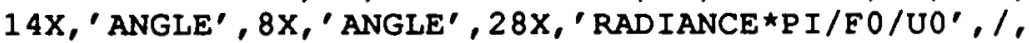

16X,'MICROMETERS', 13X,'DEG', 6X,'DEG', 10X,'DEG', 11X,' KM', 2X,

1 ' $\left.\mathrm{W} / \mathrm{M} * \star 2 / \mathrm{UM} / \mathrm{SR}^{\prime}\right)$

23 FORMAT $(3(8 X, F 6.4, F 11.4,2 X))$

24 FORMAT(' MEASURED WAVELENGTH (MWAV) ',F6.3,' IS OUT OF RANGE.THE IDATA POINT *'I4,' IS NOT PROCESSED. RANGE IS 0.486-2.189')

25 FORMAT(' MEASURED WAVELENGTH (MWAV) ',F6.3,' IS OUT OF RANGE.THE 1DATA POINT *', I4,' IS NOT PROCESSED. RANGE IS $0.486-2.189^{\prime}$ )

1000 FORMAT $(6 X, 13 F 6.0)$

1001 FORMAT $(4 X, 19 I 6)$

1002 FORMAT (11X, E7.3,19X, F5.2, 22X, F5.0,1,5X, F7.4,11X, F6.4)

1003 FORMAT (132A1)

1004 FORMAT (10E12.4)

1005 FORMAT $(3 \mathrm{X}, 13 \mathrm{~F} 6.5)$

1006 FORMAT (I5, F9.3, 5X, F5.2, 1X, ' ' ', 2X, F5.2, 3X, F6.2, 7X, F6.2, 7X,

1 F7.2, 3X, F8 .2, 4X, F8 .4, 1X, ' ' , 3X, F8.0, 3X, F7.1, 5X, F7.3)

1007 FORMAT $\left(25 x^{\prime},\left.\right|^{\prime}, 67 x, 1^{\prime}, / 25 x^{\prime}, 1^{\prime}, 67 x^{\prime}, 1^{\prime}\right)$

1008 FORMAT (2F6.3)

1107 FORMAT (I5, F9.3, 5X, F5 .2, 6X, F5.2, 3X, F6.2, 7X, F6.2, 7X,

$1 \mathrm{~F} 6.2,3 \mathrm{X}, \mathrm{F} 8.4,6 \mathrm{X}, \mathrm{F} 6.4,4 \mathrm{X}, \mathrm{F} 6.4,3 \mathrm{X}, \mathrm{F} 6.4,3 \mathrm{X}, \mathrm{F} 6.4,3 \mathrm{X}, \mathrm{F} 6.4,3 \mathrm{X}, \mathrm{F} 6.4)$

1108 FORMAT (45X,' INTERPOLATED RADIATION PARAMETERS')

1109 FORMAT (43X,'

END

FIF0 6030

FIF0 6040

FIF0 6050

FIF 06060

FIF0 6070

FIF06080

FIF06090

FIF0 6100

FIF0 6110

FIF 06120

FIF 06130

FIF06140

FIF06150

FIF 06160

FIF 06170

FIF0 6180

FIF06190

FIF 06200

FIF 06210

FIF0 6220

FIF0 6230

FIF0 6240

FIF0 6250

FIF06260

FIF 06270

FIF06280

FIF06290 
C THIS SUBROUTINE READS THE DATA FROM UNIT NUMBER 5 TO WRITE ON UNIT

C NUMBER 6 .

C

SUBROUTINE READIN

CHARACTER * 1 LINE (132)

FIF06310

FIF06320

FIF0 6330

FIF 06340

FIF0 6350

FIF06360

FIF06370

WRITE $(6,200)$

DO $10 \quad I=1,3$

$\operatorname{READ}(5,100)$ LINE

WRITE $(6,100)$ LINE

FIF0 0380

FIF0 6390

FIF0 6400

FIF0 6410

10 CONTINUE

READ (5, 101) INUM, (LINE (I), I=6, 132)

FIF06420

WRITE $(6,101$ ) INUM, ( $\operatorname{LINE}(I), I=6,132$ )

FIF 06430

$\operatorname{READ}(5,100)$ LINE

EIF0 6440

WRITE $(6,100)$ IINE

FIF0 6450

DO $20 I=1$, INUM

FIF06460

$\operatorname{READ}(5,100)$ LINE

FIF06470

WRITE $(6,100)$ LINE

FIF06480

FIF06490

FIF06500

FIF06510

WRITE $(6,201)$

REWIND 5

100 FORMAT (132A1)

101 FORMAT (I5, 127A1)

FIF0 6520

EIF0 0530

FIF06540

200 FORMAT (/,1X,'START OE INPUT DATA AS READ FROM UNIT NUMBER 5',/)

FIF06550

201 FORMAT $(/, 1 X, '$ END OF INPUT DATA SET AS READ FROM UNIT NUMBER 5',/) RETURN END

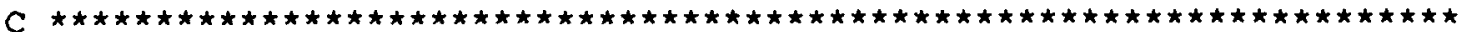

C $\star$ SUBROUTINE FINDW

FIF0 6560

FIE06570

FIF0 6580

FIF06590

FIF0 6600

FIF06610

FIF06620

SUBROUTINE FINDW (MWAV, II, INUM, KOPT, IMM, W1, W2)

REAL* 4 MWAV, WAV (8) /.486,.587,.639,.663,.837,.845, 1.663,2.189/

C THIS SUBROUTINE PICKS TWO WAVELENGTHS W1 AND W2 BETWEEN WHICH

C MEASURED WAVELENGTH MWAV LIES. THE SUBROUTINE PRINTS A ERROR MESSAGE

C IF THE MWAV DOES NOT FALL IN THE RANGE OF .486 - 2.189 UM.THE

C CONTROL IS RETURNED TO MAIN PROGRAM WITH VALUE OF LOPT.

C

$I K=7$

DO $10 I J=1$, IK

IF (MWAV.LT.WAV(1) .OR. MWAV .GT. WAV $(I K+1)$ ) GO TO 20

IF (MWAV.GE.WAV (IJ) . AND. MWAV .LE. WAV (IJ+1)) GO TO 30

10 CONTINUE

GO TO 20

$30 \quad I I=I J$

$I M M=I J+1$

WI $=\operatorname{WAV}(I J)$

$W 2=W A V(I J+1)$

KOPT $=1$

RETURN

20 WRITE $(6,2)$ MWAV, INUM

KOPT $=0$

2 EORMAT (' MEASURED WAVELENGTH(MWAV) ',F6.3,' IS OUT OF RANGE. THE IDATA POINT *', I4,' IS NOT PROCESSED. ACTUAL RANGE .486-2.189 UM') RETURN

END

FIE06630

FIF06640

FIF0 6650

EIF06660

FIF06670

FIF0 6680

FIF06690

EIF06700

EIF06710

FIF06720

FIF0 6730

FIF0 6740

FIE06750

FIE0 6760

FIF 06770

FIF0 6780

FIF06790

FIF06800

FIF0 6810

EIF0 6820

FIF0 6830

EIF0 6840

FIF0 6850

FIF0 6860 
SUBROUTINE INTHGH (LTAU, LTHE, LPHI, LTHETO, INTW, MHGHT, PITW, INTWH,
1 PITWH)

FIF07110

C

FIF07120

FIF07130

FIF07140

FIF07150

C

C THIS SUBROUTINE INTERPOLATES THE VALUES OF INTW AND PITW FOR THE

FIF07160

FIF 07170

MEASURED HEIGHT MHGHT

C

$\operatorname{REAL}$ * $4 \operatorname{INTW}(2,9,4,3,13,19), \operatorname{INTWH}(2,9,4,13,19), \operatorname{PITW}(2,13,4,3)$,

FIF07180

EIF07190

1 PITWH $(2,13,4)$, HGHT (3) $/ 80,4.5, .45 /$, MHGHT

FIF07200

EIF07210

REAL * 4 INTWH1 $(2,9,4,13,19)$, P ITWH $1(2,13,4)$

REAL * 4 INTWH2 $(2,9,4,13,19)$, PITWH2 $(2,13,4)$

$\mathrm{C}$

C INTERPOLATES IE MEASURED HEIGHT IS LESS THAN OR EQUAL TO .45KM

C (SEE DOCUMENTATION EQU. 21A, 21B)

C

IF ( MHGHT . LE. HGHT (3)) THEN

EIF07220

EIF07230

EIF07240

EIE07250

EIF07260

FIF07270

EIF 07280

EIF07290

DO 100 IWAV $=1,2$

DO 101 ITAU $=1$, LTAU

DO 102 ITHE $=1$, LTHE

PITWH (IWAV, ITHE, ITAU $)=(($ IITW (IWAV, ITHE, ITAU, 3) $\star$ MHGHT $)+$

EIF07300

1 (HGHT (3)-MHGHT) ) /HGHT (3)

DO 103 IPHI $=1$, LPHI

DO 104 ITHETO = 1, LTHETO

INTWH (IWAV, ITHET0, ITAU, ITHE, IPHI) =

1 (INTW (IWAV, ITHET0, ITAU, 3, ITHE, IPHI) * MHGHT) / HGHT(3)

IF (INTWH (IWAV, ITHETO, ITAU, ITHE, IPHI) .LE. 0.0)

104 CONTINUE

1 INTWH (IWAV, ITHETO, ITAU, ITHE, IPHI) $=1 . E-6$

103 CONTINUE

102 CONTINUE

101 CONTINUE

100 CONTINUE

C

EIF 07310

FIF 07320

FIF07330

FIF07340

FIF 07350

FIF07360

FIF 07370

EIF 07380

FIF 07390

FIF 07400

FIF07410

FIF 07420

FIF 07430

FIF07440

FIF 07450 
C INTERPOLATES IF MEASURED HEIGHT LIES BETWEEN .45 AND 4.5 KM

EIE07460

C (SEE DOCUMENTATION 3.6)

C

ELSE

FIF07480

EIF07490

IF ( MHGHT .GT. HGHT (3) . AND. MHGHT .LT. HGHT (2) ) THEN

C

C EXTRAPOLATES FOR THE HEIGHT LE. TO .45 KM.

FIF07500

FIF07510

FIF 07520

C

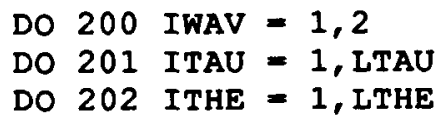

DO 200 IWAV $=1,2$

DO 201 ITAU $=1$, LTAU

DO 202 ITHE = 1, LTHE

PITWH1 (IWAV, ITHE, ITAU) $=(($ PITW (IWAV, ITHE, ITAU, 3) * MHGHT) + (HGHT (3)-MHGHT)) /HGHT (3)

1

EIE07530

FIF07540

FIF07550

FIF 07560

FIE 07570

FIF 07580

DO 203 IPHI $=1$, LPHI

DO 204 ITHETO $=1$, LTHETO

INTWH 1 (IWAV, ITHETO, ITAU, ITHE, IPHI) =

1 (INTW (IWAV, ITHETO, ITAU, 3, ITHE, IPHI) * MHGHT) / HGHT (3)

IF (INTWH1 (IWAV, ITHET0, ITAU, ITHE, IPHI) .LE. 0.0)

1 INTWH1 (IWAV, ITHET0, ITAU, ITHE, IPHI) $=1 . E-6$

204 CONTINUE

203 CONTINUE

202 CONTINUE

201 CONTINUE

200 CONTINUE

C

C EXTRAPOLATES BETWEEN THE HEIGHTS $4.5 \mathrm{KM}$ AND $80.0 \mathrm{KM}$.

C

$Z=(1 .-(\operatorname{EXP}(-\operatorname{MHGHT} / 9))$.

$\mathrm{Z1}=(1 .-(\operatorname{EXP}(-\mathrm{HGHT}(2) / 9))$.

$\mathrm{Z2}=(1 .-(\operatorname{EXP}(-\operatorname{HGHT}(1) / 9))$.

DO 300 IWAV $=1,2$

DO 301 ITAU $=1$, LTAU

DO 302 ITHE $=1$, ITHE

PITWH2 (IWAV, ITHE, ITAU) =

IPITW (IWAV, ITHE, ITAU, 2) +

1 (( (PITW (IWAV, ITHE, ITAU, 1) -

$1 \operatorname{PITW}(\operatorname{IWAV}$, ITHE, ITAU, 2)) $/(\mathrm{Z2}-\mathrm{z1})) \star(\mathrm{z}-\mathrm{Z1}))$

DO 303 IPHI $=1$, LPHI

DO 304 ITHETO $=1$, LTHETO

INTWH2 (IWAV, ITHETO, ITAU, ITHE, IPHI) =

1 INTW (IWAV, ITHETO, ITAU, 2, ITHE, IPHI) +

1 ( ( (INTW (IWAV, ITHET0, ITAU, 1, ITHE, IPHI) -

1 INTW (IWAV, ITHET0, ITAU, 2, ITHE, IPHI)) /(Z2-Z1)) *(Z-Z1))

EIF07590

FIE07600

EIF07610

EIF07620

FIF07630

FIF07640

FIF07650

EIF07660

FIE07670

EIF07680

FIF07690

EIF07700

FIF07710

FIF07720

FIF 07730

FIE07740

FIF07750

EIF07760

FIF07770

EIF07780

FIE07790

EIF07800

FIF07810

FIF07820

FIF07830

FIF07840

FIF07850

EIF07860

FIF0 07870

FIF07880

FIF07890

FIF07900

FIF07910

FIF07920

FIF07930

FIF07940

C

301 CONTINUE

300 CONTINUE

EIF07950

C CHOSSES THE VALUES THAT SHOW NOMINAL ATMOSPHERIC EFFECT. LOWER VALUES

C OF INTENSITY AND HIGHER VALUES OF PIT ARE PICKED.

FIF07960

C

FIF07970 
DO 400 IWAV $=1,2$

FIF07980

DO 401 ITAU $=1$, LTAU

FIF07990

DO 402 ITHE $=1$, LTHE

FIF 08000

IF (PITWH1 (IWAV, ITHE, ITAU) .LE. PITWH2 (IWAV, ITHE, ITAU)) GO TO 405

FIF08010

PITWH (IWAV, ITHE, ITAU) = PITWH1 (IWAV, ITHE, ITAU)

DO 403 IPHI $=1$, IPHI

DO 404 ITHETO $=1$, LTHETO

INTWH (IWAV, ITHET0, ITAU, ITHE, IPHI) =

FIF08020

FIF08030

FIF0 0040

1 INTWH 1 (IWAV, ITHETO, ITAU, ITHE, IPHI)

404 CONTINUE

403 CONTINUE

GO TO 402

405 CONTINUE

PITWH (IWAV, ITHE, ITAU) $=$ PITWH2 (IWAV, ITHE, ITAU)

DO 407 IPHI $=1$, LPHI

DO 406 ITHETO $=1$, LTHETO

INTWH (IWAV, ITHETO, ITAU, ITHE, IPHI) =

1 INTWH2 (IWAV, ITHETO, ITAU, ITHE, IPHI)

406 CONTINUE

407 CONTINUE

402 CONTINUE

401 CONTINUE

400 CONTINUE

C

C INTERPOLATE FOR THE HEIGHT BETWEEN $4.5 \mathrm{kM}$. AND $80.0 \mathrm{KM}$.

FIF0 8050

FIF08060

FIF0 0070

FIF08080

FIF0 8090

FIF08100

FIF08110

FIF08120

FIF0 8130

FIF08140

FIF08150

FIF08160

FIE08170

FIF 08180

FIF08190

FIF0 8200

FIF 08210

FIF08220

FIF08230

ELSE

IF( MHGHT . GE. HGHT(2)) THEN

$z=(1 .-(\operatorname{EXP}(-\operatorname{MHGHT} / 9))$.

$\mathrm{z} 1=(1 .-(\operatorname{EXP}(-\operatorname{HGHT}(2) / 9))$.

$\mathrm{Z} 2=(1 .-(\operatorname{EXP}(-\operatorname{HGHT}(1) / 9))$.

WRITE $(6,10001) \mathrm{z}, \mathrm{z} 1, \mathrm{z2}$

C

DO 600 IWAV $=1,2$

DO 601 ITAU $=1$, LTAU

DO 602 ITHE $=1$, LTHE

PITWH (IWAV, ITHE, ITAU) $=$

IPITW (IWAV, ITHE, ITAU, 2) +

1 (( (PITW(IWAV, ITHE, ITAU, 1) -

1 PITW(IWAV, ITHE, ITAU, 2)) / (Z2 - Z1)) * (Z -Z1))

DO 603 IPHI $=1$, LPHI

DO 604 ITHETO $=1$, LTHETO

INTWH (IWAV, ITHETO, ITAU, ITHE, IPHI) =

FIF08240

FIF08250

FIF08260

FIF08270

FIF08280

FIF08290

FIF08300

EIF08310

FIF08320

FIF0 0330

FIF08340

FIF08350

FIF08360

FIF08370

FIF 08380

FIF08390

1 INTW (IWAV, ITHETO, ITAU, 2, ITHE, IPHI) +

1 ( ( INTW (IWAV, ITHETO, ITAU, 1, ITHE, IPHI) -

1 INTW(IWAV, ITHETO, ITAU, 2, ITHE, IPHI)) $/(Z 2-z 1))$ * (Z -Z1))

FIF 08400

FIF 08410

FIF08420

CONT INUE

603 CONTINUE

602 CONTINUE

601 CONTINUE

600 CONTINUE

FIF 08430

FIF 08440

FIFO 4450

FIF0 8460

FIF0 8470

ELSE

END IF

ENDIF

ENDIF

RETURN

END

FIF0 8480

FIF0 8490

FIF 08500

FIF08510

EIF0 8520

FIF08530 


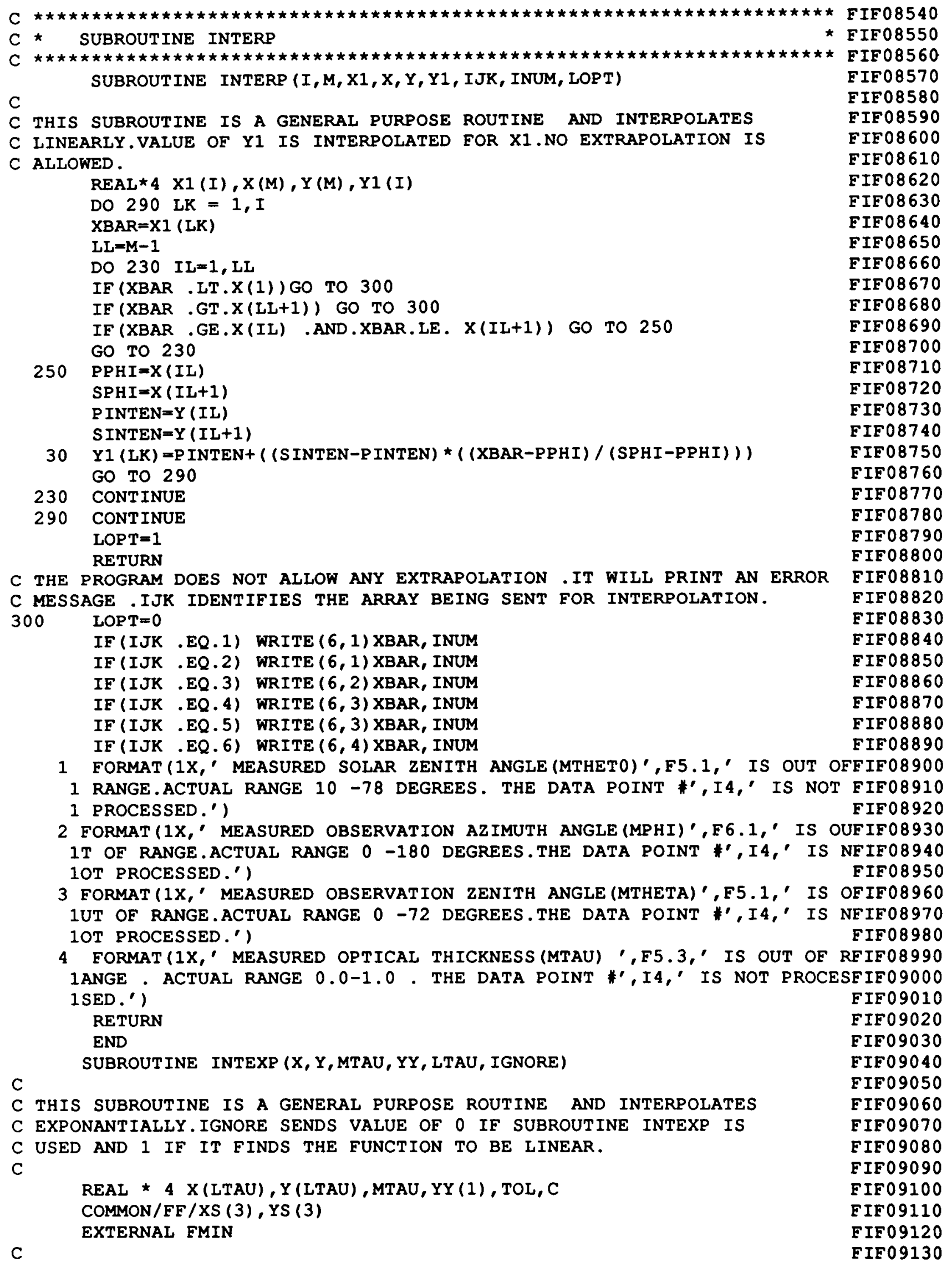


C VALUE OF IGNORE IS SET TO 0 AND IF MEASURED OPTICAL THICKNESS IS LESS FIFO9I40

C THEN OR EQUAL TO 0.25 THEN THE FUNCTIONS OF OPTICAL THICKNESSES OF FIFO9150

C $0.0,0.25,0.50$ ARE USED.

C

IGNORE $=0$

IF (MTAU . LE . 0.25$)$ THEN

$M M=1$

$M N=3$

FIF09160

FIF09170

FIF09180

FIF09190

C

C IF MEASURED OPTICAL THICKNESS IS GREATER THAN 0.25 THEN FUNCTIONS

FIF09200

FIF09210

FIF09220

C OF OPTICAL THICKNESSES OF $0.25,0.50$ AND 1.00 ARE USED.

FIF09230

C

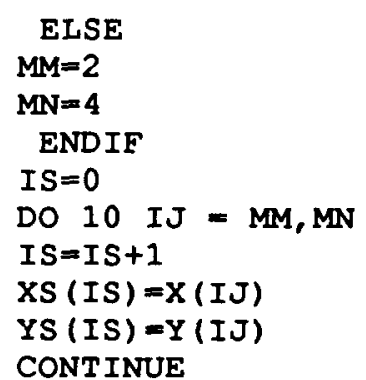

FIF09240

FIF09250

FIF09260

FIE09270

FIF09280

FIE09290

FIE09300

FIF0 9310

FIF09320

FIF 09330

FIF09340

10 CONTINUE

C

C SYSTEMS SUBROUTINE IMSL (ZXGSN) IS CALLED TO GET THE MINIMAL OF

FIF09350

FIF09360

FIF09370

C EUNCTION FMIN.

FIF09380

C

C A IS LOWER END-POINT OF THE INTERVAL IN WHICH MINIMUM OF FMIN IS TO BEFIFO9400

C LOCATED.

C B IS THE UPPER END-POINT OF THE INTERVAL.

FIF 09410

C TOL IS LENGTH OF THE FINAL SUBINTERVAL CONTAINING THE MINIMUM.

C C IS OUTPUT, THE APRROXIMATE MINIMUM OF THE FUNCTION FMIN ON THE

FIF09420

FIF09430

FIF09440

C ORGINAL INTERVAL $(A, B)$

C IER RETURNS THE VALUE OF 0 IE NO ERROR IS FOUND.

C

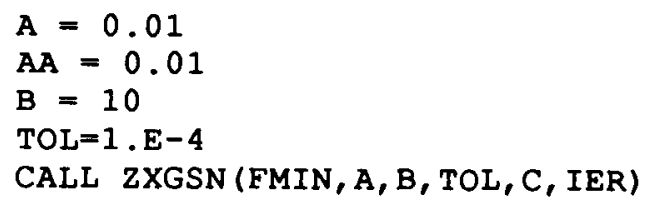

FIF09450

FIF09460

FIF09470

FIF09480

FIF09490

FIF09500

FIF09510

FIF09520

FIF09530

FIF09540

FIF09550

FIF09560

FIF09570

FIF09580

$\operatorname{IF}((C-A A) \quad . L T . \quad .001)$ THEN

FIF09590

FIF09600

RETURN

FIF09610

EIF09620

C IF FUNCTION IS NOT LINEAR, EXPONANTIAL INTERPOLATION IS USED, AND INTEFIF09630

C INTERPOLATED VALUE FOR MTAU IS YY(1) IS COMPUTED FOR THE FUNCTION. FIFO9640

C

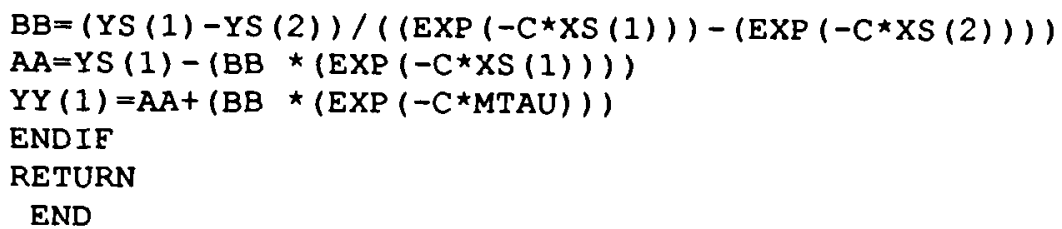

FIF09650

FIF09660

FIF09670

FIF09680

FIF 09690

FIF09700

FIF09710 
FUNCTION FMIN (C)

FIF09720

C FUNCTION FMIN IS FUNCTION TO BE MINIMIZED.

FIF09730

FIF09740

C

REAL C

FIF09750

COMMON/FF/XS (3), YS (3)

$P=(Y S(1)-Y S(2)) /(Y S(3)-Y S(2))$

FIF 09760

FIF 09770

FIE09780

$P F=\operatorname{EXP}(-C \star X S(1))-\operatorname{EXP}(-C \star X S(2))$

FIF0 9790

$P G=\operatorname{EXP}(-C \star X S(3))-\operatorname{EXP}(-C \star X S(2))$

FIF 09800

$P P=P F / P G$

$F M I N=(P-P P) \star \star 2$

RETURN

FIF0 9810

FIF09820

END

FIF09830

FIF09840 


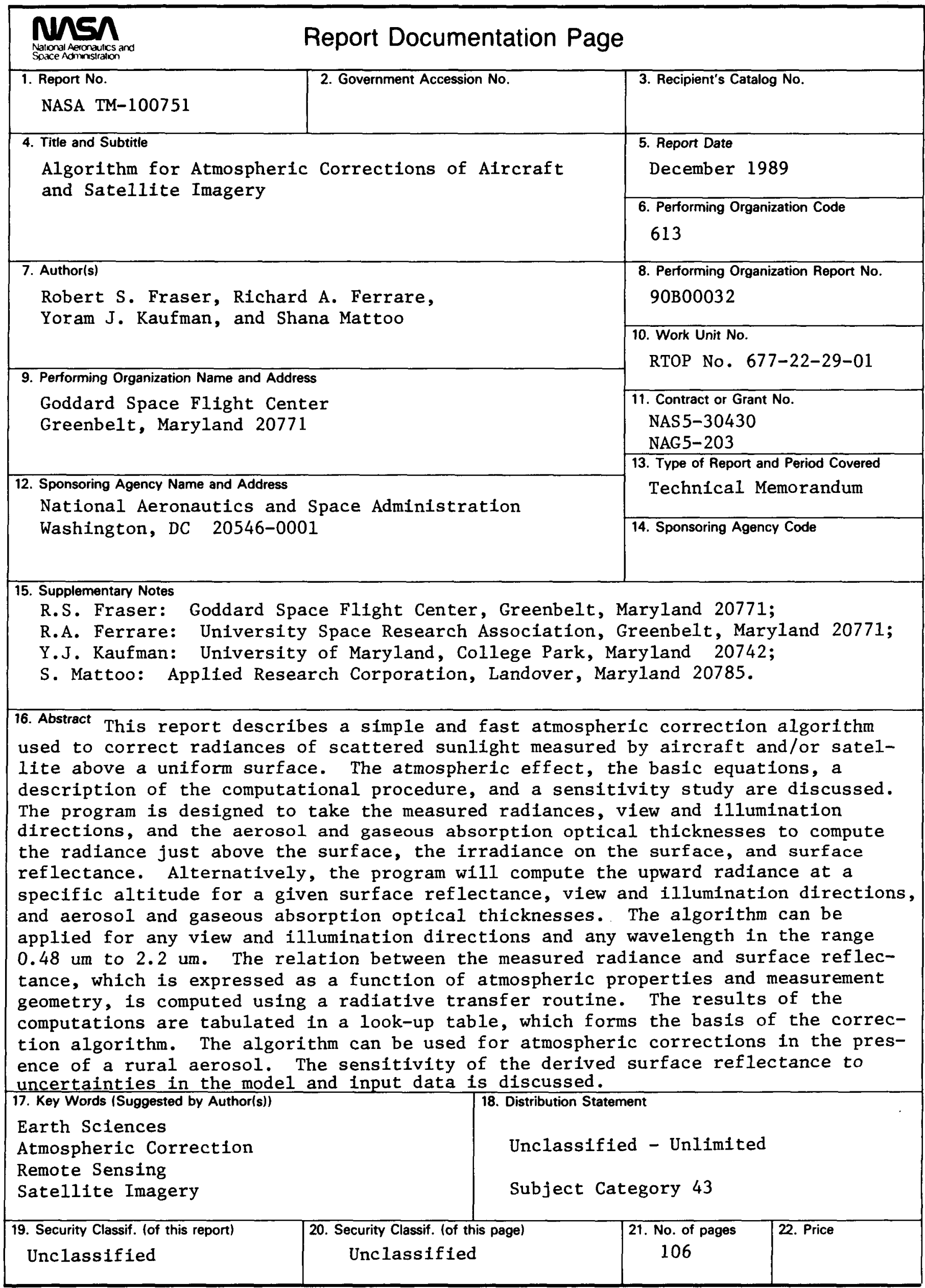

